Portland State University

PDXScholar

7-7-1977

\title{
Role Demands of Professional Women in Jeddah, Saudi Arabia
}

Soraya Wali El-Deen Assad

Portland State University

Follow this and additional works at: https://pdxscholar.library.pdx.edu/open_access_etds

Part of the Sociology Commons

Let us know how access to this document benefits you.

\section{Recommended Citation}

Assad, Soraya Wali El-Deen, "Role Demands of Professional Women in Jeddah, Saudi Arabia" (1977). Dissertations and Theses. Paper 2595.

https://doi.org/10.15760/etd.2592

This Thesis is brought to you for free and open access. It has been accepted for inclusion in Dissertations and Theses by an authorized administrator of PDXScholar. Please contact us if we can make this document more accessible: pdxscholar@pdx.edu. 
AN ABSTRACT OF THE THESIS of Soraya Wali E7-Deen Assad for the Master of Arts in Sociology presented July 7, 1977.

Tit7e: Role Demands of Professionat Women in Jeddah, Saudi Arabia. APPROVED BY MEMBERS OF THE THESIS COPMITTEE:

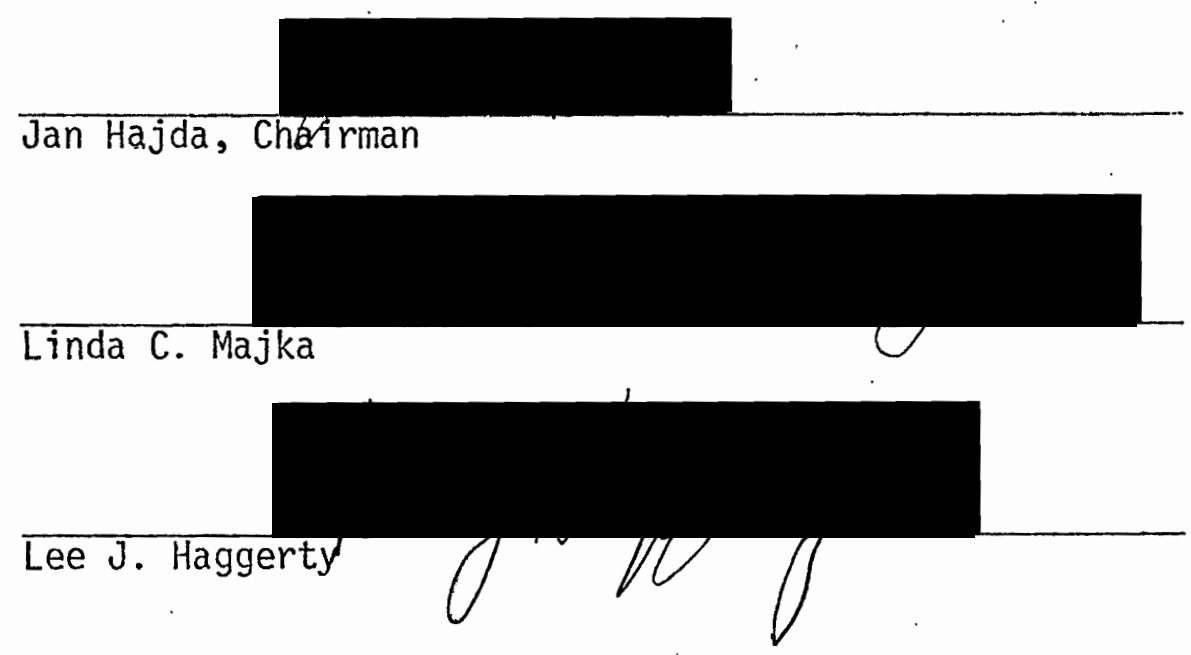

The present thesis is concerned with professional women in Jeddah, Saudi Arabia. Because of the social changes taking place in Saudi Arabia, the position of women is subject to both traditional and modernistic influences. While an increasing number of females are receiving higher education and expanding their aspirations, the traditional cultural values dealing with woman's role in the family are still an important consideration.

The thesis is based on the theoretical perspective that the individual role system is overdemanding. Fulfilling role demands causes difficulty or "strain"; if a person conforms fully in one direction, fulfillment will be difficult in another. 
The theoretical background is largely dependent upon American literature, since there is a lack of relevant empirical sociological study of professional women in Saudi Arabia. Studies cited deal with the continuing conflict between career, marriage, and motherhood: difficulty in allocation of time, support or non-support of the working woman by husband, family, and others; behavior expected from working women; and the assertion of an identity.

This thesis is of an exploratory nature. It attempts to measure the degree of difficulty with which women manage employment in combination with domestic activities. Variables considered are marital status, career type, and interaction patterns of the women with men at their place of work. Married women are compared with single women; occupations which relate to the normatively accepted women's role are compared with those which are culturally less acceptable for women; comparisons are made between women with least interaction with men, women with occasional interaction with men, and women with most interaction with men.

Based on the previous variables, four hypotheses were formulated. (1) Married women with children-are expected to experience the most difficulty in terms of time allocation, while single women are expected to experience the least amount of difficulty. (2) Women who work in fields other than education and medicine are expected to experience the most difficulty with respect to network support and women who work in the fields of education and medicine are expected to experience the least difficulty in terms of network support.

(3) Women with the most interaction with men in the work situation (e.g., physicians, broadcasters, 
interpreters, and interior decorators) are expected to experience the most difficulty in terms of contradictory expectations; women with the least interaction with men in the work situation (e.g., school teachers) are expected to experience the least amount of difficulty with respect to contradictory expectations; and women with occasional interaction with men in the work situation (e.g., college teachers and administrators, social workers, investigators, and newspaper editors) will be somewhere between the two extremes. (4) Women with the most interaction with men in a work situation are expected to experience the most difficulty in asserting an identity; women with the least interaction with men in a work situation are expected to experience the least difficulty in asserting an identity; and women with occasional contact with men in a work situation will be somewhere between the two extremes.

To serve the study purposes of discovery and measurement, data were collected from non-standardized interviews and a standardized questionnaire. Data were obtained from interviews with thirty-seven native women, college educated, between the ages of twenty and thirtyfive. Quantitative and qualitative information were incorporated.

It was found that the data generally supported Hypotheses \#1, \#2, and \#4, and that they did not support Hypothes is \#3. (1) There seems to be a consistent pattern of relationships between marital status and time allocation. Married women reported more difficulty with respect to time allocation than did single women. However, married respondents indicated their occasional use of sets of mechanisms to allocate their time effectively. (2). It was found that a relationship exists between the type of occupation and network support.: Women who work in the 
4

fields of education and medicine seem to have more positive support than do women who work in other fields. However, women who work in other fields did not report negative support from their networks.

(3) The data show that the degree of contradictory role expectations is similar for all respondents regardless of the amount of their interactimon with men at their place of work. Therefore, Hypothesis \#3 is rejested. (4) The data indicate that the exclusion of males in occupatonal settings seems, to reduce the respondents' difficulty in asserting their identities. 


\title{
ROLE DEMANDS OF PROFESSIONAL WOMEN IN JEDDAH, SAUDI ARABIA
}

\author{
by \\ SORAYA WALI EL-DEEN ASSAD
}

A thesis submitted in partial fulfillment of the requirements for the degree of

\section{MASTER OF ARTS}

in

SOCIOLOGY 
TO . THE OFFICE OF GRADUATE STUDIES AND RESEARCH:

The members of the Committee approve the thesis of Soraya Wali El-Deen Assad presented JuTy 7, 1977.
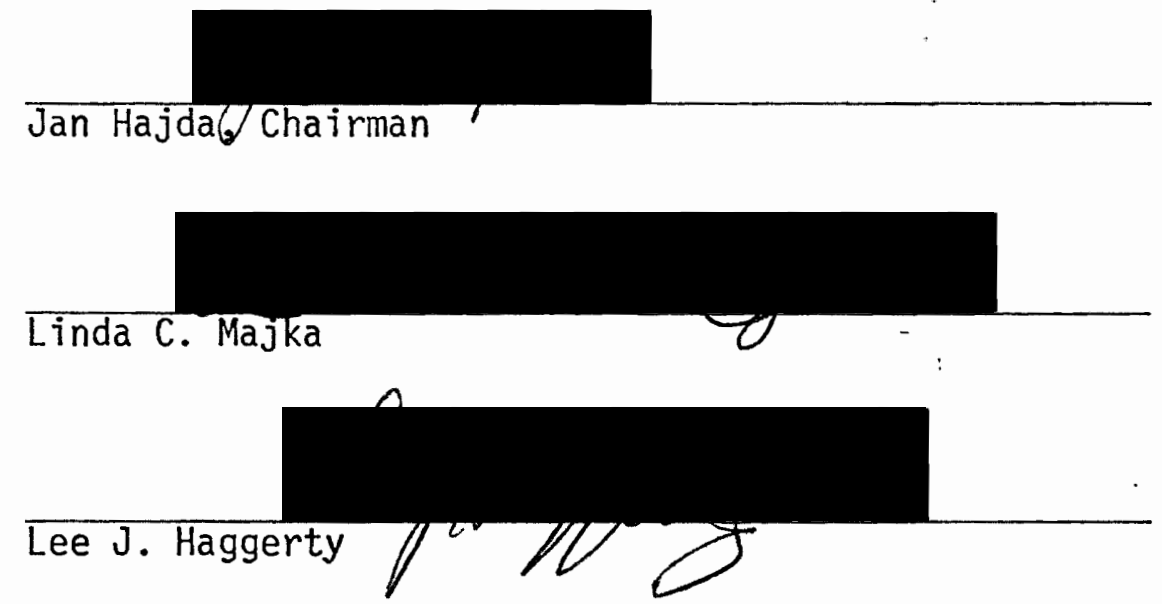

APPROVED:
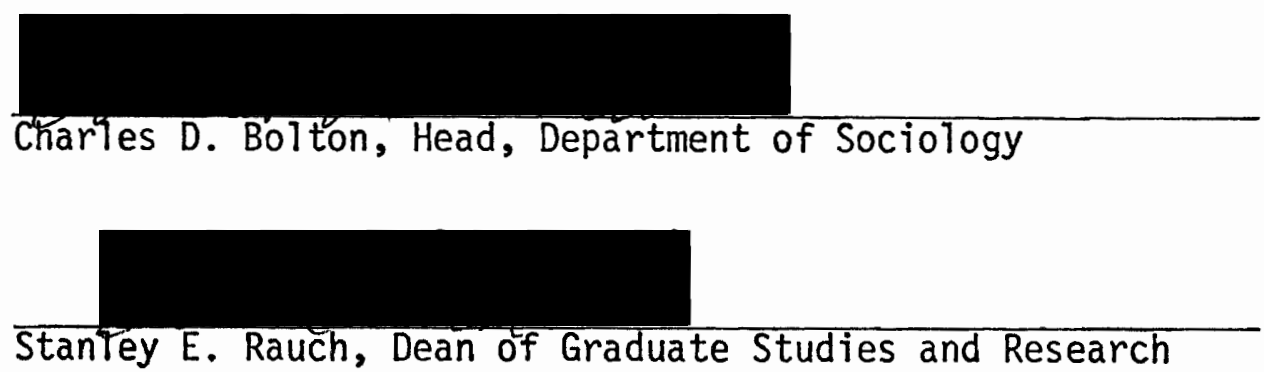
In the name of God,

Most Gracious, Most Merciful 


\section{ACKNOWLEDGMENTS}

I would like to express my deep thanks and gratitude for the help and advice given by Dr. Jan Hajda, who served as the Committee Chairman for this thesis. His encouragement, patience, and insightful counseling improved the quality of this thesis.

I wish to express my thanks and appreciation to Dr. Linda Majka and Dr. Lee Haggerty for their valuable comments and suggestions.

Acknowledgment with gratitude is expressed to government employees in Jeddah, Saudi Arabia--men and women--who provided me with information that enabled the study to take place.

I thank all of the professional women whom I interviewed for their cooperation and understanding.

My deep appreciation is expressed to my mother, brothers, sisters, relatives, and friends for their support and encouragement.

My heartfelt gratitude to my father, to whom I am greatly indebted for my initiative. His sincere advice, help, and accomplishments are appreciated and remembered by many of his students, colleagues, friends, and relatives. His ingenuous beliefs and his achievements as an educator have always been a major source of inspiration to my brothers, my sisters, and me.

Therefore, I wish to dedicate this document to the memory of my father, Wali El-Deen Assad.

This work, above all, has been made possible by my faith in God and his Prophet. 
TABLE OF CONTENTS

PAGE

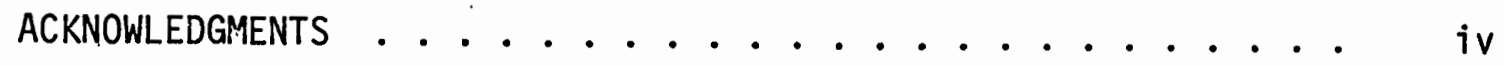

LIST OF TABLES ........................ iX

CHAPTER

I INTRODUCTION AND CULTURAL SETTING . . . . . . . . 1

II HYPOTHESES AND THEORETICAL BACKGROUND ....... 12

Hypotheses .............. . . 12

Hypothes is 1

Hypothes is 2

Hypothes is 3

Hypothes is 4

Theoretical Background ........... 15

III METHODOLOGY .............................. 31

The Respondents ............. . . 31

Preliminary Considerations ......... . 35

Procedures Used with Respondents........ 36

Sampling School Teachers

Sampling College Administrators and Teachers

Sampling Social Workers, Investigators, Newspaper Editors, Interpreters, and Interior Decorators

Sampling Physicians

Contacting the Respondents ........ 40

The Interview .................. . . 41

Combining Quàlitative and Quantitative Data ... 44 
IV TIME ALLOCATION ................ 46

Differences of Time Allocation by Marital

Status .............

Married Respondents

Single Respondents

Mechanisms for Allocating Time ........

Management of Time through Scheduling and Delegation of Tasks

Management through Compromise

Establishment of a Salient Role

The Mechanism of Redefinition

Reduction of Social Relationships

Compartmentalization through Role Distance

Compartmentalization through Role Relaxation

How Successful are the Mechanisms? ....... 66

Further Implications ............ 68

V NETWORK SUPPORT ....................... 70

Approval vs. Disapproval of the Idea of

Working .............

Married Respondents

Single Respondents

Approval vs. Disapproval of the Type of

Occupation.

Approva 1

Disapproval

Women's Reactions .............

The Conformists

The Adapters

The Progressives 
VI EXPECTED BEHAVIOR ................ 97

Contradictory Personal Behavior Expectations

by the Degree of Interaction with Men at Work Place.............

Women with Least and Occasional Interaction Women with Most Interaction with Men at Work Qualitative Data Analysis

Further Discrepancies in Personal Behavior

Expectations ............

Women's Appearance

Conservative Behavior

Working with Women vs. Working with Men

Contradictory Work Behavior Expectations .. . . . .

Work Relationships

Material to be Covered and Method of Teaching

Quality and Quantity in Education

Public. Expectations

Further Implications . . . . . . . . 120

Lack of Interest in Seeking Promotions

Lack of Opportunity for Competition

Dislike of Competition

Respondents Who Compete

Mutual Dependence and the Support of

Male Colleagues

VII THE PROBLEM OF ASSERTING AN IDENTITY . . . . . . 129

Women with Least Interaction with Men . . . . 137

Female Colleagues' Actions

Women with Occasional Contact with Men ......

Male Colleagues' Actions

Female Colleagues' Actions 
Women with Most Contact with Men . . . . . . .

MaTe Colleagues' Actions

Male Clerical Workers' Actions

Actions of Manual Workers (Drivers and Guards)

Patients' Actions

Work Discrimination ...........

Further Implications . . . . . . . . 151

Conclusion ................ 153

VIII CONCLUSIONS ........................ 155

Hypothes is \#1 ............... 156

Hypothesis $\# 2$. . . . . . . . . . 157

Hypothesis \#3 .............. 160

Hypothes is \#4 ............... 163

Recommendations for Further Research ...... 165

BIBLIOGRAPHY .......................... 171

APPENDICES . . . . . . . . . . . . . . . . . . 177

A INTERVIEW GUIDES AND STANDARDIZED QUESTIONS . . . . 178

B RESPONDENTS WHO TOOK PART IN THE STUDY . . . . . . 186

GLOSSARY . . . . . . . . . . . . . . . 188 


\section{LIST OF TABLES}

TABLE

PAGE

I Marital Status and Degree of Interaction with Men ...

II Degree of Difficulty in Time Allocation by Marital

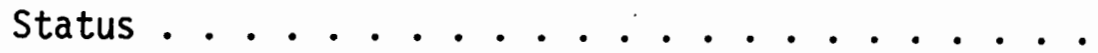

III Degree of Fatigue by Marital Status .........

IV Presence of Domestic Help by Marital Status . . . . .

$\checkmark$ Participation in Social Relationships by Marital

Status ................

VI The Use of Compartmentalization through Role Distance by Marital Status .............

VII Degree of Support from Social Network by. Type of

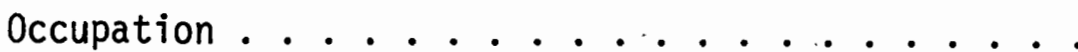

VIII Paired Responses Indicating Contradictory Expectations from Women by Degree of Interaction of Men and Woman at Work ............. 106

IX Paired Responses Indicating Contradictory Expectations from Men by Degree of Interaction of Men and Women

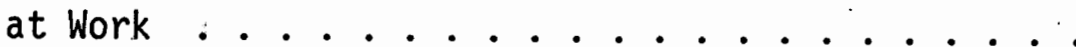




\section{CHAPTER I}

\section{INTRODUCTION AND CULTURAL SETTING}

This thes is is concerned with professional women in Jeddah, Saudi Arabia. The lives of such women have received little empirical study, and the emerging interest in expanding the labor market in Saudi Arabia necessitates the gathering and interpretation of data concerning career women.

(2) $X$ Saudi Arabia is experiencing social changes; specificially, the position of women is subject to both traditional and modernistic influences. While an increasing number of females are receiving higher education and expanding their aspirations, the traditional cultural values dealing with woman's role in the family are still an important consideration. Women have a cultural mandate to give priority to the family. One element of role stability is the socialization process in the home environment. From a social learning perspective, girls are trained for the motherhood role. Characteristics such as helping with housework and younger children, and being obedient are encouraged. Performing the expressive role is highly valued as well. A good mother is described as patient, affectionate, and forgiving; she is admired for her devotion to her home, her children, and her husband. According to Zelditch (1955), the prescribed supportive function has tended to be a specialization of women in most cultures (Bernard, 1971:89). 
It is important to note that Islamic teachings have more influence on the society of Saudi Arabia than on that of other Arab countries, because Saudi Arabia is the birthplace of Islam. The holy places of Mecca and Medina--the objects of pilgrimages--are located in Saudi Arabia. The influence of Islamic teaching has great significance because Islam has been regarded not only as a religious doctrine, but also as a social system. Therefore, the status of women in Saudi Arabia is closely associated with Islam, but does not necessarily flow from it.

Another element of role stability is the interpretation of Islamic teachings concerning women. Some Moslem literature perceives changes in the status of women as exclusively a religious problem. This interpretation propounds the view that women's traditional and proper place is in the home; women are best suited for bringing up children because of the quality of their love; women are perceived as respectable mothers, dear sisters, lovable daughters, and companionable wives. Education is desirable for women only insofar as it will help them in their wife-mother role. It is considered preferable for a woman to work in such fields as education and medicine, since these are perceived as "female occupations," and because such women serve female clientele exclusively (Gamal, 1975:141-152).

This view also reflects the cultural values which prescribe the appropriate role behavior for each sex. Women are different from men; being different in nature justifies being different in their sex role specialization. Men, as the family providers, play the "instrumental role"; women play the "expressive role." This perspective propounds 
the view that changes in women's life styles are a direct attack on Islamic order and are threatening and disturbing to Islamic ideology. The philosophy of education also partially supports the traditional wife-mother role. In providing public schools for females in 1960, the government had to overcome considerable opposition. The opponents believed that education would corrupt women and turn their minds from their primary duties of being good wives and mothers. Opponents also feared the exposure of women to male strangers. Plans were implemented to counteract that kind of opposition. First, in organizing the curriculum, home economics, sewing, cooking, and child care are emphasized for females, particularly in the elementary grades. Secondly, although secular subjects are presented, the program of studies retains a heavy emphasis on religion. Rules were made concerning female attire: students as well as teachers, when going in public to and from the schools, must wear a face covering of black cloth, in addition to a black cloak (the "Abbaya"). Scholarships for females in such fields as education and medicine are encouraged. Therefore, education has gained value in relation to its compatibility with cultural values and expectations. After the initial period of opposition, parents--and even some of the more conservative people--were swift to take advantage of educational opportunities. Parents as well as girls began to realize that financial benefits could be gained from ácquiring a degree. Earning more money is valued as a means of buying more material luxuries, and a college degree carries some social prestige. Schooling for girls now seems to be universally accepted. 
The crucial characteristic of the society of Saudi Arabia, particularly in its cities, is the limitation on interaction between men and women outside certain well-defined categories. Women are physically and/or socially segregated. Sexual segregation divides all social space into male and female spaces. One instrument of this segregation is in social life, except for the kinship group; that is, the systematic prevention of interaction between men and women not related to each other by marriage or by blood. The second instrument is the wearing of the Abbaya, or concealing cloak, by women. The woman may be completely covered; she may throw back the veil, exposing her face; or she may wear only a part of the garment. The implications of veiling are particularly relevant for the achievement of social distance, and symbolize separation of the sexes. Moslem literature associates veiling with Islamic teachings. It is argued that the Moslem ethic is opposed to the ornamentation of women's bodies and the exposure of their charms, and veiling is viewed as a protection. Moslem women should be aware that the western women's movement repudiated the exploitation of the female body in pornographic mass media. It is argued as well that western customs would not necessarity work in Saudi Arabia because seclusion is not necessarily seen as a restraint or a source of oppression, but as a protection.

Third, with the exception of kindergartens and private schools, educational institutions are completely segregated. Men are not supposed to enter women's schools.

Finally, this segregated system has created a growing demand and new opportunities for qualified women to serve a female clientele. 
Most educated women are working as teachers, school administrators, educational supervisors, social workers, college teachers, college administrators, nurses, and physicians. There are exceptions, but they are few at the present time. Convenient statistics are not available, but women's participation in the general labor force is low compared to that of other countries. According to the Minority Rights Group report, only 1 percent of women in Saudi Arabia now work outside the home (Minority Rights Group, 1975:11).

It appears that the occupations which women are entering function as an extension of the separate women's world to some degree. Consequently, this kind of social segregation may not be viewed as women's attempt to reduce the impact of their inconsistent status, i.e., being a female in a male-dominated occupation. The second consequence of this segregation is seen in the unique type of interaction between men and women in occupations. We could divide career women in Jeddah into three categories in terms of their degree of interaction with working men.

- First, there are those who have the least interaction with working men, such as grade school teachers. Schools are, to a great extent, segregated institutions which are not supposed to be entered by men. Second are the career women who have formal, indirect, and occasional interaction with male colleagues during working hours. School principals, educational supervisors, college administrators, college teachers, social workers, investigators, and newspaper editors are examples. Contacts usually take place through formal letters and phone calls; sometimes there are also formal meetings which have a respectable and 
conservative appearance. The third category is comprised of those who have considerable interaction with male colleagues at their place of work. Physicians, nurses, interior decorators, interpreters in foreign companies, and broadcasters are examples. Women work in the same buildings with men; sometimes a woman shares the same room with a male colleague. Women nurses accompany male physicians as well as female physicians. A woman worker in this third category could go to work unveiled.

To sum up, the cultural setting of this segregated system has created two situations: first, a growing demand for educated women serving a female clientele; and second, a limitation on interaction between women and men, carried over from the cultural to the occupational setting. Thus, the elements that support the persistence of the traditional role are traditional social learning through the family, the socalled "conservative" interpretation of Islamic teachings, mass media conformity to cultural values, philosophy of education, and the segregated system.

However, there are some challenges to the image of the traditional woman's role and the segregated system. The development of the oil industry has brought wealth to the country, and wealth has brought changes.

The country has had better and broader communication with other parts of the world, particularly industrial societies. With more money to spend, people have been able to travel to other countries. Travelers are being introduced to other styles of life and to more open interaction between men and women. Some men who travel for business or recreation marry women from other Arab and foreign countries, al though some 
such "outside" marriages have been officially opposed and regulated. As a result of these experiences, some families are changing their expectations about the companionship between a husband and a wife. Their social behavior is regulated by a modified version of traditional custom; they usually have mixed social gatherings with free interchange between the sexes.

The expansion of the oil industry necessitates technical skills, and the oil income has made it possible for many students to study abroad or in other Arab countries. In such countries, students have been exposed to a different ideology of women's employment, appearance, and interaction with men. Furthermore, some tend to marry persons from other Arab or foreign countries. They seem to be more permissive with regard to male-female interaction. The oil industry in Saudi Arabia has opened up opportunities for foreign industrial workers and others from Arab countries--skilled, semi-skilled, technical, and professional. Foreign women offer a new concept of appearance and dress.

The needs of the new economy have also opened up opportunities for a new middle class. This new middle class includes merchants, traders, and landowners--the bourgeoisie, managers, administrators, technicians, clerks, teachers, army officers, and others in government and business. According to Rugh's survey, the middle class in Saudi Arabia is internally differentiated into upper and lower strata. The upper stratum includes professors, doctors, engineers, some business men, and the equivalent of politicians. Most of them have had direct exposure to a modern "secular education." The lower stratum includes government clerical personnel, grade school teachers, and skilled 
industrial wage earners, most of whom have not had direct exposure to a modern environment (Rugh, 1972).

However, the emerging middle class occupies a middle level in prestige and socioeconomic power. Some members tend to have a modern attitude about the role of women in society, and to propound the view that any change in this role is predominantly an economic issue. The change in the role of women is primarily a question of the allocation of resources: the economic aims of the government of Saudi Arabia are viewed as inconceivable without an alteration of the position of women. According to Madni, the society is in the process of urbanization and industrialization; women must be utilized in the labor force, through ideal methods and in accordance with customs, traditions, and labor laws. It is a fact that housework does not require as much time as it once did, when women stayed home all day. Children grow up and go to school, leaving mothers with long and boring hours at home. The new economy requires that women be considered valuable labor resources (Madni, 1976:12).

Shobokshi also enthusiastically supports the importance of women in Saudi Arabia, as one-half of the society, taking a vital part in the developmental process. He perceives those who stand against women's participation in the labor force as obstacles to full utilization of the society's human resources. He warns that resentment of working women may cause these women to become passive, to "withdraw," and not take an active role in the developmental process (Shobokshi, 1976).

Thus, the differences lie in the divergent conceptions of women's basic role and in the extent to which women can achieve fuller 
participation in the affairs of society. It appears as well that accepting the view that woman's place is in the home results in a continuous need to hire employees from abroad.

Although mass media officially conform to traditional ideas and customs, some women have started to speak up on their own behalf. Some current writing reflects a different image of the role of women. It is asserted that a woman should specialize in fields that interest her; the labor market should open up opportunities for women to work as engineers, pharmacists, urban planners; jobs should be available for women who have the potential to enter "all-male" professions; and Saudi Arabia's development needs both men and women, not just half of the society (A1rashed, 1976:6-7).

While public recreational films are opposed by a segment of the society, a few wealthy people have access to American and European films and programs. These films are passed from house to house and are becoming an important channel of exposure to western ideas and customs. Video cassette recorders are also owned by those who can afford them, and a number of video libraries have opened. The video cassette recorders provide their owners with films and series taped from television programs in other countries, mainly England and the United States.

The custom of veiling is more and more viewed as a-symbol. When women of Saudi Arabia travel abroad, hardly any of them veil themselves; within Saudi Arabia, many women "uncover their faces" to salesmen while shopping, indicating their indifference to facing strange men. There are even a few who now work with men at radio and television stations, at hospitals, and in some foreign companies. However, there are 
still many who adhere strictly to the Abbaya as a traditional requirement. Algosaibi predicts that since the country is developing at such a very fast rate, the Abbaya will probably either fade or become a symbol and part of their national maxi-dress (Algosaibi, 1976:5).

Others have even claimed that neither the veiling of the face nor such strict seclusion were enjoined on women by Islam. The Islamic charter for women served them well through the period of the great Arab conquests. They won men's respect and even led troops into battle. Some were renowned as scholars and their opinions about politics and law were widely sought.

Izzeddin describes the status of women in early Islam:

Contemporary sources describe a society in which women moved about freely and fully held their own. Men's attitude toward women was regulated by the tradition of the desert; the teachings of the Koran and the Sunna, or precedent of the Prophet. In those days women were not secluded or veiled but appeared at public functions in the company of men (Izzeddin, 1953:299).

The veil and the seclusion of the women can be traced to times of war when Arab expansion and conquest were taking place. Women wore veils to distinguish themselves from unveiled slaves. The custom was drawn from Persian and Byzantine people whom the Arabs conquered, and whose powerful ruling families secluded their women as a sign of greatness and distance from common people. This practice was later copied by the rising Arab middle class.

Later, Arab lands were subjected to successive foreign invasions, and the seclusion of women was justified as necessary for their protection from foreign soldiers and was maintained when the Arabs were conquered by the Ottoman:Turks (Minority Rights Group, 1975:11). 
To sum up, the elements that are presently challenging the image of the traditional woman's role and the segregated system are:

(1) travel by citizens of Saudi Arabia to other Arab, Moslem, and foreign countires; (2) exposure of such travelers to a different kind of relationship between men and women; (3) marriage to persons from other Arab and foreign countries who may have different life styles; (4) the hiring of workers from Arab, Moslem, and foreign countries; (5) the emergence of a new middle class which views women in the labor force in relation to the way in which the women allocate their resources;

(6) the viewing of "video tapes"; and (7) reevaluation of the veil and the seclusion of women. 
CHAPTER II

HYPOTHESES AND THEORETICAL BACKGROUND

\section{HYPOTHESES}

The hypotheses of concern here have to do with the degree of difficulty with which women manage employment in combination with domestic responsibilities. Four hypotheses are formulated.

\section{Hypothes is 1}

$X$ Married women with children are expected to experience the most difficulty in terms of time allocation, while single women are expected to experience the least amount of difficulty. This is due to the fact that the obligation of the mother-wife role demands so much of women. Time is needed for child training, guidance, and physical care; time is also required for special problems of children--i.e., illness, preparation for school, and homework supervision; and time must be set aside for such housework as cleaning, washing, cooking, etc. It is true that the mother might get help with the housework and children; however, it is still her main responsibility to see that the home runs smoothly in her absence. The husband also makes demands on his wife: he expects her to be a good companion or just to be around in the evening. The wife role might also require time for tasks which are extension of the husband's occupational role. At the same time, professional positions necessitate time divided among several roles; for example, college 
teaching requires teaching, publication, and participation in the formal and informal network. Therefore, the professional wife must carry out the major responsibilities of the home and the children in addition to her work in the marketplace. The single woman, on the other hand, has no mother-wife role to fulfill.

Hypothes is 2

Women who work in fields other than education and medicine are expected to experience the most difficulty with respect to network support. Women who work in education and medicine fields are expected to experience the least difficulty in terms of network support. Working in education and medicine is considered to be an extension of the traditional feminine role of serving the community in the same way that women serve the family, and is therefore culturally acceptable. It is also suggested that working in such fields requires women to play roles associated with femininity, such as giving help and socializing.

Hypothes is 3

This hypothesis consists of three parts.

(a) Women with the most interaction with men in the work situation (e.g., physicians, broadcasters, interpreters, and interior decorators) are expected to experience the most difficulty in terms of contradictory expectations.

(b) Women with the least interaction with men in the work situation (e.g., school teachers) are expected to experience the least amount of difficulty with respect to contradictory expectations. 
(c) Women with occasional interaction with men in the work situation (e.g., college teachers and administrators, social workers, investigators, and newspaper editors) will be somewhere between the two extremes.

The limitation on interaction between men and women outside certain well-defined categories creates both physical and social distance. This leads to the establishment of separate worlds of men and women. "Women's world" has its own solidarity; has established common behavior expectations; and is maintained by stressing differences between. women and men. The concept of role differentiation has been internalized by women. Their homogenous environment affirms their expectations, and they expect support from each other.

In a desegregated work organization, both men and women are ambivalent about their social interaction. Ambivalence emerges as a result of not knowing how to behave and what to expect; in short, there is a lack of well-established common expectations. From a traditional perspective, a male might expect a woman colleague to be a helpful, faithfur assistant, and to exhibit encouragement and sympathy. As a colleague, he might expect her to compete, criticize, and challenge him.

\section{Hypothes is 4}

This hypothesis also consists of three parts.

(a) Women with the most interaction with men in a work situation are expected to experience the most difficulty in asserting an identity.

(b) Women with the least interaction with men in a work situation are expected to experience the least difficulty in asserting an identity. 
(c) Women with occasional contact with men in a work situation will be somewhere between the two extremes.

Treating women in sex-related roles rather than work-related roles could be partly due to the desire of men to assert their maleness. It could also derive from the fact that males are the dominant sex in the occupational sphere, where they have more authority and privilege. Women with the least interaction with men at work live in a homogenous environment; this type of environment affirms their security and identity.

\section{THEORETIICAL BACKGROUND}

The framework of this study will be heavily influenced by or dependent upon American literature, since there is a lack of relevant empirical sociological study of professional women in Saudi Arabia. For the first time in world history, a common set of influences is affecting every known society: we are all witnessing a remarkable phenomenon, the development of similar family behavior and values among much of the world's population (Goode, 1963:1).

Women of Saudi Arabia have started to occupy professional positions. Those who are married have to deal with the dual activities of home and employment. They have sets of roles pertaining to the family and to the occupation.

Difficulties or "conflicts" may be experienced as the women attempt to fulfill the two sets of demands satisfactority. Difficulties arise with the allocation of time, and with the degree of support a woman receives from her network. The professional role and the female 
role may be contradictory or opposing; that is, aggressiveness and competition--behavior required in the marketplace--are incompatible with acceptance and accommodation--behavior required of mothers. Another difficulty women may face is that of asserting an identity in the work situation; that is, the actions of their male colleagues may be interpreted by females as placing them in a typical female role rather than in a co-worker role.

Role conflict has been differentiated by social scientists into three bases. These bases are the observer differentiation, multiple positions, and legitimate expectations (Gross, 1958:244).

The observer-actor differentiation. The first basis differentiates between those who define role conflict according to incompatible expectations perceived by the observer from those who define role conflict according to incompatible expectations perceived by the actor. Jacobson, Charters, and Liberman define role conflict as a "situation in which there are differences between criterion group with respect to social role"; for example, the conflict between the "line" and "staff" executives of a factory which sometimes arises because of differing expectations about whose "role" it is to make certain kinds of decisions (Jacobson, Charters, and Liberman, 1951:22).

Seeman refers to role conflict as the exposure of the individual in a given position to incompatible behavioral expectations. Though an apparent incompatibility may be minimized, the conflicting demands cannot be completely fulfilled (Seeman, 1953:373). However, he adds that the term "role conflict" may be misleading, carrying implications of necessary personal conflict. This refers only to situations in which 
the observer notes what appear to be conflicting sets of expectations (Seeman, 1953:373).

Other social scientists define role conflict as situations in which the actor perceives incompatible expectations. Parsons sees role conflict as the exposure of the actor to conflicting sets of legitimized role expectations such that complete fulfillment of both is realistically impossible. According to Parsons, the perception of the incompatible expectations requires the actor to choose among "alternatives" (Parsons, 1951:280). Stouffer, like Parsons, is concerned with the situations in which the actor thinks incompatible expectations for his behavior are involved. In such situations, the actor must choose between a set of alternatives (Stouffer, 1949:707-717).

Multiple positions. Some social scientists specify that a role conflict requires that an actor must be exposed to incompatible expectations whether in a single position or in a multiple position. Sarbin. sees role conflict occuring when a person occupies two or more positions and where one position is incompatible with the role expectations of the other position (Sarbin, 1954:228). Bates states that psychological tension is aroused in individuals who occupy a position containing inconsistent or maladjusted roles. For example, a given position might require an individual to act both as a disciplinarian and as a good friend to the same individual. However, he adds that human organisms tend, when tension is aroused, to act to reduce that tension (Bates, 1956:315). Motz (1961) says that conflict occurs when two or more roles with a single position require the actor to perform psychologically contradictory, yet socially compatible, behaviors (Nye and 
Hoffman, 1963:393). Kretch defines role conflict as the "situation in which an individual is expected to play two or more roles that involve responses that are competing or antagonistic" (Kretch, 1962:530). For example, the woman physician is expected to perform both the female and the professional role, and the respective role expectations may be opposed to each other (Holton, 1969:638).

The role conflict analysis of Nye and Hoffman reflects that conflict occurs when two or more roles within a single position require the actor to be in two different places at the same time or when the actor is required to do two or more different actions at the same time (Nye and Hoffman, 1963:393), e.g., the dual roles of worker and mother. The pressure of trying to fill the two demanding roles can result in a state of stress (Nye and Hoffman, 1974:139).

Stouffer refers to situations in which a person has simultaneous roles in two or more groups such that simultaneous conformity to the norm of each group is incompatible (Stouffer, 1949:707). Getzels' and Guba's analysis of role conflict implies the incompatible expectations to which Air Force instructors are exposed--another example of individuals occupying multiple positions (Getzels and Guba, 1954:164-175). The role conflict analys is of Burchard concerning military chaplains is based on the dilemmas they faced. The subjects were confronted with incompatible expectations from their roles as instructors and as officers (Burchard, 1954).

Legitimate expectations. A third group specifies that incompatible expectations be "legitimate" while others do not demand this legitimacy. Parsons specifies role conflict of an actor's exposure to 
"conflicting sets of legitimized role expectations." He perceives "legitimate" expectations as "institutionalized" role expectations (Parsons, 1951:280). A similar concept is expressed by Getzels and Guba. They view legitimacy as "mutual acceptance" by ego and alter of expectations in a given situation (Getzels and Guba, 1954:165). Stouffer likewise shows concern with the universalistic and particularistic institutionalized obligations (Stouffer, 1951). Other authors such as Sarbin, Seeman, and Jacobson and his collaborators, in formulating role conflict, do not require that the incompatible expectations be legitimate. It is realized that legitimacy may be perceived from the viewpoint of the outside observer or of the involved actor.

Goode modifies the role conflict concept and uses the term "role strain." He defines role conflict as the difficulty in fulfilling role demands. He explains the sources of the difficulty as follows:

(1) role conflicts are required at particular times and places;

(2) role demands might be contradictory and/or inconsistent; (3) role relationships are role sets. If a person conforms fully in one direction, fulfillment will be difficult in another. However, he states that a strain is likely to be associated with some mechanisms in reducing it. The individual can reduce his role strain by: first, selecting a set of roles which are singly less onerous, as mutually supportive as he can manage, and minimally conflicting; and, second, by obtaining as gratifying or value-productive a bargain as he can with each alter in his total role pattern (Goode, 1960:490). However, like Seeman, he views limitations on the mechanisms for minimizing or reducing the 
strain. Such mechanisms may increase or reduce the individual's role strain. $X$ here

The prevailing studies reveal that role conflict, "strain" is the difficulty of fulfilling role demands. The difficulty is aroused in a single or multiple situation. The sources of difficulty occur: (1) when role demands are required at particular times and places; and (2) when an actor is exposed to contradictory or inconsistent behavioral expectations underlying demands. The incompatible expectations may be perceived by the observer or by the actor. The incompatible expectations may be legitimate or illegitimate. Since role relationships are role sets, a person who conforms fully in one direction will find fulfillment difficult in another. However, it has been established that role strain is associated with some mechanisms for reducing it, and that these mechanisms are limited or predominated by a larger structural context or element.

Some analysts cited have approached the concept of the employed mother conflict. They refer frequently to the continuing conflict between career, marriage, and motherhood--a conflict between the new role as provider and the roles of housekeeper and supervisor of children. They point out that domestic responsibilities are seemingly, for the majority of women (irrespective of country), additional to their work in the marketplace (Kievit, 1972:14).

Some sociologists indicate that sex roles are often contradictory and mutually discontinuous in the United States. The major discontinuity is the life cycle of the child, between the individual role as child and father: (1) responsible-nonresponsible role; and 
(2) dominance-submission and contrasted sexual roles (Benedict, 1938:

162). Parsons discusses the cultural contradictions and discontinuity. The dominant elements of the feminine role display a basic ambivalence and instability arising from the dilemma of the domestic, the glamorous, and the good companion roles of women (Parsons, 1942).

Komarovsky labeled the two general sex roles available to American college girls as "feminine" and "modern." She described the "feminine" role as having a number of variants (the "good sport," the "glamour girl," the "young lady," the domestic "home girl," etc.).

These descriptions have a common core of attributes defining proper attitudes toward men, family, work, love, etc., and a set of personality traits often described with reference to the male sex role as not as dominant or aggressive as men, or more emotional, and sympathetic (Komarovsky, 1946:184-185).

"The modern role partly obliterates the differentiation in sex. It demands of women much the same virtues, patterns of behavior, and attitudes that it does of the men of corresponding age" (Komarovsky, 1964:185). Komarovsky's study of women at an eastern college documented the fact that college women were faced with incompatible expectations and tended to be considerably disturbed. A replication of Komarovsky's investigation by Wallin produced similar results; however, Wallin interpreted them differently. He concludes that although college women are faced with incompatible expectations, the problem is less momentous and disturbing than Komarovsky has stated. The majority of cases either did not take incompatibility seriously or the incompatibility was resolved (Wallin, 1950):

Landberg and Farnham (1947) believe that the employee role is basically masculine and that the woman who is employed outside the home 
is placed in the impossible position of playing masculine roles during the day and a feminine role in the evening (Nye and Hoffman, 1963:309). They believe that the behavior required in the marketplace--aggressiveness, rationality,, and competitiveness--are incompatible with the requirements of mothers to be accepting, nurturing, and accommodating (Nye and Hoffman, 1974:11).

Holton indicates that there are different societal expectations of behavior according to sex. The source of conflict in roles seems to be society itself. While an increasing number of women are receiving higher education and expanding their horizons, many of them keep hearing that women's traditional and proper place is in the home. She adds that the woman physician is expected to perform both the female and the professional role, and that the respective role expectations may be competing or opposed to each other (Holton, 1969:638-645).

Another source of difficulty for women is the asserting of an $x$ identity in the work situation. Women may interpret the actions of male co-workers as placing them in a typical female identity; for example, when men address women colleagues with certain adjectives, such as "pretty," "pleasant," and "accommodating girls," or when men address women colleagues by their first names regardless of the women's occupational status. Such women feel that their male colleagues have placed them in sex-related roles rather than in work-related roles. Women may feel that they have been placed in a position of choosing between an identity which conforms either to the passive female stereotype or to that of the aggressive, man-like stereotype. Respective role expectations may be competing or opposed to each other, such as when men

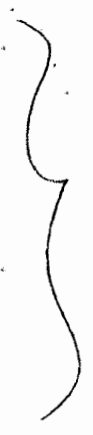


treat women colleague physicians as faithful assistants (Lopate, 1968: 110); when men do not speak to women colleagues unless it is "important" (such as judges) (Epstein, 1970:173-174); when men treat their female colleagues as 1isteners (Bernard, 1971:92); and when men resent women who are independent (such as architects) (Dinerman, 1969:634). Bernard indicates that there is a contradiction in role demands. A woman is expected to perform both the supportive function as a female and the competitive function of a career person. It is difficult to be supportive of a competitor or opponent. As a female, she is expected to be accepting, nurturing, accommodating, helpful, and to raise the status of others; as a career person. she is expected to challenge and to compete. If a woman must perform the supportive, "storking" function, she is disqualified from jobs that require fighting, competing, and challenging (Bernard, 1971). Horner argues that most women have motives for avoiding success; that is, a disposition to become anxious about achieving success because they expect negative consequences such as social rejection and/or feelings of being unfeminine as a result of succeeding (Horner, 1972:158-159).

Coser states that the difficulty experienced by professional women derives from participation in different activity systems whose claim on time allocations are incompatible and the values underlying these demands are contradictory. That is, professional women are expected to be committed to their work "just like men," and they are normatively required to give priority to their families. He added that the mechanisms of status articulation that operate to help integrate the activity systems of family and occupation are not available to 
women to the extent that they are to men. If the child is sick, it is the mother and not the father who will stay at home (Coser, 1974: 490-494). Nye and Hoffman indicate that the principle areas of difficulty between home and work for women are child care, husband's adjustment, guilt feelings about the maternal role, and inadequate performance of household tasks (Nye and Hoffman, 1963:379; 1974:139-140).

Baylin says that difficulties do exist in handling the dual roles of family and work. Difficulties derive from leaving children at home and feeling bad about it, not enough time to get things done for chi1-dren and work demands, the husband's and neighbors' hostility, colleagues' attitudes, and the lack of geographical mobility of the professional married woman (Baylin, 1964:700-710).

Epstein states that difficulties derive from the overdemanding child and household responsibilities, husband's hostility because of being threatened as a breadwinner or by sexua' competition from the men his wife encounters in the course of her work, and time needed for doing tasks as an extension of the husband's occupational role. The woman professional experiences a role strain, since she deals with two conflicting priority systems. She may often find herself under a strain trying to perform both roles adequately (Epstein, 1970:86-134). Hacker (1971) found, in a national survey, role difficulties among employed married women with respect to both children and the husband (Nye and Hoffman, 1974:212). Theodore says the professions make greater demands on the professional role. The necessity to allocate time among several roles has serious implications. College and university teaching require teaching, publication, participation in the 
formal and informal networks, and keeping up with the expanding knowledge, and these responsibilities necessitate long hours devoted to the professional role. On the other hand, the professional wife continues the major responsibilities of the home and care of children (Theodore, $1971: 1-24)$.

Graham argues that there is the difficulty of inadequate time for women in academe to spend in both child care and household tasks. The mother's concern for her children is not eased by possession of an automatic washer-dryer or a dishwasher. It is still increasingly difficult to find competent and reliable persons to assist with the children and housework. Day care centers can be helpful, but do not solve the problem of housework (Graham, 1970:729).

The previous studies show that employed married women have a set of roles pertaining to family and occupation. Difficulties do exist in fulfilling the demands of the two sets adequately. These difficulties derive from: (1) the necessity to allocate time, (2) negative pressure from the woman's network, and (3) contradictory role demands.

$X$ The married woman with children faces extremely demanding responsibilities. She must find time for child training, guidance, and physical care, as well as for the special problems of children, such as j17ness, accidents, preparation for school, and homework supervision. Doctors and schools expect mothers to take the children for checkups and to attend parent-teacher meetings. At a time of crisis the mother, not the father, is expected to sit with the sick child.: The mother finds it increasingly difficult to find persons who are reliable and 
will assist in caring for her children and running her house. Household tasks present another difficulty. The burdens of housekeeping, shopping, cleaning, washing dishes and clothes, cooking and preparing meals are usually carried out primarity or entirely by the wife. $X$ The wife also has to manage so that the husband gets a portion of her time. He expects his wife to be a good companion or just to be around. Women's roles sometimes include tasks which are extensions of their husbands' occupational roles; a woman may be required to participate in social activities related to her husband's job.

A further source of difficulty is the negative pressure which may arise from the woman's network, particularly the husband.

A husband may show hostility toward his wife's job. The husband may feel threatened that the wife will outrank him in occupation or level of success. His position as a breadwinner may be threatened in the household. The husband may fear losing power and authority at home. The husband may feel threatened by sexual competition from the men his wife encounters in the course of her work. The husband may need his wife to be available to help his own success, to free him from time-consuming tasks (shopping for clothes, planning trips, maintaining links with their kin, and administering the home)" (Epstein, 1970:118-119).

Negative pressure may also arise from parents. They may feel

uncomfortable about having a career-minded daughter; they may feel ambivalent about their daughter's occupational success. "Success" might be measured by the daughter's performance of the more traditional female roles, while at the same time the parents feel a deep sense of pride in her success (Epstein, 1970:120-121).

The public as well may not support some kinds of women's jobs. This is due to the fact that there is a cultural approval of women working in fields such as medicine and education, fields which are 
considered complementary to the female role (Epstein, 1970:143; and Gama 1, 1975:152).

A third difficulty is that role demands might be contradictory. A working woman as a female is expected to be helpful, accommodating, and sympathetic; at the same time she is expected to be aggressive, dominant, and to compete as a career person.

This discussion has given us an opportunity to specify the frame of reference of our study. We will be dealing with role conflict "strain" in terms of the difficulty of fulfilling role demands (Goode, 1960). The difficulty arises when a person is in a multiple situation. If a person conforms fully in one direction, fulfillment will be difficult in another.

Married working women deal with two priority demands: home and work. There is the problem of inadequate time, particularly for professionals, to spend on child care, household tasks, and those tasks that are extensions of the husband's occupational role. Difficulty also arises from the negative support of the woman's social network. Another source of difficulty is contradictory expectations required by the actor. A working woman is expected to put emphasis on physical appearance, to be helpful, accommodating; at the same time she is expected to be aggressive, dominant, and to compete. Men's actions might be interpreted by female co-workers as placing them in sex-related roles rather than in work-related roles. $X$

Some analysts believe that the employee role is not essentially different from the roles of wife and mother. Specifically, they assert that the employed woman may integrate both career and mother roles 
successfully by using a set of mechanisms. One such mechanism is the choice of specialization. Parsons (1955) states that

- . women are infrequently employed in executive positions in which they would be required to play roles associated with masculinity. They often specialize in fields that are usually supportive or nurturant (Nye and Hoffman, 1963:309).

According to Theodore, "The female professional developed as an extension of the traditional role functions of the female in the family in tasks requiring nurturing, socialization, and helping" (Theodore, 1971:5). Kosa and Coker indicate that "female physicians tend to practice in fields such as pediatrics, public health, and psychiatry where sex and profession can be expected to be most compatible" (Kosa and Coker, 1965:294). Holton found Kosa and Coker's hypothes is to have some credence in social perceptions. She indicates that women are inclined to select specialties which can be integrated with their female role expectations. Fields such as pediatrics, public health, and psychiatry are considered appropriate for reducing time allocation difficulties (Holton, 1969:638-645).

Hanna Papanek refers to the assimilation of jobs in medicine and teaching to traditional feminine roles. One of Pakistan's leading women doctors says, "Medicine as a profession for women, I feel, is an extension of the mother complex, to give help, love, and, in short, mothering the sick peoplè" (Papanek, 1971:525). Goldsen and Kosa (1963) suggest that

. . in nursing and teaching the professional and female role can be reconciled with relative ease because they prescribe compatible duties to such an extent that the professional duties are, in fact, but sublimated forms of the female task (Kosa and Coker, 1965:294). John Kosa's (1967) study shows that "women physicians agreed that marriage and medical careers are compatible for women, provided reasonable family planning is observed" (Kosa, 1971:710). 
Tropman, in a 1968 study, found that social workers perceive their work as an extension of the traditional feminine role of "service" --serving the community much in the same way the woman is serving the family (Poloma and Garland, 1970:742). Baylin suggests similar results. She states that specialization in fields such as pediatrics, social work, the psychology of women, and certain forms of psychiatry provides a special form of integration in a woman's life. In such fields, women lessen the distance between their two roles and hence reduce the contradictions in their self-image (Baylin, 1964:708).

Other social scientists refer to additional mechanisms to eliminate role difficulty. Epstein discusses several mechanisms: (1) mechanical housekeeping and help with the children, (2) elimination of social contact with specific persons who disapprove of the work, (3) having a small family, and (4) compartmentalization by scheduling (Epstein, 1970:103-150). Poloma's study adds other mechanisms which have been used by women interviewed for her study. These mechanisms were: (1) favorable definition of the situation, (2) establishment of a salient role, (3) compartmentalization by keeping home role distinct from professional role, and (4) compromise by limiting the extent of professional role involvement (Poloma, 1970:196). Theodore indicates that the employed professional mother tends to discard the more marginal professional tasks to free herself of investing time (Theodore, $1971: 23)$.

According to Altorki, career-family combinations can exist more easily for women in the Middle East because of Eastern values regarding family relations. 01 der members live with the younger family and 
become actively involved in socializing their grandchildren. The career mother can be assured that her children are being cared for by trusted members of the family. However, she predicts that increased mobility will change this situation (Nikkel, 1974:10). 


\section{CHAPTER III}

\section{METHODOLOGY}

This thesis is of an exploratory nature and attempts to measure the degree of difficulty with which women manage employment in combination with domestic activities. Relationships between the following variables were expected to be important and are examined: (1) marital status and time allocation; (2) type of occupation and network support; (3) the frequency of interaction with men at work and role behavior expectations; and (4) the frequency of interaction with men at work and the problem of asserting an identity.

\section{THE RESPONDENTS}

A purposive sample was selected paying greatest attention to obtaining information from women with varying degrees of interaction with men at their place of work. The sample was selected on the following basis: (1) nationality, sex, age, education. All women selected were native, between the ages of twenty and thirty-five, and all were collegeeducated. (2) Selected occupations consisted of two groups: (a) workers in the fields of education and medicine--school teachers, college teachers, college administrators, and physicians; and (b) workers in other fields--social workers, newspaper editors, radio broadcasters, interpreters, interior decorators, and investigators. (3) The frequency of the women's interaction with men in the work situation; i.e., least, 
occasional, and most. Public school teachers have no contact with men at work; female public grade schools are segregated institutions which are not supposed to be entered by men. The administrators, teachers, and manual workers are all women. The school guard, messenger, and the drivers are the only working men around, and they stay outside the school; teachers have virtually no contact with them. If teachers do talk to these men, the teachers are expected to be veiled and to leave a considerable physical distance between themselves and the men during such conversations.

College administrators and teachers, social workers, investigators, and newspaper editors usually have occasional interaction with men; such contact may take place through letters, phone calls, and formal work meetings. The frequency of contact varies. For example, telephone conversations might take place daily, weekly, or monthly. The frequency of formal meetings also varies; there is no fixed schedule. For example, college administrators and social workers might meet monthly, from five to seven weeks, or from two to three months. Meeting take place whenever there is an urgent reason, and the interaction takes place between males and females who occupy similar or higher occupational status.

Formal meetings as interaction situations are regulated by cultural expectations, norms, and work instructions. Meetings take place only for work purposes, and only subjects related to work are discussed. A female worker is expected to be conservative in the way she dresses and behaves and to keep a certain amount of space between herself and the males attending the meetings. 
The third category is comprised of those with the most interaction with males: physicians, interior decorators, interpreters, and radio broadcasters. With the exception of radio broadcasters whose work schedutes might not require their going to work every day, males and females work in the same buildings and they see and talk to each other on a daily basis. A female physician might share the same clinic with male colleagues. Male patients are sometimes treated by woman physicians except for internal examinations. There are no dress restrictions for female physicians and interior decorators; they, as well as interpreters and radio broadcasters, can go unveiled to the place of work.

(4) Marital status: single or married. The use of specifically defined categories of respondents allowed the researcher to gain some perspective on the relationships among variables to be studied. For example, comparing single with married women enables us to find out the differences in the degree of difficulty experienced by women with respect to time allocation. Types of occupations help us learn the difference with respect to the degree of support women get, depending on their type of occupation. Frequency of interaction with men in the work situation sheds light on the implications of expected behavior and the challenge to women's identity.

Thirty-seven working women were interviewed. They had the following characteristics: (1) they ranged from twenty to thirty-five years of age. Six of the respondents were between the ages of twenty and twenty-three; twenty were between the ages of twenty-four and twentyseven; eight were between the ages of twenty-eight and thirty-one; and three were between the ages of thirty-two and thirty-five. 
(2) Although all respondents were natives of Saudi Arabia, a large number of them had received some of their formal schooling in Cairo, Lebanon, or the United States; only nine of the respondents had received their complete educations in Saudi Arabia. Twenty-eight of the respondents received their education in both Saudi Arabia and abroad; i.e., neighboring Arab countries and the United States. However, the majority, twenty-two out of the twenty-eight, have been educated in Cairo. There are also variations with respect to their level of education when they went abroad: some went at grade school level, others at college level, and still others at both levels.

(3) Twenty-two of the respondents were single and fifteen were married. The length of their marriages ranged from nine months to twelve years. Thirteen of the married respondents have children, with the number of children ranging from one to five, and the children's ages ranging from six months to ten years.

(4) The length of time the respondents had worked ranged from two months to ten years.

(5) The respondents' incomes ranged from SR 1800 to SR 5300* per month. At the time of the interviews, two respondents had decided to quit working for awhile, three respondents had decided to change their jobs, and one respondent had decided to quit working and return to college for graduate study.

The findings of the study and its implications should be limited to the sample until further research is done. Respondents will not be

*\$1.00 (American) equal approximately 3.50 Saudi Riayls. 
identified in order to protect their privacy. According to Gordon, "Rarely does anyone argue with the idea of avoiding harm to the respondent . . harm can be done to the respondent by leaking information which could be used against him/her by legitimate authorities" (Gordon, 1969:147-157). The individual respondents will be referred to by a number (see Appendix B).

While including every respondent's views on every subject might have provided additional material of interest, the constraints of scholarly writing prohibited such an approach. Therefore, throughout this thesis, I have consistently noted the number of respondents who replied to each question in a similar way, followed by representative samples of some of their responses.

\section{PRELIMINARY CONSIDERATIONS}

The data for this study was collected during the summer of 1976 (May-September) in Jeddah, Saudi Arabia. Jeddah was chosen for this study since it is one of the two largest and most dominant cities. Jeddah and Riyadh, the capital of Saudi Arabia, overshadow all other cities in their educational, political, and administrative roles. Jeddah has a population estimated at between 150,000 and 300,000 (Malik, 1973:1). Being a commercial city with multi-functional characteristics, it has attracted many foreigners and others from Arab and Mosiem countries for work opportunities. The city is a major port by the Red Sea, and a major point of entry for those making Moslem pilgrimages and other travelers. Diplomatic representatives and consuls 
of foreign countries and branches of foreign firms, shipping companies, and banks are located in Jeddah.

Jeddah has also witnessed women entering some professional fields and working in salaried positions. King Abdul Aziz University in Jeddah, established in 1968, was one of the first in the country to admit females as regular students, and to provide job opportunities for women of Saudi Arabia. There are several women's organizations and clubs which have been formed for charitable, social, entertainment, and educational functions. There is also an adequate amount of information available about professional women in Jeddah, which will help achieve the purpose of this study. The researcher has lived in Jeddah, and is more familiar with the city than with other cities in Saudi Arabia.

\section{PROCEDURES USED WITH RESPONDENTS}

\section{Sampling School Teachers}

Since statistics necessary for this study are not available, much personal effort was made to determine the exact number of professional women in Jeddah. Government officials, particularly in the educational field, were contacted by phone to ascertain the number of women in their profession. The General Superintendent (male) of the female schools of the western part of the country was contacted to obtain permission to interview teachers. The Female Schools Superintendent (female) provided the researcher with figures of native workers with and without college degrees. Intermediate and high school principals were also contacted to get preliminary, information about teachers. Eight hundred seven teachers at the grade school level were excluded, since 
they had not acquired college degrees. Non-native teachers, the majority of whom teach in intermediate and high schools, were also excluded. One intermediate and one training school for teachers were excluded since they have handicapped male teachers. The survey showed that there were twenty-seven native school. teachers with college degrees at the time the survey took place. Those teachers were distributed among the nine intermediate and three high schools in Jeddah.

The twenty-seven teachers were divided into two groups: single (eighteen) and married (nine) women; then individuals were assigned numbers and a sample of four married and four single women was selected randomiy.

Sampling College Administrators and Teachers

College administrators were contacted at their places of work and by telephone. Forty-two native professional women in college teaching and administration were found. (It is not unusual for teachers at the college level to teach and/or work in administration.) Twenty-eight of the forty-two women were excluded because they reported that they did not interact with men in their work situations. Two other women were excluded; one was over thirty-five years old, and the other was on leave. This reduced the population to only twelve possible respondents. Numbers were assigned to each of the twelve women, and a sample of four single women and four married women was selected randomly. 
Sampling Social Workers, Investigators, Newspaper Editors, Interpreters, and Interior Decorators

Due to their limited number, social workers, investigators, newspaper editors, interpreters, and interior decorators were known to each other. Since they were few in number, plans were made to interview all of them. However, only four social workers with college degrees, one investigator, and one interior decorator were available; they were all interviewed. There were five newspaper editors. Only two were interviewed; the other three were difficult to contact. Newspaper editors usually have other jobs, particularly in education. There were six interpreters; however, only one was interviewed. One interpreter was out of the city, and four out of the six do not have direct interaction with males at work.

The researcher identified ten radio broadcasters. Four of the ten were interviewed--two married and two single--since they were the only ones available. The researcher had great difficulty in contacting the other six because some of them were out of the city, others were out of the country, and still others were too busy to be interviewed.

\section{Sampling Physicians}

of twelve physicians, only seven--four married and three single-were available for interviews. Two of the physicians were excluded since they did not have much interaction with males in their work situation. Another physician was not working for the government; she has her own clinic. One refused to be interviewed and another was out of the city. 
Some professional women hold identical or similar occupations, but do not have the same degree of interaction with males at work (e.g., college administrators, interpreters, and physicians). This discrepancy is due to the fact that they work under different organizational systems with different work rules. In addition, they might work in the same organization, but some of their jobs require less interaction with males than others.

The sampling frame for the purposive sampling, then, consisted of six types of women: married with least interaction with men, married with occasional interaction with men, married with most interaction with men, single with least interaction with men, single with occasional interaction with men, and single with most interaction with men. Table I illustrates the breakdown of respondents into these six categories.

\section{TABLE I}

MARITAL STATUS AND DEGREE OF INTERACTION WITH MEN

\begin{tabular}{|c|c|c|c|}
\hline $\begin{array}{l}\text { Degree of Inter- } \\
\text { action with Men } \\
\text { at Work } \\
\end{array}$ & Married & Single & Occupation \\
\hline Least & $\begin{array}{l}4 \\
5\end{array}$ & $\begin{array}{l}4 \\
4 .\end{array}$ & $\begin{array}{l}\text { School teachers } \\
\text { College administrators and teach- } \\
\text { ers }\end{array}$ \\
\hline Occasional & 1 & $\begin{array}{l}4 \\
1 \\
1\end{array}$ & $\begin{array}{l}\text { Social workers } \\
\text { Newspaper editors } \\
\text { Investigators }\end{array}$ \\
\hline Most & $\begin{array}{l}3 \\
2\end{array}$ & $\begin{array}{l}4 \\
2 \\
1 \\
1\end{array}$ & $\begin{array}{l}\text { Physicians } \\
\text { Radio broadcasters } \\
\text { Interpreters } \\
\text { Interior decorators }\end{array}$ \\
\hline Totals & 15 & 22 & \\
\hline
\end{tabular}




\section{CONTACTING THE RESPONDENTS}

Respondents were contacted by telephone to make appointments for interviews. Finding respondents' homes was time-consuming because streets and building names/numbers were not always available. Transportation for the researcher was available, but not very convenient, since women are not allowed to drive in Saudi Arabia. It was often frustrating waiting for a male relative to' provide a ride when the family driver became tired. He did not understand what I was doing, and was not very comfortable with the idea of a woman going to a "stranger's" house in the evening. He once commented, "You are just wearing yourself out, Aunt, while other women are relaxing at home and enjoying their tea."

I was impressed with the enthusiasm exhibited by the respondents who participated in this study. They discussed their situations easily and comfortably; they were cooperative and appeared to be open in their respondent role; and many had outstanding verbal and conceptual skills. Some respondents showed much curiosity about the nature of this study, and expressed the hope that they could read it when it was completed.

Although respondents appeared to be answering questions honestly and frankly, discussing relationships between males and females in the work situation was a touchy subject. The topic produced several reactions among the respondents: some seemed uncomfortable, while others seemed surprised that the subject was broached. However, respondents were candid during their interviews. Respondent \#37 said to me, "I'm highly impressed by what you are doing. I feel comfortable talking to you. You are doing a good job as an interviewer." The researcher was 
also supported by Respondent \#21, who said, "After seeing what you are doing, I'm encouraged to go to graduate school."

For the most part, respondents kept the focus of the study in mind. Some who had a great deal to say sometimes wandered off the subject, but it was easy to bring them back to the focus of this study. It was decided in advance to interview at least thirty-two women; after thirty-seven respondents had been interviewed, it was felt that enough information had been collected. A sample of thirty-seven respondents seemed adequate considering the number and availability of professional women in Jeddah. Time was also a factor in bringing the data collection to an end, and it was felt that no new information would be added by further interviews. According to Glaser and Strauss, the researcher should stop data collection when no new data are found.

The criterion for judging when to stop sampling the different groups pertinent to a category is the category's theoretical saturation. Saturation means that no new additional data are being found whereby the sociologist can develop properties of the category (Glaser and Strauss, 1967:61).

\section{THE INTERVIEW}

It took almost ten weeks to complete the interviews. On the average, four respondents were interviewed each week. It was inconvenient for most respondents to be interviewed on weekends or during the day. Respondents were interviewed in a place where they felt comfortable and secure. According to Gordon, "If ego threat is to be minimized, it is usually necessary to find a place where privacy is assured" (Gordon, 1969:251). Twenty-four respondents preferred to be interviewed at their homes, and thirteen chose their work place. 
Each interview lasted almost two hours. Conversation during interviews, taking notes, and the standardized questions were all in Arabic (the researcher's and the respondents' native language). However, most respondents read and speak English and some of them commented spontaneously in English.

This study is of an exploratory nature, but there was also interest in testing the hypotheses stated; consequentiy non-standardized interviews as well as standardized questions were felt to be valuable research tools. According to Gordon, "It is possible to combine the objectives of discovery and measurement in the same interview" (Gordon, 1969:72).

A considerable part of the interview was open-ended with the aid of the guide questions. During the interview the conversation was focused on the following areas: (1) the difficulty of combining job and home responsibilities, (2) the support women get from their social network in the choice of their professions, (3) the behavior expected from professional colleagues, and (4) the way women are treated at work.

The sequence of the topics was varied by the interviewer and subtopics were discussed to fit particular situations. Some questions were omitted when it was felt that the information had already been obtained indirectly. From time to time the researcher added or removed some of the questions if the situation warranted such changes. However, the interviews were structured by the guided questions to serve the main objectives of the study. The interview guide was also helpfut in recording the answers in certain topical areas. After a number of 
interviews, the researcher almost memorized the questions and they appeared spontaneous.

In standardized questions, respondents were asked about the adequacy of time they had for both work and home responsibilities. The standard responses ranged from "much" to "little." They were asked how much support they received from their social network for the type of occupation a woman was pursuing; answers ranged from "much" to "little." The network includes a woman's own family, husband, parents, sisters, brothers, her own relatives, husband's family, and people she comes into contact with at work (e.g., drivers, guards clients, patients).

The third index was the degree of contradictory behavior expectations perceived by working women at their place of work; responses ranged from "much" to "little." "Contradictory behavior expectations" was interpreted to mean the expectation that a professional woman was expected to be helpfur, accommodating, accepting, and sympathetic, and at the same time was expected to be aggressive, dominant, and to compete as a career person. Respondents were given questions with responses which ranged from "very much" to "little." The respondents' answers were paired according to the amount of contradiction. In the section of the questionnaire dealing with the way women are treated in. sex-related roles vs. work-related roles, no standardization was used. It was felt that open-ended questions were more appropriate. According to Gordon, "It is possible to collect part of the information in one way and part in the other" (Gordon, 1969:78). 
COMBINING QUALITATIVE AND QUANTITATIVE DATA

Editing the vast amount of data included: (1) translating the material into English. Translation from one language to another is time-consuming, and there is always the possibility of modification since some expressions and ideas are culturally grounded. However; great care was taken to maintain the context as much as possible.

(2) Selecting the material relevant to the objectives of the study.

(3) Searching for concealed meanings that are reported plainiy.

(4) Developing a systematic analysis to summarize the material.

Although data obtained from interviews and standardized questions were combined, the emphasis in this study is on qualitative data analysis. According to Gordon, "It is possible to combine the objectives of discovery and measurement in the same interview, but as more emphasis is placed upon one objective, the other must be subordinated" (Gordon, 1969:72). There is always difficulty in assessing qualitative data, since it is not standardized. However, Goode and Hatt indicate that in order to gain standardization, depth is often sacrificed, thus the qualitative interviews, if properly analyzed, may get at deeper meanings (Goode and Hatt,:1952). The standardized questions were used to fulfill the measurement objective of this study. Due to the small size of the sample and sampling procedures, no statistical tests have been attempted.

Combining quantitative and qualitative data aided in the analys is of the data and provided more insight. It also proved useful as a check in analyzing the information. In general, quantitative data was compatible with qualitative information. However, some respondents', 
answers in some cases were not consistent. When such inconsistencies occurred, more reliance was placed on the information obtained from the lengthy interviews. Inconsistency could have been due to the fact that some respondents felt ambiguous about some questions. There was also the possibility that the order in which the questions were presented influenced the results (Carp, 1974).

The complete interview guide, with examples of questions and probes used in the open-ended portions of the interview, and the standardized question used, are included in Appendix $A$. 
CHAPTER IV

TIME ALLOCATION

In this chapter we are investigating the relationship between marital status and time allocation. It was hypothesized that married women with children would experience more difficulty than single women in allocating time between work and home roles due to the fact that the obligations of the mother-wife role are so demanding. In the mother-wife role, time is required for child care, housework, and the husband; in the professional role, time is required for a variety of professional duties. The professional wife-mother must fulfill the responsibilities of both her home and her job.

Both the qualitative and the quantitative data support our hypothesis. It was found that relationships do exist between marital status and time allocation. Married women reported more difficulty with respect to time allocation than did single women. However, it was found that the degree of difference was not as great as might have been expected. Married women reported the use of various mechanisms to allocate their time satisfactorily.

In this chapter; qualitative and quantitative data will be incorporated to illustrate the degree of difference in the difficulty of allocating time between married and single respondents. For clarity of presentation, a discussion of married respondents will precede that of single respondents.' Secondly, the mechanisms used to reduce time 
difficulty will be explained. It was found that these mechanisms were not equally successfur. The data on the success of time-allocation mechanisms indicates that the respondents fell into three categories: the adaptors, the temporary withdrawers, and the non-compensators. These categories will be discussed in the last part of this chapter.

\section{DIFFERENCES OF TIME ALLOCATION BY}

MARITAL STATUS

Married Respondents

The data suggest that married women had more difficulty than single women with respect to time allocation. Ten of the fifteen married women in the sample indicated that they had difficulty with the allocation of their time. They reported that they did not have enough time to do housework properly, and that they did not have enough time for their children and husbands. They were also concerned about the limited amount of time for their own rest and entertainment.

Respondent \#5, a school teacher and mother of a preschool child, described her situation in the following way:

Working hours are inconvenient. I wish we could leave school after teaching our classes. That way I would use the time for personal things, like reading. What bothers me sometimes is that I don't have enough time to do my housework the way I want to. The housework gets done, but I want to do it better and rush less. What bothers me is that I feel so tired after work. This could be due to the fact that opportunities for entertainment are so limited. Teaching is so demanding, and the constant hot weather depresses me.

Respondent \#7, a school teacher, married, with no children, said:

I don't like the working hours. We are not allowed to leave after teaching our classes. I could use more time to rest, to do more for the house, and to spend more time with my husband. The limited amount of time I have doesn't allow me to rest enough. What realiy 
bothers me is that I am so exhausted physically. This could be due to the fact that I do work as a volunteer in the evenings. I work thirteen hours a day.

A college administrator and teacher with three children (Respondent \#17) expressed similar sentiments. She described her situation of working, being a mother, and being a wife in the following manner:

Working, being a mother and a wife could be managed but at the expense of your own rest and entertainment. I try to devote enough time to my children and my husband. Then if there is time left, which is little, it is for myself.

A physician with a preschool child (Respondent \#27) reported dissatisfaction with her working hours:

I don't like the working hours. Since I have to work in the evening, I don't have enough time for my own rest and entertainment. I have a governess, and my cous in lives with me. This helps; however, I wish I had more time for my child, and to do housework the way I like it done. It is just that there is not enough time.

A physician with a preschool child, who was very dissatisfied with the small amount of time she devoted to her child (Respondent \#28), said:

I don't like to work because I want to take care of my child at this age. My job doesn't allow me to devote enough time to my child, since I have to work in the mornings and in the evenings. Working mornings and evenings doesn't allow me enough time to rest, to run the house the way I want to, and to schedule my time the way I want to.

An editor, mother of two preschoolers, also expressed dissatisfaction with the amount of time she could devote to her children, housework, and husband. Respondent \#37 reported:

Working for a newspaper requires a lot of time. It might be more appropriate for a single woman. I found out that my job demands a lot of time, since I was doing original work. It makes me feel that I do not give enough time and care to my children, housework, and husband. 


\section{Single Respondents}

The data suggest that only seven of the twenty-two single women in the sample expressed difficulty in the allocation of their time. Four of the seven reported some difficulty because of home responsibilities. Such situations as the absence of the father (divorced mother, father travels occasionally) or a sick mother to care for created a burden for the working daughter. Respondent \#2, a school teacher, the eldest daughter with five siblings and a divorced mother, reported:

I don't like my working hours. I wish we could leave after teaching our classes. That way I would be able to use the time for things that interest me. For example, I enjoy sewing and reading. What really bothers me most is feeling responsible for supervising the household, since my mother is divorced.

However, she reported that housework was distributed: "Most of the housework is taken care of by my mother, my sisters, and the servant. I also help on weekends and in the evenings."

A social worker, Respondent \#20, the eldest daughter of a family with one brother, often helped with her father's business. She was also in charge of the house when her father was away. As a dependable person, she wanted to participate more in the housework. She reported dissatisfaction because she did not have time to help her mother: "My mother always has somebody to help her with housework. However, I still wish I had more time to help. I don't have enough time to do that. This is what bothers me."

A school teacher, Respondent \#4, reported that her mother and sister had physical problems. Consequently, she was entirely responsible for housework. She talked of her situation:

What bothers me sometimes is that I lack opportunities for entertainment and visiting. I don't have much time for those things. 
The thing that bothers me quite a bit is trying to find a servant to help. Besides, servants are expensive. My mother and sister have physical problems; they need help with housework, so I help them.

Large families with low incomes, unable to afford servants and receiving no help from sons, place a burden on their daughters. Respondent \#3, a school teacher whose family had fourteen members, told of her situation: "What bothers me is that I have no opportunity for entertainment. I have many sisters and brothers. There's a lot of housework and brothers don't help at all. We can't afford to hire a servant."

It appeared that professions such as medicine and college teaching demanded a great deal of time. Three single professional respondents told of their physical tiredness and lack of time for adequate rest. Respondent \#11, a college administrator and teacher, reported her physical weariness. She was very involved in her career, and also had responsibilities at home as the eldest and only daughter.

I am expected to help with housework--sometimes I am in charge of everything at home when my mother is away. I don't have enough time for all of my responsibilities. What bothers me is that. sometimes I worry about home chores. I wish I did not have to do so much. What really bothers me is that I am physically tired. Working in administration, teaching, sometimes going back to work in the evening, and helping with housework is more than I can handle sometimes.

Respondent \#26, a physician, expressed her dissatisfaction at not getting enough rest because of her professional time schedule:

What really bothers me is that I am too exhausted psychologically and physically. I can't stay at home enough--I don't socialize enough with my family, and I don't do enough visiting. All I do is go home to eat and sleep. My job requires a lot of time. I work evenings and mornings. I don't lead a normal 1 ife; I'm not myself. My job takes so much out of me. When I get home, I don't feel like talking:or laughing or being myself. I just don't have 
enough time to rest, to be with my family, and to help with the housework.

From a structural viewpoint, more married than single women experienced difficulty in the allocation of time between work and home roles. However, the quantitative data show, in general, that the degree of difference in difficulty is not as great as might be expected. Table II summarizes the differences in degree of difficulty in time allocation by marital status.

Table II shows that 29 percent of the married women, compared with 36 percent of the single women, reported adequate (much) time for housework (Question 1). Time for children was also reported as adequate, with 42 percent of the married women, compared with only 14 percent of the single women, reporting that they have much time for child care. Only 8 percent of the married women reported that they had too little time for child care, compared with 36 percent of the single women. Time for husband was also reported as adequate: 46 percent of the married respondents reported much and 46 percent reported some (Question 3). Of course, no comparison can be made with single women in this regard. It appeared that single women had more time for visiting than the married women (Questions 4 through 7 ). However, the differences were not striking.

The main differences appeared with respect to time for doing work-related jobs at home. Forty-three percent of the married women showed little time, while none of the single women reported having little time (Question 3). Differences also appeared with respect to dedicating time for themselves. Only 14 percent of the married women reported having much time compared to 48 percent of the single women. 
TABLE II

DEGREE OF DIFFICULTY IN TIME ALLOCATION BY MARITAL STATUS

\begin{tabular}{|c|c|c|c|c|c|}
\hline Question & $\begin{array}{l}\text { Marital } \\
\text { Status } \\
\end{array}$ & Much & Some & Little & Total $(\mathrm{N})$ \\
\hline $\begin{array}{l}\text { 1. Do you have time after } \\
\text { ing hours for housewori }\end{array}$ & $\begin{array}{l}\text { Sin } \\
\text { Mar }\end{array}$ & 29 & 5 & $\begin{array}{l}18 \\
14\end{array}$ & $\begin{array}{l}100 \%(22) \\
100 \%(14)\end{array}$ \\
\hline $\begin{array}{l}\text { 2. Do you have time after work- } \\
\text { ing hours for child care or } \\
\text { younger brothers, sisters, } \\
\text { the aged? }\end{array}$ & & 1 & $\begin{array}{l}50 \\
50\end{array}$ & $\begin{array}{r}36 \\
8\end{array}$ & $\begin{array}{l}100 \%(14) \\
100 \%(12)\end{array}$ \\
\hline $\begin{array}{l}\text { le time to devote to } \\
\text { and? }\end{array}$ & & $\ddot{46}$ & $\overline{46}$ & $-\overline{8}$ & $\begin{array}{c}-- \\
100 \%\end{array}(--)$ \\
\hline $\begin{array}{l}\text { 4. Do you have time to get to- } \\
\text { gether with your family? }\end{array}$ & $\begin{array}{l}\mathrm{Si} \\
\mathrm{Ma}\end{array}$ & $\begin{array}{l}50 \\
29\end{array}$ & $\begin{array}{l}50 \\
50\end{array}$ & $\overline{21}$ & $\begin{array}{l}100 \%(22 \\
100 \%)(14\end{array}$ \\
\hline $\begin{array}{l}\text { have time to } v \\
\mathrm{~s} \text { ? }\end{array}$ & $\begin{array}{l}\text { Sir } \\
\text { Mar }\end{array}$ & $\begin{array}{l}14 \\
--\end{array}$ & $\begin{array}{l}52 \\
57\end{array}$ & $\begin{array}{l}33 \\
43\end{array}$ & $\begin{aligned} 99 \% & <21 \\
100 \% & (14\end{aligned}$ \\
\hline $\begin{array}{l}\text { 6. Do you have time to visit } \\
\text { relatives? }\end{array}$ & $\begin{array}{l}\text { Sil } \\
\text { Mai }\end{array}$ & $\begin{array}{r}26 \\
7\end{array}$ & $\begin{array}{l}47 \\
64\end{array}$ & $\begin{array}{l}26 \\
29\end{array}$ & $\begin{array}{l}100 \%(19 \\
100 \%(14\end{array}$ \\
\hline $\begin{array}{l}\text { 7. Do you have time for famil } \\
\text { social activities? }\end{array}$ & $\begin{array}{l}\text { Sin } \\
\text { Mar }\end{array}$ & $\begin{array}{r}23 \\
7\end{array}$ & $\begin{array}{l}55 \\
64\end{array}$ & $\begin{array}{l}23 \\
29\end{array}$ & $\begin{array}{l}101 \%(22 \\
100 \%(14\end{array}$ \\
\hline $\begin{array}{l}\text { 8. Do you have time to do } \\
\text { related to your job at }\end{array}$ & $\begin{array}{l}\text { Sin } \\
\text { Mar }\end{array}$ & $\begin{array}{l}55 \\
29\end{array}$ & $\begin{array}{l}45 \\
29\end{array}$ & $\overline{43}$ & $\begin{array}{l}100 \%(20 \\
101 \%(14\end{array}$ \\
\hline $\begin{array}{l}\text { - Does J } \\
\text { to dec }\end{array}$ & & $\begin{array}{l}48 \\
14\end{array}$ & $\begin{array}{l}38 \\
50\end{array}$ & $\begin{array}{l}14 \\
36\end{array}$ & $\begin{array}{l}100 \%(21 \\
100 \%\end{array}$ \\
\hline
\end{tabular}

Table III shows that married women experienced more fatigue than single women. Twenty-nine percent reported that they felt very tired while doing housework, compared with 10 percent of the single women (Question 10). This is consistent with the qualitative information, since married respondents often expressed their opinion that housework was monotonous. 
TABLE III

DEGREE OF FATIGUE BY MARITAL STATUS

\begin{tabular}{|c|c|c|c|c|c|c|}
\hline & Question & $\begin{array}{l}\text { Marital } \\
\text { Status }\end{array}$ & Much & Some & Little & Total (N) \\
\hline 10. & $\begin{array}{l}\text { Are you tired when you do } \\
\text { your housework (or help } \\
\text { with housework)? }\end{array}$ & $\begin{array}{l}\text { Single } \\
\text { Married }\end{array}$ & $\begin{array}{l}10 \\
29\end{array}$ & $\begin{array}{l}48 \\
43\end{array}$ & $\begin{array}{l}43 \\
29\end{array}$ & $\begin{array}{l}101 \%(21) \\
101 \%(14)\end{array}$ \\
\hline 11. & $\begin{array}{l}\text { Are you tired when you take } \\
\text { care of your children or } \\
\text { younger siblings or the } \\
\text { aged after working? }\end{array}$ & $\begin{array}{l}\text { Single } \\
\text { Married }\end{array}$ & $\begin{array}{r}9 \\
17\end{array}$ & $\begin{array}{l}45 \\
25\end{array}$ & $\begin{array}{l}45 \\
58\end{array}$ & $\begin{array}{r}99 \%(11) \\
100 \%(12)\end{array}$ \\
\hline
\end{tabular}

It is interesting to note that married respondents did not report the same result with respect to child care. Fifty-eight percent reported that they were a little tired for child care (Question 11). This could be due to the fact that most married women wanted to devote more time to their children, and to do things for them. They might have felt deep down that they should give priority to their children's demands.

\section{MECHANISMS FOR ALLOCATING TIME}

Qualitative data indicated that married respondents have not internalized difficulty in the allocation of their time. Respondents occasionally spoke of sets of mechanisms that facilitated handling home and work responsibilities. According to Goode (1960), strain "difficulty" is likely to be associated with a mechanism of reducing it.

The mechanisms mentioned by the respondents could be categorized as follows: (1) management of time through scheduling and delegation of tasks. Most married respondents arranged schedules to 
coordinate work and home responsibilities, with no overlapping. All married women in the sample except for one had domestic help. They also reported that they had help with their children. (2) Compromise. Wives were careful to control the extent of their career involvement. (3) Establishment of a salient role; that is, giving priority to family demands when the strain became too great. (4) The mechanism of redefinition. Women redefined their situation favorabiy and were thus able to overcome psychological feelings of guilt. A woman might also legitimize her occupational role and commitment to her family and herself. (5) Reduction of social relationships. Most married respondents reported limited visiting with neighbors, friends, and relatives, and attendance at few, if any, social activities.

There are other techniques which were seldom mentioned by the respondents. These techniques are: (1) compartmentalization through role distance. That is, the wife tries to keep her home role distinct and separate from her professional role. (2) Compartmentalization through role relaxation. For example, absence of the husband makes the fewest demands. Three respondents reported that their husbands worked in the evenings and during the day. This freed the wives from investing a portion of their time for their husbands' demands. In addition, the husbands' absence facilitated the wives' organization of their time.

Management of Time through Scheduling and Delegation of Tasks

Most married women in the sample arranged schedules to coordinate work and home activities. All married respondents except one had 
full-time domestic help. Four of the women relied on their mothers when they were temporarily without domestic help. Two of the respondents lived with their husband's family. One lived with a sister-in-law in the same house, and the other lived in the same building with her husband's parents. Two of the respondents lived with their own families, and one respondent lived in the same building with her family. One respondent's cousin lived with her. To sum up, eight of the married respondents had help from their mothers, and the other two had help from their husbands' families.

This is consistent with the quantitative findings. Table IV shows that 79 percent of the married women reported that they frequently had servants, compared with 71 percent of the single women (Question 12). This is also confirmed with the findings of Question 13, since 86 percent of the married women frequently had some help with housework compared with 95 percent of the single women. It appears also that 75 percent of the married respondents frequently had help with their children (Question 14).

TABLE IV

PRESENCE OF DOMESTIC HELP BY MARITAL STATUS

\begin{tabular}{|c|c|c|c|c|c|}
\hline Question & $\begin{array}{l}\text { Marital } \\
\text { Status }\end{array}$ & $\begin{array}{l}\text { Fre- } \\
\text { quent- } \\
\text { Ty }\end{array}$ & $\begin{array}{l}\text { Some- } \\
\text { times }\end{array}$ & Never & Total (N) \\
\hline 12. Do you have a servant? & $\begin{array}{l}\text { Single } \\
\text { Married }\end{array}$ & $\begin{array}{l}71 \\
79\end{array}$ & $\begin{array}{l}14 \\
14\end{array}$ & $\begin{array}{r}14 \\
7\end{array}$ & $\begin{aligned} & 99 \%(21) \\
& 100 \%(14)\end{aligned}$ \\
\hline $\begin{array}{l}\text { 13. Do you have somebody to } \\
\text { help with the housework? }\end{array}$ & $\begin{array}{l}\text { Single } \\
\text { Married }\end{array}$ & $\begin{array}{l}95 \\
86\end{array}$ & $\begin{array}{r}5 \\
--\end{array}$ & $\overline{14}$ & $\begin{array}{l}100 \%(21) \\
.100 \%(14)\end{array}$ \\
\hline $\begin{array}{l}\text { 14. Do you have somebody to } \\
\text { help with the children? }\end{array}$ & $\begin{array}{l}\text { Single } \\
\text { Married }\end{array}$ & $\overline{75}$ & $-\overline{8}$ & $\overline{17}$ & $\overline{100 \%}(-\overline{12})$ \\
\hline
\end{tabular}


This finding was supported by four respondents. Respondent \#5

described her situation as manageable:

The difficulty that I have sometimes is finding a servant to stay with my child. I worry about leaving my child when I hire a new servant. However, this is a temporary problem. Servants usually come and go. I am thinking about having my mother live with me when I have my second child.

My eldest child will be going to school, and my mother will be supervising the younger child. If my mother can't come and live with me, I might quit working for one year.

Then the respondent went on to explain how she was managing her responsibilities:

In general I can manage home and work activities. My husband works in the evening and that's why I have time to do some work in the evening. I do cooking, work related to my job which doesn't take much time, and I supervise my child. I think with time scheduling I will be able to manage my responsibilities even after I have my second child.

In general I'm satisfied with myself. It's just that sometimes I feel bad when my child is sick, and I go to work. I don't want to quit working--I prefer to work. I quit working once for one year and I didn't like it. It was boring. I felt that I wasn't doing anything usefur.

Respondent \#7 lived with her in-laws in the same building. She

described her situation quite favorably:

Time scheduling is very important in handling my responsibilities. I don't really have a problem of time allocation. I organize my time to do things, but at the expense of my rest. It bothers me that my husband doesn't help. He feels housework is women's responsibility. However; I have a houseboy who comes twice a week. I cook early in the morning. I have two days off, and that helps. I visit relatives only on special occasions.

Teaching doesn't demand as much time as being a physician, which was my real desire. My husband prefers that I teach, since it is a clear-cut job. The time needed for doing homework, for example, is not much.

Then this respondent redefined her situation favorably to legitimize her occupational involvement and commitment. She expressed selfsatisfaction: 
My husband's family doesn't like me to work. They feel it would be better if I spent more time with my husband--their son! Colleagues sometimes give me the impression that I am too involved in my work. I don't really care. I am very satisfied with myself. I want to contribute to developing my country. I realize our society's urgent need for qualified teaching of religious subjects. That is why I am insisting on working. One of my. obligations as a member of this society is to participate in teaching the illiterate. That is why I feel it is necessary that I work in the evenings. I will continue even if my husband objects.

Then this respondent reported her pregnancy. At that stage she was thinking of quitting her evening work only:

My mother-in-law lives in the same building. She doesn't mind having my child when I go to work. However, I feel it wouldn't be fair to leave my child all day. That's why I won't be able to continue working in the evenings. I wish we had good nursery schools. I don't mind leaving my child with my mother-in-law. The thing that I am thinking about is that, you know, she is a different generation. Her socialization of my child will be different from mine.

Respondent \#13 lived with her sister-in-law in the same house and often had a servant. This helped her manage her work and home activities. It was obvious that she was dissatisfied with the way things were going:

Everything is running in the house. However, I don't like the way things are. I feel that I want to discipline my children my way. It bothers me that I don't run the house myself. It bothers me that I don't cook for my husband.

However, she was insistent about continuing to work. She reported that she got satisfaction from working. She talked about her attempt to manage and have more time for housework through compromise as well as by having domestic help:

If I just teach, I' 11 be able to have more time to rest, to care for my children and my house. I'll try to get the necessary qualifications so I can teach in the university without working in administration. My husband suggests the same thing. That way I would be able to just teach my classes on certain days and not have a daily schedule of going to work. Consequently, I would have more time to run my family life better. I don't want to stop working, 
and I won't. Sitting at home is boring and monotonous. My husband is not much in favor of my working. However, he doesn't show it; he agrees mainly to please me. He also feels that if I quit working I will be spending my time visiting, which I don't find very interesting. My husband doesn't like it either. I do visit, but not continuously--just occasionally.

Management through Compromise

The data also suggest that wives were careful to control the extent of their career involvement. Like Respondent \#13, Respondent \#16 expressed her attempt to compromise between home and profession, and to allocate more time for home demands. This respondent lived temporarily with her own family and they often had a servant.

I am living with my family temporarily until I can furnish my own apartment. When I move out, a servant will help me with my housework. I'll send my child to school when he reaches school age. My husband is not demanding. Because I don't feel comfortable about leaving my children with servants, I'll take them to my parents' house. They won't mind at all.

This respondent was managing because she got a lot of help from her own family. She felt that in order to solve the problem of time allocation, professional involvement had to be cut back as deemed necessary:

I will try to just teach, so I can organize my time better. When I am just teaching, I can go to the university on certain days. I don't like to go to work daily. I would like to just teach my classes and go home, then I could organize my life better. I will be so happy if I can do that. My husband suggests that I quit teaching and work only in administration, since teaching is so time-demanding.

In the future, if I find it difficult to handle both responsibilities--for example, if I have another child--I might just work in administration, although I prefer teaching.

Then the respondent expressed priority to family demands when strain became too great. "Most important to me is my family. If I ever feel unsatisfied, or my husband is bothered, or the children are not happy, I will quit working." 
This leads us to the establishment of a salient role, which was expressed by two respondents, \#28 and \#37.

Establishment of a Salient Role

At the time I interviewed them, Respondents \#38 and \#37 had decided to resign their jobs in order to alleviate their problems with time allocation. When the strain becomes too great for some women, they may resign from their jobs, at least temporarily, to alleviate the tension.

Both respondents felt that their families came first in importance when the job began to take too much time. However, it should be noted that neither of these respondents had family help, and both were very concerned about socializing their children themselves. Respondent \#28 expressed herself as follows:

The first five years are very important for a child's socialization. I worry about my child when I leave him with a servant. My mother is not always available to stay with my son. I would prefer to stay at home until my child reaches school age. My job doesn't allow me to devote enough time to my child. Society and I benefit when I work, but at my child's expense. My son has priority; working makes me less caring about my child.

Respondent \#37 expressed a similar attitude. She reported:

I was feeling guilty about my children. I worry about them. My husband expects too much. We socialize a lot. He doesn't realize I'm tired. I don't like to do work related to my job at home. Conflict of time was the major reason that I decided to quit working. Neither my family nor my husband's family live in the city so they are not able to help me. I don't want my children to be raised by a servant. I don't like to work at the expense of my children.

However, the respondent showed her desire to work when the children reached school age:

When my children reach school age, I will go back to work. I love my work. It's a good job--very interesting. Sitting at home is 
boring and monotonous. As a working woman, I feel respected. People look up to me.

It is interesting to note that only one respondent expressed dissatisfaction at giving priority to her family. Actually she was oscillating between giving priority to the family and participating in other activities. On one occasion, Respondent \#35 reflected on her traditional socialization: "I feel that when a woman gets married, she should devote her time to her husband and children. She has to give priority to her family. So I feel as a wife I have to give priority to my fami7y." Then she expressed her deep desire to do other things, and her dissatisfaction at being restricted to just a family role. Her response indicated the way in which the female role places 1 imitations on the full realization of the professional role. She said:

However, I feel that as a person, I am not only created to be a wife and a mother. It is not an ultimate goal. I feel I have the potential to do other things. I am capable of organizing an effective women's organization, and can do more for broadcasting.

My responsibilities as a wife and a mother restrict me. What bothers me so much is that I am not patient enough with my children. It is something in my personality, and not because I work. I do find children's demands are fairly irritating. I wish I participated more in other activities, but family responsibilities do not allow me to. It bothers me sometimes. I wish I did not have kids so I could do other things. I give enough time to my family members--I'm satisfied with myself in that respect. However, I wish I could do other things. I don't like to be just a good mother and a wife.

The Mechanism of Redefinition

Another mechanism to manage time allocation cited by some women in the sample is the mechanism of the favorable redefinition of the situation. This was best described by Respondent \#15, who was determined to continue working. She described her situation as favorable because of the help she gets from her family and domestic servants. She 
also talked of her limited involvement in social activities as a method of managing her time:

I spend more time with my children than non-working mothers. Some of them spend a lot of time visiting, shopping, and in beauty shops. I don' $t$ want to stay at home--housework doesn' $t$ require much experience or brains. I won't learn by sitting at home. When I'm at work, my mother and sister supervise my children. Since we live in the same building, I seldom have to worry about leaving my children with a servant. It's hard to find good servants. However, I'm not going to quit working.

Reduction of Social Relationships

It appears from qualitative data that married respondents tend to reduce their social relationships in order to spend more time at home. Respondent \#5 said:

I don't do much visiting. I never did enjoy it--even before I was married. I don't participate in women's organizational activities. I prefer to spend evenings at home with my child and my husband, when he comes home from work. Most of our friends are working men and women. We visit them, but not often.

Respondent \#15 expressed a similar sentiment:

I don't participate in women's organizational activities. When my children become older, I might participate if child care facilities are available. I don't like going visiting; I would rather stay with my kids. I often visit my family, since I can take the children with me. I don't participate in job-related activities because I don't have the time and transportation is a problem. My husband is out of the city, my children are still young, and I prefer to stay with them.

Table $V$ shows that married respondents reduced their social relationships, whereas single respondents showed greater participation in all areas except those surrounding the respondent's job. Sixty-two percent of the married women reported little participation, compared to 19 percent of the single women, with half the single women reporting much participation (Question 15). This finding should be interpreted in light of the fact that some respondents (e.g., physicians, radio 
broadcasters, interpreters, and newspaper editors) reported that work activities were limited and/or that women were not allowed to participate.

TABLE $V$

PARTICIPATION IN SOCIAL RELATIONSHIPS BY MARITAL STATUS

\begin{tabular}{|c|c|c|c|c|c|}
\hline Question & $\begin{array}{l}\text { Marital } \\
\text { Status }\end{array}$ & Much & Some & Little & Total (N) \\
\hline $\begin{array}{l}\text { 15. How much do you participate } \\
\text { in activities related to } \\
\text { your job? }\end{array}$ & $\begin{array}{l}\text { Single } \\
\text { Married }\end{array}$ & $\begin{array}{l}50 \\
23\end{array}$ & $\begin{array}{l}31 \\
15\end{array}$ & $\begin{array}{l}19 \\
62\end{array}$ & $\begin{array}{l}100 \%(16) \\
100 \%(13)\end{array}$ \\
\hline $\begin{array}{l}\text { 16. How much do you participate } \\
\text { in activities related to } \\
\text { husband's job? }\end{array}$ & $\begin{array}{l}\text { Single } \\
\text { Married }\end{array}$ & $\overline{42}$ & -- & -- & $\begin{array}{cc}-- & (--) \\
100 \% & (12)\end{array}$ \\
\hline $\begin{array}{l}\text { 17. How much do you participate } \\
\text { in social organizational } \\
\text { activities? }\end{array}$ & $\begin{array}{l}\text { Single } \\
\text { Married }\end{array}$ & $\begin{array}{r}24 \\
8\end{array}$ & $\begin{array}{l}24 \\
--\end{array}$ & $\begin{array}{l}53 \\
92\end{array}$ & $\begin{array}{l}101 \%(17) \\
100 \%(13)\end{array}$ \\
\hline $\begin{array}{l}\text { 18. How much do you participate } \\
\text { in family of orientation or } \\
\text { relatives' activities? }\end{array}$ & $\begin{array}{l}\text { Single } \\
\text { Married }\end{array}$ & $\begin{array}{l}52 \\
29\end{array}$ & $\begin{array}{l}29 \\
57\end{array}$ & $\begin{array}{l}19 \\
14\end{array}$ & $\begin{array}{l}100 \%(21) \\
100 \%(14)\end{array}$ \\
\hline $\begin{array}{l}\text { 19. How much do you visit your } \\
\text { family or close relatives? }\end{array}$ & $\begin{array}{l}\text { Single } \\
\text { Married }\end{array}$ & $\begin{array}{l}65 \\
62\end{array}$ & $\begin{array}{l}30 \\
38\end{array}$ & $\begin{array}{r}5 \\
--\end{array}$ & $\begin{array}{l}100 \%(20) \\
100 \%(14)\end{array}$ \\
\hline
\end{tabular}

This lack of opportunity could also be true in regard to the participation of women in activities related to their husbands' jobs, since 58 percent of the married respondents reported little participation (Question 16). Reduction of social relationships is well documented in the data with respect to participation in social organizational and other activities. Ninety-two percent of the married women, compared to only 53 percent of the single women, reported little participation in social organizational activities (Question 17). 
However, it should be noted that there are other factors which are related to the limited participation of women in organizational activities. Transportation problems were reported by some respondents, while other respondents felt they should devote evenings to their families, since they worked in the mornings. Also mentioned were the inconvenience of taking their children with them, and feeling uncomfortabel about leaving children home and being away from them both morning and evening. However, the significant finding is that both married and single women considered family visiting important. Sixty-two percent of the married women and 65 percent of the single women reported much visiting (Question 19). This could be due to the fact that in Saudi Arabian society the individual's loyalty and obligations to his/her family are significant, although some changes are taking place. Another possible explanation is that family gatherings are one source of entertainment, since outdoor entertainment facilities are relatively limited in Saudi Arabia.

On the other hand, it appears that married respondents were not much involved with frequent family marginal activities such as weddings, meals, and invitations. Fifty-seven percent of the married women reported some participation in these activities compared to 52 percent of the single women who reported much participation (Question 18).

The qualitative data also show that most married respondents reported that their visiting was limited to neighbors, friends, and acquaintances--not close relatives. Part of being a housewife is visiting; the respondents did not seem to approve of this custom. Visiting. as a social interaction was less important to them than social 
interaction associated with employment. In addition, the qualitative data show that married respondents reported little participation in activities related to their jobs or in social organizational activities when compared to single respondents.

Compartmentalization through Role Distance

Few married respondents defined their management of home and work activities as "role distance"; that is, keeping home roles distinct and separate from work roles. For example, Respondents \#8 and \#15 commented, "At work I am an employee; at home I am a wife and mother." Quantitative findings are consistent with this information. Table VI shows that 50 percent of the married women reported that they did "some" thinking or talking about family problems at work and 43 percent reported "little" of such behavior (Question 20). Fifty-eight percent of the married respondents reported some worry about their children at home (Question 22). This finding is compatible with qualitative information, since most mothers did worry about leaving their children to go to work. However, this was not an overriding feeling, but rather an occasional one. Qnly 17 percent of the married women reported that they did "much" thinking and worrying about children.

Married respondents seemed to think about and discuss work problems at home less than single respondents. Only 36 percent of the married women reported that they thought about or discussed work problems at home compared with 52 percent of the single women (Question 21).

To sum up, compartmentalization through role distance was used by married respondents as one mechanism of managing home and work activities smoothly. However, it appears that married respondents thought 
TABLE VI

THE USE OF COMPARTMENTALIZATION THROUGH ROLE DISTANCE BY MARITAL STATUS

\begin{tabular}{|c|c|c|c|c|c|c|}
\hline & Question & $\begin{array}{l}\text { Marital } \\
\text { Status }\end{array}$ & Much & Some & Little & Total (N) \\
\hline & $\begin{array}{l}\text { How often when you are at } \\
\text { work do you think/speak } \\
\text { about family problems? }\end{array}$ & $\begin{array}{l}\text { Single } \\
\text { Married }\end{array}$ & $\begin{array}{r}14 \\
7\end{array}$ & $\begin{array}{l}38 \\
50\end{array}$ & $\begin{array}{l}48 \\
43\end{array}$ & $\begin{array}{l}100 \%(21) \\
100 \%(14)\end{array}$ \\
\hline 21. & $\begin{array}{l}\text { How much when you are at } \\
\text { home do you think or talk } \\
\text { about your work problems? }\end{array}$ & $\begin{array}{l}\text { Single } \\
\text { Married }\end{array}$ & $\begin{array}{l}38 \\
36\end{array}$ & $\begin{array}{l}52 \\
36\end{array}$ & $\begin{array}{l}10 \\
29\end{array}$ & $\begin{array}{l}100 \%(21) \\
100 \%(14)\end{array}$ \\
\hline 22. & $\begin{array}{l}\text { When you are at work, do } \\
\text { you think of your children } \\
\text { and worry? }\end{array}$ & $\begin{array}{l}\text { Single } \\
\text { Married }\end{array}$ & $\overline{17}$ & $\overline{58}$ & $\overline{25}$ & $\overline{100 \%}(--)$ \\
\hline
\end{tabular}

about and discussed work problems at home far more (36 percent) than they thought about and discussed family problems at work (7 percent).

Compartmentalization through Role

Relaxation

Three married respondents indicated that their husbands' evening and morning employment enabled them to organize their time more efficiently. This was best described by Respondents \#5, \#6, and \#7: "My husband works in the evenings as well as during the day, and that's why I have time to do what I want and can organize my time." This is consistent with Epstein's statement, " . . When the obligations of one or more statuses are under-demanding, the possibility of role strain will be reduced." The absent husband makes the fewest demands (Epstein, $1970: 143)$. 
HOW SUCCESSFUL ARE THE MECHANISMS?

It should be realized that the mechanisms for reducing difficulty are not always necessarily successful. It appears from the data that respondents could be divided into three groups: first, women who are successful in managing both responsibilities; second, women who feel their jobs are too demanding and who have decided to resign, at least temporarily; and third, women who continue to work but are dissatisfied with their performance.

The first group we label the "adaptors." The view of this group was best described by Respondent \#6, a married school teacher with two children:

I'm satisfied with myself in general. I organize my time. My husband works both mornings and evenings. This gives me time to do the things I want to do. I usually spend my evenings supervising my child with his homework, doing my homework for my job, and cooking for the next day. I don't have an evening job. I rarely visit relatives and friends, and I never participate in women's organizational activities. One of my children goes to school, and I usually have a servant sit with my preschool child. When I don't have a servant, I take my child to my mother. I worry when my child is sick and I have to go to work. Most of my friends are teachers and physicians.

I enjoy my present working hours--I have two days off and I usually do personal things during weekends like taking my children for a ride or going to the beach or shopping.

I devote most evenings to my family. I feel my family has priority over anything else. If I ever feel I can't handle both home and work responsibilities, I'll quit working. In other words, my famiiy has top priority. I will not work at my family's expense.

She continued, speaking for the majority of working mothers in the sample:

The problem that working women are faced with is the difficulty of finding a servant or a nursery and kindergarten school that is convenient. Sometimes I have problems finding a servant. I don't want to quit working. When there is a convenient nursery school, I'll send my son to it. Sitting at home is boring. I did that once, 
and I didn't like it. Besides, I want to benefit others by working.

Although I have had difficulty finding a servant this year, I won't have that problem next year. I plan to put my child in a school. Sometimes I have transportation problems. My husband usually has to take me to work. I feel that our main problem is the lack of entertainment facilities, particularly for children. We spend most of our leisure time on weekends at home. It's a long ride to the beach, and it's not always convenient to make the trip.

The second group is labeled the "temporary withdrawers." This group includes women who feel that their jobs demand too much of their time and that they do not get enough help from their families. They alleviate the tension by deciding to resign from their jobs, at least temporarily. This solution was best described by Respondents \#28 and \#37. Respondent \#28 said, "I would prefer to stay at home until my child reaches school age. My job doesn't allow me to devote enough time to my child. I work evenings as well as mornings." Respondent \#37 reported:

My job demands a lot of my time. It makes me feel that I don't have enough time for my family. Conflict of time was the major reason I decided to quit working. When my children go to school, I'll go back to work.

The third group is the "non-compensators." It includes a few women who expressed dissatisfaction with their situation of oscillating between two values: (1) giving priority to children and husband, and (2) desiring more involvement in other activities. This point of view was best expressed by Respondent \#35:

I feel that as a wife and mother I have to devote my time first to my husband and children. However, I feel that as a person I have the potential to do other things. I wish I could devote more time to other activities besides my family. 
FURTHER IMPLICATIONS

The data suggest several issues.

(1) Distress about leaving children to go to work was felt by most mothers, but this feeling was occasional and situational rather than overriding. Only Respondents \#28 and \#37 revealed signs of guilt because of possible harm to their children.

(2) The need for good nurseries and kindergarten schools for preschool children was mentioned by most working mothers in the sample. The data suggest that this need has arisen due to: (a) the occasional difficulty in finding satisfactory servants, (b) the high cost of servants, (c) dissatisfaction with servants as mother substitutes, (d) the inconvenience of taking children daily to the woman's mother, and (e) dissatisfaction with child care by the husband's family.

(3) The data also show that eight of the fifteen married respondents did not wish to quit working. They felt that sitting at home was boring and monotonous. Some reported that housework was a low status type of job.

(4) Transportation was seen as a problem by both single and married women. Six of the fifteen married women mentioned this problem, as did nine of the twenty-two single women. Transportation became a serious problem for women whose jobs required morning and evening attendance as well as for those which required movement from one place to another. The data suggest that (a) brothers and husbands provided transportation for some respondents, but it was sometimes an inconvenience for them; (b) respondents complained that husbands sometimes disapproved of their wives riding in cabs by themselves; $(c)$ in some 
fields women were prohibited from riding in cabs by themselves; and (d) taxis were expensive. Respondent \#11 spoke for the majority of working women, "Transportation is a common problem for working women, particularly for those in professions such as medicine and college administration, which require morning and evening attendance."

(5) It appeared that the difficulty of allocating time which married women experienced came from traditional patterns of working hours. Institutions which employed women did not seem to adjust working hours to permit women to allocate their time more efficiently.

(6) Feeling physically tired was also mentioned by respondents. This could be due to the lack of institutional facilities for physical exercise.

(7) Some respondents may have put more importance on the way their children were raised than others. The length of time they had worked could have been another interval variable. Women who had worked longer might have learned to develop schedules and to allocate their time more effectively.

To sum up, the findings with respect to time allocation do support our hypothesis. It appears that married women experience more difficulty with time allocation than do single women. However, the degree of difference in difficulty is not as great as was expected, partly because single respondents contributed to housekeeping duties. 


\section{CHAPTER V}

\section{NETWORK SUPPORT}

Network support is important if a woman is to increase her selfconfidence and secure her occupational identity. Supportive networks are crucial as well in the reduction of role conflict. According to Epstein, "The woman is dependent on the emotional and practical support of all family members. Where the network of role relations is supportive, role strain will be eliminated" (Epstein, 1970:147-148).

The husband's approval or favorable attitude toward the wife's employment is important for her career plans. According to Theodore, "In order to minimize conflict, the professional woman must be married to the 'right' husband" (Theodore, 1971:24). A woman probably needs the husband's cooperation and good will to combine her career and home obligations effectively.

In this chapter, the relationship between the type of career and the nature of network support is examined. Careers are divided into two groups: (1) those in the fields of education and medicine such as school teaching, college administration and teaching, and the practice of medicine; and (2) those in other fields such as social work, newspaper editing, roadio broadcasting, interpreting, interior decorating, and investigating. "Network" is defined to include a woman's own family (e.g., husband, parents, sisters, brothers, her own relatives, and her husband's family) and people with whom she comes into contact at work 
(e.g., drivers, guards, messengers, clients, and patients). The term "support" implies "approval" and "agreement."

It was hypothesized that women who worked in the fields of education and medicine would experience the least difficulty with respect to network support. Women who worked in other fields were expected to experience the most difficulty with respect to network support. This hypothesis was partially based on the fact that working in the fields of education and medicine is culturally approved as an extension of the feminine role, and because an all-female clientele is served by women in these professions.

It was found that the data support our hypothesis. Women who work in education and medicine do receive more support than women who work in other fields. However, it should be pointed out that the amount of support received is determined not only by the type of career, but also by the work structure. Women might get less positive support from the network when: (1) jobs require working at night, movement from one place to another, and traveling; (2) working for long hours; or (3) working with men. This is what is meant by the work structure. In this chapter, approval or disapproval of the idea of women working by their husbands, their husbands' families, and their own families--particularly their parents--will be discussed. Respondents, during the interviewing and answering of standardized questions, tended to synthesize the idea of working with the type of career they were pursuing. The discussion on married women will precede that on single women, since married respondents have more complicated networks. 
Secondly, approval or disapproval of the type of occupation and work structure will be discussed. The discussion in this section consists of two parts: (1) more support for working in education and medicine vs. less support for working in other fields; and (2) disapproval vs. approval for work structure.

Quantitative and qualitative data will be incorporated to support our analysis. However, the emphasis will be on the qualitative data, particulariy in the section on the approval vs. disapproval of the idea of working, since standardized questions were not used in this section.

APPROVAL VS. DISAPPROVAL OF THE IDEA OF WORKING

\section{Married Respondents}

The data on network support do not present a clustered pattern. There is a diversity of approval and disapproval for the idea of working. The qualitative, data suggest the following pattern: (1) five out of fifteen married women interviewed reported that the husband did not approve; (2) ten of the fifteen married women did not report disapproval on the part of their husbands; (3) all married respondents reported approval from their own families except two; (4) only three of the fifteen married women reported disapproval on the part of the husbands' families; and (5) respondents reported that they had noted both approval and disapproval on the part of drivers, guards, and messengers, with some respondents stating that they did not know how these workers felt.

(1) Husband's Disapproval. The data suggest several reasons that husbands disapproved of the idea of working. These reasons included: (a) working was tiring and took too much of their wives! time; (b) it 
was difficult to manage the demands of both work and home smoothly;

(c) husbands did not like the idea of leaving children with a servant;

(d) husbands liked to see everything in order in the house; (e) husbands did not approve of their wives working because of vacation schedule conflicts; ( $f$ ) husbands complained about providing transportation; ( $g$ ) husbands might not have liked to see their wives financially independent; and ( $h$ ) husbands might have felt deep down that a woman's place was in the home.

Five married respondents described their situation succinctly.

Respondent \#8, a married school teacher, reported:

My husband is not in favor of my working. He thinks working takes up too much of my time and is exhausting. However, I like to work, and enjoy having my own income. My husband feels I should be at home and everything in the house should be in order. He feels it's difficult for me to manage work and home demands. This could be true because this is my first year of marriage. He also thinks it will be more difficult to manage if. I have a baby. He doesn't like the idea of leaving children with a servant. I don't live for washing and cleaning. Work gives me more satisfaction than doing housework.

I shall insist on working even when I have a baby. I can leave him with an aunt. She would like to keep my child, since she doesn't have any children of her own. When my aunt is not available, I'll leave my child with the servant. When the child gets to school age, I'll send him to school. Some people think that a woman works just for money--that if she were well off she wouldn't work. I don't agree with that assumption. I don't work just for the money. Working is' stimulating; you feel useful. It's boring to sit at home and wait for your husband. My parents don't mind if I work.

Respondent \#13 commented,

My husband doesn't object to my working to please myself. In general, he's not in favor of my working for the following reasons:

I go to work at the same time he does; we have a schedule conflict with respect to vacation; and he complains because he has to provide my transportation.

My parents are very supportive and often encourage me to continue working. I enjoy working and I expect to continue working. I don't want to be restricted to housework and go from one visit to another. 
Respondent \#15, a married college administrator and mother of five children, reported:

My husband is not very supportive. He says, "Why don't you quit working?--you don't need to work." My husband's objections could be due to the fact that he might feel I don't give him enough time or that he feels I am too independent.

My brothers are surprised that I am working. They say, "Now you have worked and you know what it's like to be employed. Why don't you quit?"

My husband and brothers might still feel deep down that woman's place is in the home--or maybe they feel that working is tiring for me. My father is more supportive of me that anyone else.

I like to work and enjoy it. I learn from working. It's good experience. I feel that I'm more confident and that I can express myself better. I'm happy with myself.

(2) Husband's Approval. Ten of the fifteen married women reported that their husbands did not disapprove of the idea of their working. Husband approval could be due to the fact that these women were able to manage both demands smoothly. Respondent \#6, a married school teacher with two children, said, "My husband doesn't mind. if I work at a11. It's up to me. He feels I am managing. I don't know about my husband's family--they live out of the country." Respondent \#35, a married broadcaster with two children, reported, "My husband is encouraging, but was jealous at the beginning. It also bothers him when I have trouble at work. My father used to encourage me very much."

(3) Family of Orientation. All of the married respondents reported that they received support from their fathers. Even the six respondents whose fathers were not alive at the time of the study reported that they had always received a great deal of encouragement. Fathers might be supportive because their daughters' accomplishments are an extension of their own. Practically all married Moslem women keep their fathers' names after marriage. All respondents except two reported that 
they were supported by their mothers and by the rest of their families of orientation. The encouragement women get from their mothers could be due to the fact that the daughters are fulfilling the dreams the mothers once had. The two respondents declared that their mothers were not very supportive; these two mothers felt that working was too tiring for their daughters and that the daughters were shirking their home duties. Respondent \#15, a married college administrator and mother of five children, reported, "My mother feels that my work is tiring for me." Respondent \#29, a married physician with two children, said, "My own family encourages me and is proud of me, and they want me to continue working. My mother just feels that my work tires me."

(4) Husband's Family. Only three of the fifteen married women reported that their husbands' families--particularly mothers-in-law-were disapproving to some extent. Those three mothers-in-law felt that the wives should give:more time and care to their husbands and their houses. Disapproval of sisters-in-law might have been due to the fact that they were envious because they did not have comparable professional qualifications.

Respondent \#7, a married school teacher, said, "My husband's family feels that I should devote more time to my husband and housework, and that I don't need to work since I don't need the money. However, I don't care--I feel I am enjoying what I do." Respondent \#13, a married college administrator with two children, reported, "My husband's family discourages me from working. However, I feel that deep inside they wish they were capable of working like I do." Respondent \#16, a married college teacher with two children, said, "My husband's family, 
especially my mother-in-law, were not very encouraging about my working. At the beginning my mother-in-law was worried that I wouldn't be able to handle both demands, but now she realizes that I can."

(5) Drivers, Guards, and Messengers. It appeared that respondents were not sure about the way drivers, guards, and messengers felt about working women. In describing their individual experiences, they assumed that some approved while others did not. Some respondents reported that they did not know how the drivers, guards, and messengers felt. Respondent \#8, a married school teacher, said, "The drivers sometimes tell us that woman's place is in the home. It's difficult for a woman to handle home and work demands." Respondent \#13 commented, "I don't know how drivers and guards feel. However, one messenger seems to respect working women." Respondent \#14, a married college administrator and mother of one preschooler, said, "The driver who takes me to work seems understanding. He reads the newspapers and makes positive comments about women who obtain jobs."

\section{Single Respondents}

The qualitative data show that the family of orientation, with few exceptions, is supportive of single professional women. The data suggest the following pattern: (1) none of the single respondents reported that their parents disapproved of their working; (2) only two respondents reported that one member of the family of orientation disapproved of their working; (3) only one of the twenty-two women reported that, except for sisters, all members of their families were critical.

(1) Family Approval. Four single respondents explained quite clearly how their families supported them. Respondent \#11, a college 
administrator and teacher, reported, "Everybody in my family approves and supports my job. They don't mind if I work." Respondent \#22, an investigator, said, "My family doesn't mind if I work. They are sympathetic to me and felt sorry for me when I couldn't find a job." Respondent \#26, a physician, commented, "My family doesn't interfere with my work decisions. It's up to me to work or not to work, and where I work is my decision." Respondent \#32, a radio broadcaster, said, "My parents don't mind at all that I work. It doesn't matter to them where I work either."

(2) Disapproval of Member(s) of the Family. Two respondents reported a lack of support from a member or members of the family. Respondent \#20, a social worker, said,

My uncle, in general, is not supportive of my working. In general, women relatives in the family seem to accept the idea of working. They say today's younger generation has a different way of life. It's better for me to work than to be sitting around in the house. Some say, "God bless you and help you, since today your generation has to work." My father is proud of me because I am educated and I work.

Respondent \#31, an interior decorator, reported:

Sometimes relatives wonder why I'm working and why I allow myself to become tired. For example, my grandmother doesn't value my working. She feels it's nonsense for women to go to work. My parents are very encouraging, however. My father is the one who suggested I start my own business and he will help me financially.

(3) Family is Critical. Respondent \#21, a social worker, de-

scribed her situation:

Men and women in my family are sort of critical, just about the idea of working, since I am the first girl to work in my family. Almost all girls in my family are supportive of me because I work. It doesn't matter what I do. 
APPROVAL VS. DISAPPROVAL OF THE

TYPE OF OCCUPATION

The data suggest that women working in education and as physicians received positive support from their social network, but women working in other fields experienced ambivalent reactions from their social network, experiencing both positive and negative support. Perhaps the latter group of respondents received--or thought they received--conflicting or contradictory values or messages from society. On one hand, society respects professional occupations; on the other hand, society disapproves of work structure which disturbs the traditional and expected behavior of women.

\section{Approval}

The data show that the professions of teaching and medicine were considered more prestigious than those of social work or interpreting. There was less positive support for women who provided services with which the public was unfamiliar (e.g., broadcasting, newpaper editing, and doing surveys for social work). Women who specialized in such fields as law, political science, and clinical psychology appeared to receive the least support, since these fields are not yet open to women.

Education and Medicine (More Support). Four respondents described public approval of women working in education and medicine. Respondent \#9, a college administrator, reported, "My mother and brothers approve of my job. My mother feels I have high social prestige because I work for a university." Respondent \#30, a single interpreter, said, "My father doesn't mind my job as an interpreter and my working with men. 
However, he would prefer that I work for the university because of the social prestige and to avoid peoples' comments because I work with men." Respondent \#18, a single social worker, reported, "Women relatives and friends of the family (men and women) often comment, 'Why didn't you choose teaching? Teaching would be better for you--it has more social prestige and you would be more popular.'" Respondent \#26, a physician, said:

Patients seem to approve of women working as physicians because we have high social prestige. Male patients I come into contact with often say they want their daughters to be physicians. Teaching, I feel, is the only profession that this society accepts. But being a physician comes next.

Social Work, News Editing, and Broadcasting (Less Support).

There appeared to be less public support for women who did surveys for social work, or engaged in broadcasting or news editing. Four respondents described reactions and comments they had received from others. Respondent \#19, a single social worker, said:

People we meet don't seem to know what we are doing. They don't accept our work because they are not familiar with it. They feel that what we do is not useful--there is no appreciation for what we do.

A driver asked me, "Why don't you work as a teacher?" Some people think that teaching is the best occupation for a women. This could be because teaching is the first thing that women do.

A broadcaster, \#34, described the manual workers' disapproval, "Guards and drivers don't know how to evaluate our work because they don't know what we are doing inside the station." Respondent \#37, a married editor with two children, reported, "I don't know how the drivers feel. It seems to me that the driver who takes me to work thinks I go to work for the money. He doesn't understand why I work. I feel that he disapproves of my working." 
Law, Political Science, and Clinical Psychology (Least Support).

Respondent \#22, a single investigator who had graduated from a college

of law, reported:

Both men and women have said to me, "You're really in bad shape. What made you decide to go to a college of law? That's a man's occupation--you won't find a job." Some relatives, friends of the family, and neighbors have said, "Men don't like to marry women who graduate from law schools. We wonder who is ever going to marry you."

People in charge--men--felt that 1 aw was a man's field. It was an unfamiliar situation for them to deal with. When I asked permission to start a private business, I got no reply. I faced difficulties because this was a new field for women. This has happened in other societies.

I suffered a lot from society's rejection. I felt sick, I wasn't sleeping well, I was taking pills to help me relax. Here I went through all that effort, I got a degree, and I couldn't get a job in my field. I felt as if I had been rejected by the whole system.

I insisted that I wouldn't work in any other field. After two years, I finally got a job. My male colleagues were surprised that I got the job. My boss was encouraging, and my colleagues accepted me. I have been conservative, serious, and have dressed respectably. Everybody was so happy for me after I got my job.

Two other respondents--a psychologist and a woman with a degree in political science--had difficulty finding jobs in their fields. They finally gave up their searches; one settled for social work and the other for journalism. Respondent \#21, a single social worker, expressed her dissatisfaction at being unable to find a position in clinical psychology, "The thing that really bothers me is that I don't work in my field of specialization. My schooling was a waste of time and effort." Respondent \#37, a married editor, said, "My field of specialization is political science, but there are no opportunities available to me. I didn't realize that when I specialized in that area I wouldn't have any opportunity to work."

Conclusions. The quantitative data appeared to support the findings of the qualitative data. 
Table VII shows that all those who worked in the education and medical professions received much support from their sisters compared to 92 percent of those who worked in other fields (Question 26). Ninety percent of those who worked in the fields of medicine and education received much support from their mothers compared to 85 percent of those who worked in other fields (Question 27).

A lack of approval was evident among drivers and guards. Fiftyfive percent of those who worked in other fields received little support from drivers and guards compared to only 7 percent of those who worked in education and medicine (Question 30). Those who worked in education and medicine received "much" support (43 percent) or "some" support (50 percent), while those who worked in other fields received 18 percent and 27 percent respectively. It should be realized that lack of approval fromdrivers and guards is associated with behavior accompanying certain jobs. For example, the qualitative data suggest that working at night, working with men, going to peoples' houses, and being unveiled were not approved. It is also suggested that some drivers and guards might have generally disapproved of the idea that women went to work. Differences in husbands' degrees of support could not be made, since only three of the fifteen married women worked in fields other than education and medicine. Consequently, percentages are not meaningful. However, the qualitative data show the type of occupation was not a determinate factor in a husband's support. A husband's support was likely to be associated with the idea of working in general, and of the work structure. Five of the fifteen married women reported that their husbands disapproved of the idea of working, and four reported 


\section{TABLE VII}

DEGREE OF SUPPORT FROM SOCIAL NETWORK BY TYPE OF OCCUPATION

\begin{tabular}{|c|c|c|c|c|c|}
\hline Question & $\begin{array}{r}\text { Occu- } \\
\text { pation }\end{array}$ & Much & Some & Little & Total (N) \\
\hline \multicolumn{6}{|l|}{$\begin{array}{l}\text { How much support do you receive } \\
\text { in the choice of your career } \\
\text { from your network? }\end{array}$} \\
\hline 23. Your husband & $\begin{array}{l}\text { Ed/Med* } \\
\text { Other** }\end{array}$ & $\begin{array}{r}69 \\
+\end{array}$ & $\begin{array}{l}31 \\
+\end{array}$ & $\bar{t}$ & $\begin{array}{cc}100 \% & (13) \\
+ & +\end{array}$ \\
\hline 24. Your father & $\begin{array}{l}\text { Ed/Med } \\
\text { Other }\end{array}$ & $\begin{array}{r}100 \\
82\end{array}$ & $-\overline{9}$ & -- & $\begin{array}{l}100 \%(20) \\
100 \%(11)\end{array}$ \\
\hline 25. Your brothers & $\begin{array}{l}\text { Ed/Med } \\
\text { Other }\end{array}$ & $\begin{array}{l}95 \\
76\end{array}$ & $\overline{15}$ & $\begin{array}{l}5 \\
8\end{array}$ & $\begin{array}{l}100 \%(21) \\
100 \%(13)\end{array}$ \\
\hline 26. Your sisters & $\begin{array}{l}\text { Ed/Med } \\
\text { Other }\end{array}$ & $\begin{array}{r}100 \\
92\end{array}$ & -- & $-\overline{8}$ & $\begin{array}{l}100 \% \\
100 \%(12)\end{array}$ \\
\hline 27. Your mother & $\begin{array}{l}\text { Ed/Med } \\
\text { Other }\end{array}$ & $\begin{array}{l}90 \\
85\end{array}$ & $\begin{array}{l}10 \\
15\end{array}$ & -- & $\begin{array}{l}100 \%(21) \\
100 \%(13)\end{array}$ \\
\hline 28. Your own relatives & $\begin{array}{l}\text { Ed/Med } \\
\text { Other }\end{array}$ & $\begin{array}{l}78 \\
46\end{array}$ & $\begin{array}{l}13 \\
38\end{array}$ & $\begin{array}{r}9 \\
.15\end{array}$ & $\begin{array}{r}100 \%(23) \\
99 \%(13)\end{array}$ \\
\hline 29. Your husband's family & $\begin{array}{l}\text { Ed/Med } \\
\text { Other }\end{array}$ & $\begin{array}{r}54 \\
+\end{array}$ & $\begin{array}{r}23 \\
+\end{array}$ & .23 & $\begin{array}{c}100 \% \\
\dot{T}\end{array}$ \\
\hline $\begin{array}{l}\text { 30. Drivers, guards, and manual } \\
\text { workers }\end{array}$ & $\begin{array}{l}\text { Ed/Med } \\
\text { Other }\end{array}$ & $\begin{array}{l}43 \\
18\end{array}$ & $\begin{array}{l}50 \\
27\end{array}$ & $\begin{array}{r}7 \\
55\end{array}$ & $\begin{array}{l}100 \%(14) \\
100 \%(11)\end{array}$ \\
\hline
\end{tabular}

* Education/Medicine

** Other Occupations

$\rightarrow$ Numbers that are less than ten are excluded, since they do not show meaningful percentages.

that their husbands were less supportive about the wives working with men. Regarding the husbands' families, meaningful comparisons could not be made since orily three of the fifteen married women worked in fields other than education and medicine. However, the qualitative data show 
that only three of the married women reported disapproval from their husbands' families.

There was greater support from relatives for those who worked in education and medicine than for those who worked in other occupations. Seventy-eight percent of the educators and physicians received "much" support compared to 46 percent of other professionals (Question 28). However, qualitative data suggest that the support was also related to the idea of working and of work structure. Differences also appeared in the degree of support respondents got from their fathers. Those who worked in education and medicine received greater support than those who worked in other fields: 100 percent compared to 82 percent (Question 24).

The qualitative data are consistent with this finding. All respondents spoke of their fathers' encouragement and approval of their working. However, some respondents reported that their fathers were less supportive when their daughters worked with men, worked at night, or traveled for their jobs.

There was greater support by brothers of women who worked in education and medicine than of those who worked in other fields. Ninetyfive percent of the former group received much support compared to 76 percent of the latter group (Question 25).

To sum up, qualitative and quantitative data seem to support our hypothesis. Women who worked in education and medicine experienced less difficulty with respect to network support than women working in other fields. 
It should be noted, however, that respondents working in these other fieids implied that they had received network support. Ten respondents spoke of the support they had received. A social worker, Respondent \#18, reported, "In general, professional women are respected in our society and looked upon highly." Another social worker, Respondent \#21, said:

I have gotten the impression that my education and professional status are admired by others. People I meet, although illiterate, look up to me. They hope to see their daughters. educated one day, just like me.

Respondent \#22, an investigator, said:

Women who come to my office like my job. They feel more comfortable having a woman make the investigation than they would with a man. Male co-workers feel I am something special. They want to have me around, since I'm the first woman to work in this field. My boss is encouraging and supportive; he wants me to work hard and get experience. After I got the job, everybody was so happy for me. I felt I had proved that a woman from Saudi Arabia would work in the field of law.

A radio broadcaster, Respondent \#33, commented, "My family--including my father--doesn't mind if I work in broadcasting. I like my job, especially since not many natives work in this field. I'm proud of myself; I feel confident." Respondent \#37, a newspaper editor, said:

My husband, my family, my husband's family, my relatives, and my friends respect me and are very proud of me. They all encourage me. They are open-minded. I feel I am respected because I work in journalism, and I have to be intelligent.

\section{Disapproval}

It appears that the work structure had an effect on the degree of support women received from their network. The data suggest the following pattern: (1) disapproval of working at night, movement from one place to another, and traveling for the job; (2) disapproval of 
commitment to work (i.e., working long hours is not supported); (3) with respect to contact with men at work, the data show three trends:
(a) those who do not approve but give no clear reason;
(b) those who worry about societal disapproval; and (c) those who do not object to women working with men.

(1) Working at Night, Movement from One Place to Another, and Business Traveling. Six respondents spoke of the disapproval they had experienced. Respondent \#19, a single social worker, reported:

My father doesn't like it when my job requires me to travel. I'm trusted by my family, but they are afraid people will talk. They say, "What would people say about a girl who travels and stays away from home overnight by herself?" Comments like that come from relatives, friends, women, and men, but mostly from those who are uneducated. The traveling I do is inside the country, from one city to another.

Our driver doesn't approve, and it bothers him if we go to peoples' houses in the evening or at night for research purposes. He doesn't approve of our work--maybe because we're women working at night.

Respondent \#24, a physician, said:

I like to go to the hospital occasionally to follow up on my patients. If I were a man, I would probably have more freedom of movement. A male physician can go to the hospital occasionally to follow up on his patients. In my case, I can't take a cab by myself because my brother-in-law doesn't like it. He's the one who takes me to work.

Respondent \#37, a co-editor, reported:

I feel it's difficult for a woman to be involved in the news business because of our lack of freedom of movement. A woman can work just for the women's section of the paper. Other news work might require that I travel, and my husband doesn't allow that.

(2) Working Long Hours or Commitment to Work. Five respondents

had experienced disapproval because they worked long hours or were very committed to their careers. Respondent \#16, a married college teacher and administrator, said: 
My parents are proud of me, particularly since I'm the eldest in the family. They encourage me to work. My husband complains and doesn't like it at all when I sometimes go to work in the afternoons. I almost quit my job because of this situation. My husband said, "If your job continues to require that you work in the afternoon, you should quit." He provides me with transportation; he doesn't like me to take a cab by myself.

Respondent \#23, a single physician, reported:

My fiance encourages me to work and to be active. However, he feels that getting too involved in different activities might wear me out. My father used to encourage me to be a doctor when I was young. My mother doesn't mind at all that I work--she just likes to see me rested and doesn't like to see me wear myself out.

Respondent \#24, a single physician, described her situation:

I feel that people around me are happy that I am a doctor. They are very supportive. The technicians are happy because I'm a doctor and the women's husbands feel the same way. Women patients trust me. They sometimes go to see a male doctor and then come back to me. Some of them will not let male doctors examine them. They feel more comfortable around me because I'm a woman--it's less embarassing to them. I feel that the reason people are happy with me might be due to the fact that I am a gynecologist and they feel that my specialization fits me best as a woman.

As a gynecologist, I sometimes have to be away from home most of the day. I can't be bound by fixed, regular hours. I feel this disturbs my family, particularly my brother-in-law. I wish I had more freedom to go to work whenever I feel like it.

I'm applying for graduate study abroad. My brother-in-law doesn't like the idea, and my uncle doesn't accept it either. They feel I have enough degrees. My brothers are encouraging, but wish I would get married first, so I wouldn't be alone. My mother and sisters feel the same way.

(3) Contact with Men at Work. The data suggest a pattern of both disapproval and approval of working with men. The approval/disapproval comes from the family, the public, and drivers. There are, in fact, three groups: (a) those who do not approve but give no clear reason; (b) those who worry about societal disapproval; and (c) those who do not object to women working with men. There is no single pattern of disapproval or approval with respect to family members. 
Ten of the thirty-seven women interviewed expressed disapproval of working with men. Seven of the ten are single and three are married; six are working in the field of education, three are social workers, and one is an investigator; and three have least interaction with men at work, seven have occasional interaction. The disapproval of the ten respondents shows this pattern: (a) three mentioned father's disapproval; (b) two mentioned mother's disapproval; (c) four mentioned husband's disapproval; (d) two said one member of the family disapproved (i.e., grandfather, uncle); (e) four mentioned drivers' disapproval; (f) two said father did not disapprove; $(g)$ one said drivers and guards did not mind if women were veiled; and $(h)$ two said they did not know how the drivers and guards felt.

Respondent \#7, a married school teacher, described her situation:

I wanted to be a doctor, but my father discouraged me. He thought I would be on call at night. Sometimes I have to accompany strangers at night for. emergencies. He has told me, "You are not used to working in a mixed atmosphere, men and women together at work." This is how he justifies his argument. He also has said, "As a girl from Saudi Arabia, you have a cultural setting that is completely different from any other girl in other societies."

My husband is in favor of the kind of work I do, but he is not in favor of the idea that women work with men.

Respondent \#9, a single college teacher and administrator, said:

My mother doesn't want me to work with men. For example, she says she doesn't want me to work on TV or radio, be a nurse, or work for a foreign company, because I will come into contact with men. My brothers feel the same way, but don't feel as strongly as my mother. I rarely talk to the drivers or guards. I don't like to do that. It seems to me that they don't mind women working as long as they are veiled.

Respondent \#14, a married college administrator, said, "My husband is jealous--he doesn't like me to work with men." Respondent \#16, a married college teacher, agreed, "My father might disagree with the idea 
of working with men. My husband doesn't like it either. Sometimes I have formal meetings with male colleagues, and I dress respectably." Respondent \#20, a single social worker, said:

My father doesn't mind if I come into contact with men at work. My grandfather does. He doesn't mind if I work as a teacher, but he is not supportive of the kind of job I have, since I come into contact with men.

In general, drivers we come into contact with are afraid of something happening to us as girls and sisters. If somebody looks or stares at us, they yell at them. They act as protectors. However, the older drivers are the ones that are really bothered, especially if we have a formal meeting with the man in charge. Once he sent a message through the female maintenance worker that we should be veiled.

Respondent \#18, a single social worker, reported:

One driver doesn't seem to approve of my work. He says, "You're from a well-off family--why do you work? You also come into contact with men at work." He doesn't like it, and sometimes he refuses to give me a ride. I wish I worked on TV, but my brother advised me not to for the time being. He advised me to wait until society becomes more familiar with and accepts the idea of seeing native women on TV.

Respondent \#4, a single school teacher, reported, "My mother supports my working as a teacher. She doesn't like women working with men." She continued:

My father doesn't mind if I work with men. He doesn't mind if I work as a radio broadcaster or as a secretary in an embassy. He doesn't even mind if I work for a TV station. I think his liberal attitude is a reaction to my mother's conservatism. My father doesn't mind my working with men as long as I'm respectably dressed.

My uncle would object to some extent if I worked with men. I don't know how drivers and guards feel--my contact with them is so limited.

Respondent \#1, a single school teacher, said, "My father is not in favor of women working with men, but he doesn't mind that I work. I don't know how drivers and guards feel about it. My contact with them is so limited." 
With respect to women working in radio broadcasting, the data

show that such work was not accepted, particularly at the beginning.

Two respondents who were employed as radio broadcasters spoke of their

experiences. Respondent \#34 said:

At the beginning, working in radio broadcasting was not desirable. Disapproval usually came from the older generation men and women-relatives and friends of relatives. They gave me the impression that announcers were not good moral1y. They made me feel that I shouldn't do it. This could have been due to religious beliefs. They might have felt that it was wrong for my woman's voice to be heard on the air.

However, there are fewer objections now that they've seen women on TV. Therefore, I'm much better off. I think' if I decided to work for a TV station, my relatives would be upset--they wouldn't forgive me.

I17iterate drivers and guards give an impression of disapproval. I don't know why. They don't evaluate what we're doing. It could be because I work with men, I go unveiled, and I don't say things of interest to them. They might feel that woman's place is in the home. Once a driver said to me, "You'd be better off at home raising your kids." Our private driver is open-minded and he respects what I do. However, society is gradually changing. It seems that the drivers will just have to face the fact that they should accept us, since they see us daily.

Another radio broadcaster agreed that working for a radio station was more acceptable than it had been previously. Respondent \#32 had been working for only four months. She commented:

The people I work with seem to accept my working at the station, since the ministry has agreed that I'll be an official employee. Now I'm just a broadcaster; I don't go to work every day.

Guards seem to be surprised that I am a native and work with men, not because I work at the radio. station. They often ask me if I'm from Saudi Arabia.

The second group of women contended that their families did not object to their working with men, but they worried about what other people would say. Respondent \#5, a married school teacher, said:

I wanted to work as an interpreter. I would have preferred that to teaching. There are two reasons I decided not to work for foreign companies or foreign affairs: first, these are not government jobs and I could be laid off any time; second, society doesn't 
accept women working with men. I don't want to be a leader in this--I'm afraid of society's disapproval. My father and husband aren't very much in favor of my working with men. This is not their personal opinion, because we socialize with mixed groups. It could be due to the fact that they're afraid of society's disapprova1. My husband feels that working for the Ministry of Education is better, since it is more secure and safe for a woman. He feels they protect women more, since they are more reserved.

Respondent \#30, a single interpreter, reported:

My father doesn' $t$ mind if I work in a place with men and my fiancé doesn' $t$ mind either. My brothers don' $t$ mind if I work with men. They would be more in favor of my working in a field with women only to avoid people's comments. They do not mind themselves; they are quite aware that I could manage.

Relatives and friends of the family (men and women) are surprised when I mention that I work in the hospital or with a foreign company. They ask, "Why don't you work in the university or teach?"

I've thought of quitting my job and working somewhere else where there are just foreigners. However, I feel I should try to prove that women from Saudi Arabia can work with men with no problems.

The respondent transferred to another job in a foreign company at the time I interviewed her.

The third group of women indicated that they had family approval of their working with men. Respondent \#8, a married school teacher, reported, "My husband doesn't mind if I work in radio broadcasting or TV. My parents don't mind if I work with men." Respondent \#31, a single interior decorator, said, "My father doesn't mind if I come into contact with men at work. Working in my field requires a woman to meet men. If a woman is from a conservative family, she won't be able to manage." Respondent \#33, a single broadcaster, described her situation, "My parents don't mind if I work at the radio station. My father doesn't really mind if I come into contact with men at work." 
WOMEN'S REACTIONS

The society of Saudi Arabia is changing rapidly and it seems that women are getting conflicting or contradictory values or messages from society. Society respects professional occupations, yet disapproves of the social structure of the work when that social structure challenges the traditional social setting of women and the traditional, expected behavior. In other words, society approves of professional occupations only when traditional expectations are carried to the work situation. There is an ambiguity with respect to the positive image "support" women get from the public. On the one hand, the public approves of professionals; on the other hand, it disapproves of nonconformity to traditional, expected behavior. In other words, the public does not yet provide a positive, clear approval for modern behavior accompanying professional occupations.

Respondent \#30, a single interpreter, spoke of reactions she had received from others because she worked with men:

Drivers were surprised. They don't seem to approve of my job because I work with men. It bothered them that we were with men and because we weren't veiled. They don't respect women workers who work with men.

The biggest difficulty is that others [society as a whole] are not supportive. I get this impression from relatives and some friends of my family, not from educated and working women. Their disapproval is based on the fact that I work. with men, not because I am an interpreter. This bothers me a lot. They can't believe that I can work with men and still be conservative. This was the most difficult thing I faced: society's disapproval of my working with men. I don't have any other difficulties. I love my work.

Respondent \#36, a single editor, said:

I get much encouragement in my writing, even from people in charge [Minister of Education]. Female colleagues and friends of my uncle are also encouraging. I wish I worked just for the newspaper and could quit my other job. 
The way I feel is this: although I receive all this encouragement, I feel that society does not yet accept women working in the journalism field as colleagues. I have gotten that impression from people's comments. One colleague said, "Can you imagine?--a colleague woman came to the office to hand in her work, and she wasn't covering her face. Some men colleagues came in to look at her." My brother said, "Try not to pass by the printing press to pick up your mail. Try not to talk so long with men on the phone." This gives me the impression that our society is not ready yet to have women in the journalism field as colleagues.

I was offered a job with the newspaper and would have had a separate private room, and would have come into contact with male colleagues only for work purposes. I refused. I'm not in favor of men and women working together. I might be too conservative--more than I should be. I think women could work in all fields: in telephone companies and computer centers, for instance, but not in airports, since they would come into contact with men. I support limited contact with men to avoid problems. Some tell me I am too conservative.

I prepare a program for the radio, but I can't present it myself since it is against the instructions of the ministry I work for. They prevent women who work for them from working on radio or TV.

Respondent \#37, a married editor, reported:

Another problem I. have faced is my behavior--what is right, and what is wrong? I. had an appoiritment to inverview an authority, and I asked a woman friend to accompany me, just to be on the safe side. In other societies I could meet with him alone. Some people have a double standard of morality. Anything might seem all right for them when other women do it, but not when it comes to their own daughters or sisters.

Society has created an obstacle. A woman can have a professional occupation, but is expected to practice traditional behavior. Society does not yet present positive support for modern, marginal behavior.

Expected traditional behavior, as drawn from the data, is as fol-

lows: (1) a woman is not expected to work, at night, do much moving from place to place, or travel as a part of her job; (2) a woman is not expected to work long hours; (3) a woman is expected to do two jobs and to handle them both smoothly, and she is expected to give priority to her family; (4) a women is expected to avoid contact with men, if at all possible, but if the job requires such contact, she is expected to 
dress and behave conservatively; (5) a woman is expected to be accompanied in public by a man who is related by blood or marriage, and she is not expected to take a cab by herself; and (6) a woman is expected to be veiled and not to be heard or seen by the public.

This kind of paradox may be natural in a society which is undergoing change. Changes in material culture have been much greater than in immaterial culture (cultural lag). Consequently, women find themselves in an ambiguous situation. Society approves of women in professions, but does not yet accept the modern behavior that usually accompanies those professions.

With respect to behaviors such as interaction with men, appearing in public without a man related by blood or marriage, taking a cab alone, and wearing the Abbaya, respondents could be divided into three groups: the conformists, the adapters, and the progressives.

\section{The Conformists}

The conformists are those who react to social disapproval by behaving in a conservative manner. Respondent \#9, a single college administrator, reported:

My family doesn't like the idea that I work with men. I don't like it either. Working with women is comfortable. I don't have to worry about the way I dress or talk, and I don't have to cover my hair. A woman who works with men is under pressure with respect to her behavior. Besides, my religion forbids me to be among strange men.

Respondent \#16, a college teacher, described her situation:

I wouldn't feel comfortable working with men. I would have to be conservative in the way I dress and behave. When we socialize with mixed groups, my husband and I are concerned that I dress respectably. 
Respondent \#25, a single physician, although a cooperative and understanding person, attempted--more than other respondents--to answer questions during her interview cautiously and carefully. She said, "I don't mind traveling to other countries outside Saudi Arabia to participate in professional conferences or meetings if there is a man there who is related to me by blood or marriage." Respondent \#7, a school teacher who has no contact with men at work, reported, "I don't like working with men. Women are more understanding about my problems and needs. If there were good reasons for women to mix with men, our religion would have permitted it."

\section{The Adapters}

The adapters are those who behave in a conservative manner, in keeping with societal customs, but are not personally satisfied. They feel that this is the safest path to follow. Seven respondents discussed their adaptive behavior. Respondent \#7, a married school teacher, and Respondent \#24, a single physician, expressed their dissatisfaction at not being able to take a cab by themselves without risking family and work disapproval. They had both decided that they would have to adapt to the situation: Respondent \#7 reported:

According to instructions I received at work, a woman is not supposed to take a cab by herself. Sometimes I wonder if they realize that I teach hundreds of students and am a dependable person. It is rather ridiculous to be told that I cannot be responsible for myself.

Respondent \#24 said, "I wish I had more freedom to go to work whenever I liked. I would like to be on my own--for example, to take a cab. However, I don't like to upset my family." 
Respondent \#20, a single social worker, described her solution to the problem of going from place to place as a part of her job:

During field work I sometimes pretend that my co-worker is my brother. This way the public is more accepting. Sometimes if the driver shows disapproval that we are going from one place to another, we pretend that we don't like it either.

Respondent \#11 expressed her dissatisfaction with the custom of veiling:

I don't believe in covering my face, but as an employee, I'm required to do it. What bothers me most is that I have to instruct students to cover their faces. I tell them I don't agree with the custom myself, but that I am instructed to tell them to cover their faces.

\section{The Progressives}

The progressives are those who are trying to get more social approval for their modern behavior. Respondent \#22 said, "I insisted that I was going to work in my field. I was unemployed for two years before I got a job. I wanted to open up the law field for women." Respondent \#23 reported, "I don't wear the Abbaya. I express my opinion openiy, freely, and frankly. Some people think that I'm not from Saudi Arabia." Respondent \#30, a single interpreter, was very expressive and determined:

I am persistent and confident about what I'm doing. Even though society didn't accept the idea of women working with men, I did it. A11 I wanted was to prove that a woman from Saudi Arabia could work with men and manage.

Respondent \#34 reported:

I don't wear the Abbaya when I work. The way I feel is the society should accept everything that is new. Society is gradually changing. Some don't seem to realize that there are changes going on. Their mentality is 'way behind.

It seems that the so-called virtual social identity vs. actual social identity exists. That is, the character and behavior expected 
from women by the society comprise the virtual social identity, while the character that the women could possess, were there fewer restrictions, is their actual social identity. 
CHAPTER VI

\section{EXPECTED BEHAVIOR}

Difficulty, or "strain," occurs when an actor is expected to play two or more roles that involve behaviors which are contradictory. The actor's perception of the contradictory behavior determines the extent of the strain. It has been delineated that employed women are placed in this impossible position. Behavior required in the marketplace (aggressiveness and competitiveness) is incompatible with the requirement that women be accepting and accommodating. A women is expected to perform a supportive function as a female and a competitive function as a career person. As a female, she is expected to raise the status of others; as a career person, she is expected to challenge and to compete.

It was hypothesized that women with the most on-the-job interaction with men (physicians, broadcasters, interpreters, and interior decorators) would experience the most difficulty in terms of contradictory expectations. Women with the least interaction with men at work (school teachers) were expected to experience the least amount of difficulty with respect to contradictory expectations. Women with occasional interaction with men (college teachers and administrators, social workers, investigators, and newspaper editors) should be somewhere between the two extremes. 
It is assumed that in a segregated society, there is a common standard of behavior to which all women are expected to conform. The women support and help each other and learn to relate well to each other. In a desegregated work situation, both sexes are exposed to an ambivalent social interaction situation. This ambivalence could be due to the lack of well-established common expectations. Contradictory expectations might come from male colleagues. A man might expect a woman colleague to be helpful and accepting as a female, while at the same time he might expect her to compete and challenge as a career person.

The frequency of interaction of career men and women in Jeddah, Saudi Arabia was found to fall into three categories: least, occasional and most. Working women with the least interaction were those who actually had no interaction with men at work. Women in the "occasional" category were the ones who came into contact with men through phone calls and formal meetings. The third category comprised women with the most interaction with men. They worked in the same building with men, seeing and talking to the men on a daily basis.

The data, in general, do not demonstrate that contradictory expectations are affected by the degree of interaction of men and women at work. Instead, the data suggest the following: (1) women with least and occasional interaction with men can be divided into two groups: (a) those (the majority) who perceive no discrepancy in personal behavior expectations; and (b) those who express dissatisfaction with female colleagues' expectation that they will be overly supportive. Members of both groups tend to fulfill the sex-role expectations of their colleagues. 
(2) Women with the most interaction with men at work can also be divided into two groups: (a) those (the majority) who do not perceive any discrepancy in personal behavior expectations; and (b) those who report that contradictory behavior is expected by male colleagues.

(3) It was found that qualitative data, in general, are consistent with the quantitative data. The quantitative data show that the amount of contradictory role expectation is similar regardless of the degree of interaction between men and women on the job. For the most part, women with the least interaction do not experience the least contradiction in role expectations from women colleagues. Likewise, the expectations of male colleagues do not show a clear pattern of greater contradiction among respondents with the most interaction.

For clarity of presentation, differentiation will be made between the two types of behavior; that is, personal behavior expectations and work behavior expectations. In this chapter, qualitative and quantitative data will be incorporated to illustrate the differences in the amount of contradictory personal behavior expectations by the degree of interaction women have with men at their work. Further discrepancies in personal behavior, such as women's appearance and manner, will also be discussed.

Secondly, different types of contradictory work behavior expectations will be examined, apart from the degree of interaction women have with men in their work. These contradictory work behavior expectations include: relationships between teachers and students and among colleagues themselves, material to be covered, quality vs. quantity in. education, and public expectations. Two additional issues were discussed 
by respondents: (1) the dominant trend in the work situation is cooperation rather than competition, and (2) it appears that males are supportive of women colleagues. These two issues will be discussed later in this chapter.

\section{CONTRADICTORY PERSONAL BEHAVIOR EXPECTATIONS BY THE DEGREE OF INTERACTION WITH MEN AT WORK PLACE}

Women with Least and Occasional Interaction

The qualitative data show that women with least and occasional interaction could be divided into two groups: (1) those (the majority) who showed no discrepancy in personal behavior expectations by colleagues, and (2) those who expressed their dissatisfaction with discrepancies in personal behavior expectations. It appears that respondents in a more homogenous environment found that this environment reaffirmed their security and was not threatening to their identity. They reported that they were expected to be supportive and cooperative, and on occasion to discuss and argue. They tended to behave in the manner expected by their colleagues. This group could be labeled "high positive conciliators." Six respondents illustrated this point of view.

Respondent \#6 said:

The work atmosphere is characterized by mutual understanding and closeness. In general, I am a cooperative and forgiving person. I'm not sure what they expect from me. I assume that they expect me to support them. I do that when it is convenient.

Respondent \#10 reported: 
I am more helpful with female colleagues than with males. I cooperate with female colleagues and support them. I'm also encouraging and sympathetic. I'm not a shy person--I discuss and argue. They expect me to do so. Sometimes female colleagues expect me to be helpful because we are all women. Male colleagues expect me to cooperate more than anything else, but they also expect me to take part in discussions about work.

Respondent \#12 said:

I try to cooperate with female colleagues--not because of duty, but because of sisterhood. I take their family emergencies and i11nesses into consideration. Our work atmosphere is one of cooperation, not competition. Female colleagues expect me to be helpful and cooperative. In fact, they think I'm a more cooperative person than they expected me to be. I don't like to be critical and picky. with my colleagues, and I really don't feel that contradictory behavior is expected from me. I cooperate with male colleagues. Our work is complementary and interrelated. They expect me to cooperate and accept their opinions. What I actually do is agree when I am convinced that they are right and argue when I feel they are wrong.

Respondent \#15 commented:

During formal meetings with male colleagues, I'm serious, formal, shy, and conservative. I'm not myself; I just talk and smile when it's necessary. Male colleagues expect me to be conservative and shy and to agree with them. They expect agreement because they are in higher positions. In fact, our relationship with males is limited, and they don't really know much about us. There's no contradiction in the behavior I'm expected to exhibit.

The data show that what women actually did was consistent with what they were expected to do.

The second group was few in number and could be labeled "low positive conciliators." They tended to behave as expected by colleagues but they expressed their dissatisfaction with discrepancies in personal behavior expectations.

Respondents reported that, as women, they were expected to be very helpfur and sympathetic, yet as workers, they felt that they should 
be more critical and assertive. Respondents indicated that female colleagues showed ambivalence about being critical, assertive, and showing independence. Colleagues might admire such traits, but actually preferred the supportive colleagues. Four respondents spoke of their ambivalence. Respondent \#8 described herself as follows:

I'm usually cooperative with female colleagues because there's a bond between us. I sympathize with them and support them. They expect me to be that way. Sometimes I wish I didn't feel that I have to be supportive with my colleagues. I wish I could be more critical. It seems to me that sometimes some colleagues take advantage of me because they know that I'm a supportive person. They might think I'm not capable of being any other way. I notice that colleagues don't take advantage of those who are independent, critical, and competitive. Sti1l, they dislike that kind of personality. They prefer the supportive personality.

Respondent \#11 said:

I sometimes sympathize with female colleagues when it comes to vacation plans. I don't punish my colleagues, except verbally. I do criticize their work if I feel it's necessary. I am a very rational person when it comes to making decisions and evaluating. What bothers me is that women expect me to be very sympathetic about their vacations and when they don't come to work on time. They expect me to consider their family problems, such as a child's sickness. They feel we are all women and know and understand each other. They feel there should be a kind of forgiveness and understanding since we are all women. So I really sympathize with female colleagues, whether I like to or not. I really can't say exactly what male colleagues expect from me. We don't have much contact with men--just formal meetings ten or twelve times a year. We frequently talk on the phone on a day-to-day basis. Those who have worked with me for a long time expect me to speak my mind. They know that's the way I really am.

Respondent \#13 reported:

What I would really like to do sometimes is refuse to do favors. For example, when I am asked to let a student register for more hours than she is supposed to. I'd like to be able to refuse to do extra work when I'm asked too--somebody else could do the work for a change. 
Women with Most Interaction with Men at Work

The qualitative data show that women with most interaction with men at work could be divided into two groups: (1) those (the majority) who do not perceive contradictory role expectations, and (2) those who do perceive contradictory role expectations. Respondents reported that they were expected to be supportive and to argue occasionally. This group might be called "conciliators," since they appeared to behave as expected by colleagues. Three respondents described their situations.

Respondent \#27, although reporting her supportive role, wished she could change it somehow. She said:

I try to be forgiving, cooperative, and friendly with colleagues, but I express my opinion frankly. I try not to hurt others or be too critical. That's why I feel I couldn't have a job that required exercising a lot of authority and giving orders. I try not to be aggressive, and I try to sympathize with others. Colleagues expect me to be this way. That's why being a physician is appropriate to my nature. However, I would like to behave differently sometimes.

Respondent \#30 expressed herself clearly:

I don't feel I'm expected to perform in a way that is contradictory to my real nature. At work I argue, discuss, cooperate, and sympathize only when necessary. Colleagues expect me to behave in this manner, according to how I feel.

Respondent \#35 reported:

In general, I cooperate, forgive, show affection, support, and encouragement. I like to be this way. I don't really know what colleagues expect from me exactly. Our relationship is formal and serious. I assume that this is what they expect.

Members of the second group of respondents were aware of incongruent expectations and they tended to violate those expectations. They were the ones who told me what they were expected to do, and how they 
violated the expectations of males. This was best described by Respondent \#26:

Female colleagues expect me to forgive and sympathize. A female colleague expects me to cooperate because of affection and kindness, and to empathize because we are all women. Men are different. In general, I'm a cooperative, sympathetic, and forgiving person. That's the way I am with both males and females. But I also argue, object, and discuss. Males want me to accept their opinions more than women do. Males expect me to cooperate with them because they feel they have more responsibility. They expect me to be forgiving like a woman, yet serious like a colleague. Males don't expect me to argue, discuss, and object, but I do it a lot anyway.

Males expect me not to compete, but I do. I don't compete with them for promotion to hospital director. It would be pointless, because there is no opportunity for me, as a woman, to be a hospital administrator. However, I compete with male colleagues with respect to the number of patients I examine and the number of successfui operations I perform. Sometimes I agree with male colleagues, but they expect more. Male colleagues want me to ask their advice more than female colleagues do. They feel good if I ask for their help. Male colleagues also expect me to accept their opinions when it comes to making decisions.

Respondent \#31, an interior decorator, expressed similar feelings:

Male colleagues expect me to be conservative and yet to be myself. At the beginning they were afraid to talk to me. They know I am native, and they assume that women from Saudi Arabia are conservative. However, I started to talk to them and sometimes I asked their opinion. Most of the time I tried to be conservative. I want to talk to them, and I don't want to. I didn't like the work atmosphere, partly because I felt I had to be conservative.

Respondents' awareness of incongruent expectations could have been due to the fact that they were in a heterogeneous social environment; that is, they came into contact with men in a work situation.

Qualitative Data Analysis

As a means of indicating the degree to which women felt contradictory expectations from colleagues in the work setting, the 
respondents were asked how much they were expected to behave in particular ways by male and female colleagues. These "expected ways of behaving" consisted of four pairs of contradictory types of behavior. Thus, if a respondent indicated that she was expected to be accepting "much" of the time, and also indicated that she was expected to argue "much" of the time, this was recorded as "much" contradiction in role expectations. On the other hand, if the response pattern in these two behavior expectations was accepting "much" of the time and arguing "little" of the time, this was recorded as "little" contradiction in role expectations. Paired responses of "some" of the time to one behavior expectation and "much" or "little" to the contradictory behavioral expectation were recorded as "some" contradiction in role expectations. The four sets of paired behavioral expectations were: Accepting-Arguing, Raise the Status of Others-Critical, Sympathetic-Assertive, and HelpfulCompetitive.

Table VIII shows the percentage of paired responses to all four sets of contradictory behavioral expectations which indicated much, some, and little contradiction by the degree of contact with men in the work place. These expectations were felt to be possessed by the women colleagues with whom the respondents worked. In general, Table VIII indicates that contradictory role expectations were experienced to a similar degree by all respondents regardless of the amount of contact the respondents had with men on the job. At each of the three different levels of contact with men ("least," "occasiona1," "most"), the most frequent response pattern showed little contradiction in role expectations, with much contradiction being the least frequent response. 
It is interesting to note, however, that there was somewhat less contradictory behavior expected by female colleagues in occupations where there was occasional contact with men than in occupations where there was little or much contact with men. It is aiso interesting that the greatest degree of contradictory expectation was indicated by women who had little contact with men (17 percent indicating much) and not in those occupations where women had the most contact with men (10 percent indicating much).

\section{TABLE VIII}

PAIRED RESPONSES INDICATING CONTRADICTORY EXPECTATIONS FROM WOMEN BY DEGREE OF INTERACTION OF MEN AND WOMEN AT WORK

\begin{tabular}{crcr}
\hline Amount of & \multicolumn{3}{c}{ Degree of Contact } \\
\cline { 2 - 4 } Contradiction & Least & Occasional & Most \\
\hline Much & $17 \%$ & $7 \%$ & $10 \%$ \\
Some & $33 \%$ & $33 \%$ & $38 \%$ \\
Little & $47 \%$ & $60 \%$ & $46 \%$ \\
N/A & $3 \%$ & -- & $5 \%$ \\
Total & $100 \%$ & $100 \%$ & $99 \%$ \\
Number of Paired \\
Responses (N)
\end{tabular}

Table IX utilizes the same format as Table VIII, but shows the expectations of males rather than female colleagues. Here, the results are more in line with the hypothes is that women in occupations with much contact with men would show a much larger percentage of "much 
contradiction" (14 percent) than women in occupations where there was only occasional contact with men (4 percent). This comparison, however, should not be over-interpreted, since responses from those in occupations where there is much contact with men also show a larger percentage of responses indicating "little contradiction" than do the responses from those in occupations where there is occasional contact with men (50 percent and 40 percent respectively).

TABLE IX

PAIRED RESPONSES INDICATING CONTRADICTORY EXPECTATIONS FROM MEN BY DEGREE OF INTERACTION OF MEN AND WOMEN AT WORK

\begin{tabular}{|c|c|c|}
\hline \multirow{2}{*}{$\begin{array}{c}\text { Amount of } \\
\text { Contradiction }\end{array}$} & \multicolumn{2}{|c|}{ Degree of Contact } \\
\hline & Occasional & Most \\
\hline Much & $4 \%$ & $14 \%$ \\
\hline Some & $36 \%$ & $25 \%$ \\
\hline Little & $40 \%$ & $50 \%$ \\
\hline$N / A$ & $19 \%$ & $11 \%$ \\
\hline Total & $99 \%$ & $100 \%$ \\
\hline $\begin{array}{l}\text { Number of Paired } \\
\text { Responses }(N)\end{array}$ & 47 & 36 \\
\hline
\end{tabular}

To sum up, the hypothesis must be rejected. Women with the least contact with men do not experience the least contradiction in role expectations from women colleagues, and the expectations of male colleagues do not show a clear pattern of greater contradiction among respondents who have the most contact with men. However, this conclusion should be 
viewed cautiously, since the qualitative data are more in line with the hypothesis. They show that the perception of women with least and occasional interaction with men is that contradictory expected behavior is a by-product of personality differences of the various respondents. Women with the most interaction with men at work perceive the contradictory role behavior as a by-product of a positional factor; that is, of being with men at work. This finding should be examined more thoroughly, using a larger sample.

\section{FURTHER DISCREPANCIES IN PERSONAL}

\section{BEHAVIOR EXPECTATIONS}

Regardless of the degree of interaction with men, the respondents reported various contradictory personal behavior expectations: These contradictions dealt with women's appearance and conservative behavior at their place of work.

\section{Women's Appearance}

Although school teachers had no interaction with men at work, they were expected to be conservative in the way they dressed. Some reported that although they did not believe in covering their faces in public, they did it because of orders from their superiors, and asked students to cover their faces also. Three respondents spoke of the way they dressed and of their feelings about covering their faces.

Respondent \#1 reported:

We are instructed to wear long sleeves, even though we are all women working together and no men are allowed inside the school. It is not considered desirable for women teachers to dress up, al though some do during the time that we are turning in grades and the 
students aren't around. It seems unreasonable, even to students, that teachers have to act this way.

Respondent \#2 said:

I notice that some teachers--particularly those who teach religious subjects--uncover their faces in public. This is a double standard. They ask students to do things they do not conform to themselves.

This causes value confusion for the students.

Respondent \#8 reported:

There are many instructions regarding our appearance. For example, we're not supposed to wear short sleeves. Using make-up, wearing wigs, and polishing our nails are all frowned upon. I don't believe in covering my face, but as an employee I have to. I don't believe that uncovering the face is against religious teaching. Some colleagues believe as I do. I have seen them coming to work uncovered, then covering their faces when they reach the institution guard.

Conservative Behavior

The data also suggest that conservative behavior among respondents is the dominant behavior when women come into contact with men. However, there are differences among respondents. The data show a development of four types: (1) respondents who felt that they should be conservative with male colleagues (conformists); (2) respondents who acted conservatively out of fear of being misunderstood; (3) respondents who were conservative because they were following work instructions; and (4) respondents who behaved in a conservative manner but reported dissatisfaction.

(1) Conformists. Five respondents felt that they should be conservative with their male colleagues in the way they dressed, talked, and sat. They reported satisfaction with their own behavior among male colleagues. They felt that they were expected to be conservative and that by being conservative, they would be assured of self-respect. 
Respondent \#9 said, "I am usually conservative in the way I dress when I attend formal meetings with male colleagues. I do that so I don't draw attention to my appearance. I usually talk about subjects related to work." Respondent \#30 reported:

In general, I am conservative in the way I dress and behave. For example, I don't laugh much or tell jokes. I'm not conservative because of any work regulations, but because this is the way I am. I'm careful about the way I set my hair, and don't use much make-up. I feel that I'm behaving in the right manner, since our society is not yet accustomed to the idea of women working with men. That's why I'm serious.

Respondent \#35 said:

The relationship with colleagues in general is a sort of brotherhood and companionship, while at the same time it's formal and conservative. I wear the Abbaya and I sit with considerable distance between myself and males. I leave the door open when there is a meeting with one male colleague. This doesn't bother me--it's the way I like to behave. They expect me to be this way, and they support this kind of behavior.

(2) Fear of Misinterpretation. Five of the respondents expressed

their fear of being misunderstood if they behaved less conservatively.

This fear is partially due to the fact that there is a lack of association between males and females, and, therefore, a lack of common expectations. Several respondents discussed their uneasiness.

Respondent \#12 said:

Generally I'm careful, formal, and conservative with male colleagues. I don't want to be misunderstood, and I don't want them to think of me as immature. I don't know enough about their backgrounds, values, and attitudes.

Respondent \#20 commented:

I feel more comfortable with female colleagues about the way. I talk, the subjects I talk about, and the words I use. I'm more relaxed with women because I know how they think. I also have some idea about their work performance. I'm less confident with male colleagues. This is partly due to the fact that I don't know how good they are at their work. I'm still a relatively new employee. I don't know all the rules yet, and I'm afraid I' 11 do something 
wrong. In general, I'm careful around male colleagues--I just try to be serious and talk about subjects related to work. I'm afraid if I act natural, they might misunderstand me.

However, I feel that if I continue to work with male colleagues, this fear might go away. In fact, this already happened to some extent after we worked with them in one project. I also became more relaxed when I found out that one of the male colleagues is a relative of mine.

Respondent \#32 stated:

In general, I'm conservative because I'm afraid my behavior will be misunderstood. I feel more at ease with female colleagues than with men workers. We are instructed not to close doors when we are alone with male colleagues, and we are also instructed to wear long dresses. That's because other workers--particularly guards--are watching us carefutiy.

(3) Being Conservatively Dressed because of Work Instructions.

Two respondents talked about instructions they had received concerning their dress at work. Respondent \#10 said, "I generally dress as I please around male colleagues, except for what is necessary, such as wearing the Abbaya. Respondent \#33 reported:

We are instructed to wear long dresses and cover our hair. However, I don't wear the Abbaya around male colleagues. Our relationship is a professional relationship. It's formal and serious, and there's no time for talking about other subjects. I'm usually conservative in the way I dress, walk, and talk. I don't talk loudly, laugh, or tell jokes in the halls. Guards are usually in the halls staring at us. I usually wear loose clothes and don't use make-up.

(4) Dissatisfaction with Conforming. Four respondents reported dissatisfaction because they felt they could not be themselves at work. They felt they had to be conservative in order to conform to the expectations of colleagues, husbands, and society.

Respondent \#15 stated:

I wish I could act more naturally in formal meetings with male colleagues. I mean, I'd like to be less serious and shy, and be more at ease. I feel like I'm playing a role--like I'm acting. I want to be formal and conservative, but not shy. I wish I could be myself and discuss, argue, and criticize. 
It seems to me the reason I'm not myself is because there is so little interaction between the two sexes. I guess I'm also afraid of what male colleagues would think of me if I acted differently. Besides, I know that my husband and father are not in favor of my meetings with men. That might explain why I don't smile, laugh, or discuss anything except work.

I am usually afraid that I'11 be misunderstood, but since meetings are held oniy once a month, I don't have to worry about this situation very often. However, I would be more bothered if meetings were held often--like once a week.

Respondent \#26 said:

I feel I'm confined to a certain behavior. I have to be serious, formal, and conservative. I do this, since the idea of men and women working together is still new to our society. I'm afraid of being misunderstood if I smile. This bothers me.

Respondent \#31 expressed a similar feeling, "There is no 'dress code' where I work, so I go to work without the Abbaya. A1l my colleagues are non-native. But it still bothers me that I feel I have to be conservative." Being under pressure to act conservatively was also mentioned by Respondent \#4, who had no interaction with men at work:

I wouldn't mind working with men. However, I feel that some problems might arise. When a woman works with a man, she is under pressure to be conservative in the way she dresses, talks, and behaves. Working with women is much easier. Women colleagues talk easily, laugh, and tell jokes. A woman can't be that way with male colleagues, particularly at the beginning of the professional relationship. A woman would be afraid that her behavior would be misinterpreted.

Respondent \#34, who had most interaction with men at work, expressed her dissatisfaction with job regulations which regulated relationships between male and female colleagues. She said:

With the increased number of female workers--particularly from other Arab countries--instructions are issued to regulate the relationships between male and female colleagues. For example, males and females are not supposed to be seen together a lot. The door is not supposed to be closed when one male and one female are in a room together. Rules like this make the relationship a little bit tense. However, the relationship between male and female colleagues is much easier and friendlier when there is a small number 
of female workers. I don't wear the Abbaya and I go unveiled. This seems to surprise the guards, and they act rough.

Differences among respondents could be due to factors such as:

(1) differences among respondents individually (traditionally-oriented or modern-oriented); (2) marital status (married or single); (3) differences in instructions regulating male and female interaction (strict or flexible); (4) the length of time women had worked with men: (5) the number of male workers compared to the number of female workers; and (6) the nationality of the male workers.

Working with Women vs. Working with Men

The data also imply that women prefer to work with other women because there is less pressure to behave in a conservative manner, and because there is more opportunity for close personal relationships. However, some women would like to work with men in order to have the opportunity to be exposed to a different perspective: to learn more and to gain valuable experience. Respondents also reported that there was a more serious work atmosphere and a better professional relationship when men and women worked together professionally.

Respondents \#4 and \#11 spoke of the advantages and disadvantages of men and women working together. Respondent \#4 said:

Working with women is relaxing. However, I feel that when the boss is a man, women are more under control. They are more organized, less contentious, and more obedient.

I have noticed that women argue and object even when the woman boss is right. It seems to me that with men bosses, there is less discussion and argument. Then the women only argue when they feel they are right.

Respondent \#11 commented:

Working with women bothers me in one way. Sometimes I feel they are too comfortable together and not serious enough. For instance, 
one will say, "I'll write this letter tomorrow instead of today." It would embarrass me to show anger or dissatisfaction when they act unconcerned. However, working with women is better in another way. If I have a personal problem, I'm able to talk about it. I feel more at ease with women than with men.

Respondent \#27 stated:

I don't care whether I work with men or women. However, I feel I would prefer working with men, since they discuss different subjects. A man devotes much of his time to work. A woman devotes only part of her time to work since she has other responsibilities.

Respondent \#35 reported:

Working with males is good--you get a chance to learn more and to benefit from their experience. Women somehow have a limited perspective.

I wish I had more opportunity to attend work meetings with male colleagues. Maybe this doesn't happen because I'm not an official employee. Another explanation might be the traditions surrounding the relationships between men and women.

\section{CONTRADICTORY WORK BEHAVIOR EXPECTATIONS}

Regardless of the degree of interaction women have with men at work, they seem to expect various types of contradictory work behavior. These contradictory expectations include: (1) work relationships (e.g., between teachers and students, and among workers themselves); (2) material to be covered and methods of teaching; (3) quality and quantity in education; and (4) public expectations.

Work Relationships

It appears that work-related relationships oscillated between non-institutionalized and institutionalized behavior.

(1) Relationships between Teachers and Students. Teachers were expected to have both formal and informal relations with students. Two respondents expressed their dissatisfaction with instructions regarding 
their relations to students. Respondent \#2 said, "Teachers are expected to be formal and keep distance between themselves and their students.

This is inconsistent with modern educational objectives." 'Respondent \#9 agreed:

I'm expected to be strict with students and I'm not in favor of doing this. I know that some students might take advantage of a teacher if she's friendly and nice, but I feel that treating students nicely is much better than being strict.

This response was affirmed by Respondent \#11, who complained that some students took advantage when teachers were nice. At the same time, students seemed to disilike strict teachers. She said:

Sometimes I feel that the students hate me. This could be due to the fact that I'm serious and objective. They argue and object about their grades. I feel that exceptional grades should be earned, not given away. They want to have higher grades than they deserve.

I also object when they come to class late. I do this for their own benefit, but they don't seem to appreciate it. They want me to be less serious and less formal with them. They want to be spoiled. This situation bothers me very much. Non-natives sometimes give them better grades than they deserve. They do it because they want to avoid problems.

It seems that the way in which teachers spoke to their students played an important part in the determination of the teacher/student relationship; that is, the relationship depended not only on what the teacher said to her students, but how she said it.

(2) Relationships between Colleagues. Some respondents felt that personal relationships were in conflict with professional relationships. For instance, some workers were allowed flexibility in their working hours, sometimes arriving late or leaving early. Occasionally workers found themselves in the difficult situation of receiving orders from highly-placed citizens which were in conflict with the work instructions of their organization. Five respondents expressed their dissatisfaction 
with the existence of personal relationships in the work situation. It appeared that the emerging values of bureaucracy were conflicting with traditional values, and respondents felt ambivalent about this conflict.

Respondent \#2 stated, "Permission to take the day off or to come to work late because of family problems or sickness are usually given to those who have a friendly relationship with the boss." Respondent \#13 said, "Some students are allowed to register more than they are supposed to because of favors; other students are not. Personal relationships are also considered with respect to employee attendance." Respondent \#19 was very dissatisfied with professional/personal relationships. She commented:

No professional relationship exists at work--instead, there are personal relationships. Competition is not based on good performance, but on other things. You feel you don't have any privacy. Most subjects discussed at work are personal rather than intel lectual. It is a close-minded atmosphere, and there's no opportunity for learning. There's not much opportunity to express an opinion frankly and honestly. It's possible that we're influenced by nonnatives. They tend not to "rock the boat." This has a bad effect on the work atmosphere. Bosses are not used to being criticized.

Respondent \#21 reported, "Sometimes at work you are ordered to do things. This creates conflict between what you feel you should do and what you are ordered to do."

(3) The Hierarchy of Authority. Ambiguous feelings about the distribution of authority and responsibility were mentioned by respondents. For instance, a school guard represents authority simply because he is a man. Having too many directors, as well as having responsibility with no authority, caused women to feel they were being pulled in too many directions. Respondent \#8 reported: 
I feel that the school guard represents authority. He feels he's more powerful than the teachers. Just because he's a man, he's considered the school protector. I can't argue or fight with him even if I'm right. Some teachers cover their faces as they approach the school so the guard won't see them uncovered. The same thing applies to the messenger. The guards and messengers watch the teachers going in and out of the school. Sometimes teachers are questioned at work after guards or messengers have reported something about them to the teachers' superiors.

Respondent \#10 said:

The relationship between the director and the employees is not clear. I get instructions from several different directors. I have no clear authority to make decisions. What I have is responsibility without precise and clear authority.

Respondent \#17 was very dissatisfied with the centralization of authority:

I'm in a top position where I work, but I don't have much authority. There is a tendency to centralize authority. This centralization encompasses student affairs and employee affairs. The authority is centralized in the hands of the general director. They don't want centralization of authority in the women's section. This really bothers me very much. It's contrary to the development of this college and it causes confusion about responsibility and authority. I had a hard time getting qualified administrators and teachers for our college--I even had trouble getting furniture!

\section{Material to be Covered and Method of Teaching}

Three teachers told of the material they were expected to cover and the new teaching methods they were expected to use. Respondent \#1 said, "There is so much material to be covered and the students are expected to understand it a11 we11." Respondent \#2 added, "There is much material to teach. At the same time, I am expected to perform as well as my students." Another teacher expressed her dissatisfaction with the old and new methods of teaching, as well as the amount of material to be covered. Respondent \#4 reported:

I am instructed to follow the new method of teaching--that is, starting with the sentence in teaching English as a second Tanguage. 
However, there is so much material to be covered, and I know from my own experience that the old method--starting with letters--is much better.

The comments of the respondents implied their dissatisfaction with their lack of adequate power or authority. They also pointed out the practice by their superiors of controling women workers.

\section{Quality and Quantity in Education}

There is disagreement about the relative values of quantity and quality of education. A possible explanation for this dissension is the country's urgent need for native labor. However, trying to conform to the seemingly incompatible requirements of quality and quantity has created a difficulty situation for education professionals.

A number of respondents were dissatisfied with the concern about quantity rather than quality of education. Respondent \#2 said:

We're instructed to watch students carefully during tests, and students who cheat are supposed to be punished. However, the people in charge feel it's undesirable if the success rate of students is low. Students who don't show up for exams get an " $F$," then we're asked to make up tests for them.

Respondent \#5 agreed, "Written instructions are quite clear--the teachers are supposed to be strict with students who cheat. However; the people in charge expect a high ratio of successful students." Respondent \#6 reported, "It bothers me a lot to be asked to be strict with students while at the same time I know that the number of students who 'make it' is considered very important." Respondent \#8 said, "People in charge seem to be more concerned with quantity than quality." Respondent \#11 commented, "I feel that education should be fair and strict, but sometimes I feel I don't have to be this way. It seems to me that quantity is considered more important than quality." Respondent 
\#17 stated, "I wish more consideration was given to the quality of our students instead of just the number who pass."

\section{Public Expectations}

Respondents perceived contradictory public expectations. Parents interfered with educational instruction and expected their demands to be met. Patients expected all the treatment they wanted, with no consideration for the number of patients each physician had. Clients asked for specific designs and then asked for something entirely different. The public expected newspaper editors to confine themselves to the advocacy of the society's values; they wanted no discussion that would disturb those values.

A number of respondents described the situation as it affected their professions. Respondent \#11, a college administrator, said:

Public opinion is very powerful. It has a lot of influence on the way the education system is run. Students' families interfere with the way students dress; some have objected to letting female students attend school unless they are in uniforms. Parents interfere with the way teachers treat students. With regard to admission and registration, people complain and write letters. Sometimes their objections and demands are unreasonable. It's a shame that complaints, objections, and asking for favors sometimes come from the educated class and those who have power in terms of money and occupation. As a result, people in charge are afraid of complaints. They don't want problems.

Respondent \#23, a physician, reported:

Many patients come in every day. I'm expected to give each patient as much time as they want, and I can't. Sometimes patients are aggressive and rough. They complain that they don' $t$ get enough treatment and attention. Patients don't realize how limited our time is or how many patients have to be examined. Besides, there's a lack of equipment.

Some patients don't trust the doctors. It could be due to the fact that some physicians are non-native, and patients think that they only care about money. Another reason is that sometimes patients have a certain medicine in mind; and want to use it. They want to be treated nicely and with a lot of patience. 
Respondent \#31, an interior decorator, stated:

Clients sometimes change their minds after we have agreed on a design. For example, one buys a rug, then comes to me and expects me to change my design. This bothers me a lot. If they don't want to confine themselves to a certain design, why bother to go to an interior decorator?

Respondent \#37, an editor, said:

From people's reactions to my writing, I get the impression that some don't like the direct approach, and some misunderstand my writing. For example, when I wrote about the Abbaya, some women thought I was insulting them since they don't wear it; others thought I was trying to "corrupt" women or make them revolt against the Abbaya. Still others commented that I didn't know enough about our Islamic teaching. What I was trying to say was that the Abbaya was not an obstacle--that women could continue to wear it and still work.

\section{FURTHER IMPLICATIONS}

The data suggest that the dominant trend among the respondents in the work situation was cooperation rather than competition. Competition was relatively rare for the following reasons: (1) some respondents were not interested in promotion, because promotion was sometimes based on something other than good qualifications or job performance. (2) Another explanation may be that there was no opportunity for competition. For example, the work was complementary or separated; family and friendship ties existed among some colleagues; feedback and guidance were not available; male colleagues were in higher positions, worked longer, and had more access to power; and workers were few in number in any one field of specialization. (3) Some respondents reported that they did not like to compete. (4) Oniy three respondents reported that they competed in their work. Three women reported that competition existed in their places of employment, but that it was hidden and was not based on professional relationships. 
Lack of Interest in Seeking Promotions

Some respondents reported that they were not interested in seeking promotions. This could be due to the fact that the bases for promotion were not based on competence and professionalism. Respondent \#6 expressed her feelings about promotion:

I don't care to be promoted to principal or whatever. I'm only concerned with doing good work. For example, I want to take teaching methods courses. I'm not interested in competition. Promotion is based on the number of years at work--my income will be raised automatically next year. I just want to get more experience and learn more.

Respondent \#10 reported:

I've noticed that promotions aren't always based on qualifications, experience, or good performance. That's why I'm not interested in promotions or competition. I have no interest in having a top position or being in charge. It's artificial to be in charge or to be in a top position.

Respondent \#12 said:

Being in a top position doesn't interest me. I just don't like it when unqualified persons are promoted over me. I'd just like to see our work being done better. But I'm not interested in being promoted or in being in a top position.

Lack of Opportunity for Competition

Complementary or Separate Work. A number of respondents reported that opportunities for competition with men were not available, since the two sexes worked in a complementary fashion or were completely separated from each other. Respondent \#9 reported, "There's no opportunity for competition since our work is complementary. Besides, male colleagues have the higher positions." Respondent \#11 said:

With women colleagues, no opportunity is available for competition. I don't even know enough about what the other colleague does to compete with her. I like to see my students have higher grades and better performances, but this doesn't mean that I wish others bad luck. I don't want to compete with men either. The male section 
is the source of decisions and instructions, though they occasionally ask for our opinions. Our work is complementary; we depend on the men's section to solve our academic as well as our administrative problems.

Competition appears more between male and female students. Girls try to get better grades. Teachers also compete with each other.

Respondent \#18 reported:

There is no opportunity for us to compete with male colleagues. Our work is separate. We're responsible for women's affairs and they're responsible for men's affairs. We sometimes might try to show male colleagues that we're doing a better job. However, they aren't interested in competing with us.

Family and Friendship Relationships. Family and friendship relationships appeared to facilitate a cooperative atmosphere rather than a competitive atmosphere. Respondent \#4 talked of friendships at her school:

Teachers usually cooperate at work. Only one teacher is competitive. She wants her students to get better grades than the other students. In general, the reason there's not much competition is that colleagues know and visit each other. Some teachers were friends before they became teachers; some went to school together. This makes the work atmosphere one of cooperation rather than competition.

Lack of Available Feedback. The lack of feedback to professional

women was best described by Respondent \#34:

The reason there's no competition is that the library is inconvenient, and we don't have enough qual ified supervisors. There's not much criticism or guidance, and no feedback from the public. Every colleague has his own program and tries to do it well. The relationship is mainly a work relationship. I go to the station to tape and then go home. There's no competition, but there may be if one program is divided between two colleagues.

Position of Male Colleagues. The position of males was described by two respondents. Respondent \#22 reported:

I don't really compete with male colleagues. There's no opportunity for competition. I'm still a new worker and I don't have much experience. In fact, I ask their advice, since I'm not familiar with the nature of the work yet. 
Respondent \#35 said:

No opportunity to compete with males exists since they occupy higher positions and have more power. The number of programs I tape is limited. I'm not an official employee, and I don't hold a high position or go to meetings or conferences. I don't have any authority to make decisions--to add or cancel a program, for instance. This bothers me a great deal.

Number of Professionals. Three respondents spoke of the relatively few women in some professions. Respondent \#20 reported:

There's no opportunity for competition. I have no colleagues whose work is similar to mine. That's why we consider each other's interests. Even if we do similar jobs, the client is the one who benefits.

Respondent \#23 said:

I have only two female colleagues and they don't really care to compete. One has been working for a long time, and she's not very enthusiastic; the other is dissatisfied with the work atmosphere. It seems like they only do what they are supposed to do. There's no opportunity for competition. I wish there was--it makes people perform better.

Respondent \#29 commented:

I'm the only professional in my field where I work, so there's no opportunity for competition with colleagues. There used to be one male colleague, and there was competition between us. We competed over the number of patients we examined.

\section{Dislike of Competition}

Some respondents did not like competition; seven respondents expressed their disapproval of competition. Respondent \#1 reported, "I don't compete. Cooperation is better than competition." Respondent \#2 said, "I don't care for competition. I just want to be satisfied with myself and my work." Respondent \#16 commented, "I don't care much for competition. What I care about is the interests of my students. There is no other teacher teaching my subject. If there were, I think I would cooperate with her." Respondent \#21 showed disapproval of competition: 
There is so much competition these days. I've had a negative attitude toward competition ever since I spent time in the United States. I think competition is useless. I would be feeding on others in order to win. I'm sort of pessimistic and I think negatively. I don't value such things as competition. Even though it may be a good thing at work, I can't do it.

Respondent \#27 said:

I don't like competition. I just don't care for it. I want to be good to my patients. I'm still in the process of learning and at the beginning of my professional career. I ask for colleagues' advice and suggestions.

Respondent \#28 reported her dissatisfaction with the limited atmosphere for learning, "I don't compete, and I don't like competition. There's no opportunity for, learning--no work meetings, no discussions, no seminars."

Respondents Who Compete

Three respondents reported that they did compete. Respondent \#13 said, "Although the general atmosphere at work is cooperation, I sometimes try to finish my work before female colleagues and I try to make my work look good." Respondent \#20, a social worker, stated, "I sometimes compete with male colleagues by trying to finish my work faster and better. I feel we are attempting to prove to male colleagues that we are capable as women and as co-workers." Respondent \#26, a physician, commented, "I do compete with male colleagues with respect to the number of patients I examine and the number of successful operations I perform. However, I don't compete with them for the position of hospital administrator."

Three respondents reported the existence of competition where they worked. Respondent \#8 said: 
Competition is there, but it's hidden. You see it among teachers comparing their students' grades, and you see it when supervisors praise teachers' performances. I do compete, but I consider the feelings of my colleagues. I don't take advantage of a situation to show that I'm better than my colleagues.

Respondent \#19 reported:

I have noticed competition between two female colleagues. They do their best to show that they are better than others. I don't mind competition, but I wish it were based on a work relationship, rather than a personal relationship.

Respondent \#33 stated, "Competition is hidden among my colleagues. Everybody tries to improve his/her program."

It appears that cooperation among the majority of the respondents was more valued than competition. However, this condition may change as the number of qualified native professionals in any one field increases. Competition will become more prevalent when the supply of professionals is greater than the demand.

Mutual Dependence and the Support of MaTe Colleagues

A number of respondents reported that male colleagues have been supportive of them. They said that male colleagues encouraged them in their work, helped them, and gave them suggestions. There is a sort of mutual dependence between men and women. The dominance that men enjoy in the traditional world is carried over to the professional world; thus the men have no reason to feel threatened. Men have authority; they make the main decisions; and they occupy higher positions than women. Women do not compete with men, but turn to them for help and guidance.

Nine respondents mentioned the support they had received from male colleagues. Respondent \#12 said, "I'm teaching one class and 
working in administration. The male teacher encourages me to continue my graduate study. He also praises my students and my work." Respondent \#18 stated, "Male colleagues are encouraging, helpful, and cooperative with me. Male colleagues respect us. Most of them have more experience, since they have worked longer. They give us suggestions." Respondent \#24 reported, "Male and female colleagues are cooperative. I ask both for advice, since they are older and have worked longer. In general, they are helpful to me." Respondent \#27 said:

I'm still in the process of learning. I ask colleagues for their advice and suggestions. I want to learn from them. They are nice to me, help me, and teach me how to treat patients. I have two male relatives working in the same hospital. This might be the reason everybody--males in particular--treat me so well.

Respondent \#30 reported:

Our relationship with native male colleagues is one of cooperation, brotherhood, and companionship. In fact, we asked for help from one of them when we were told that we should consider the way we dress and behave. We asked him to help us with our objections to this kind of attention.

Respondent \#34 said, "There's a lot of respect from colleagues. You can see it in the way they talk to us--they give us straight answers. There's consideration for my physical and family emergencies." Respondent \#36 stated:

I consider my male colleague as my spiritual father. He is the one who guides me. He helps me, gives me suggestions, and criticizes my work constructively. Male colleagues praise my work. They are supportive.

To sum up, the degree of contradictory role expectation is fairly similar for all women professionals, regardless of the degree of interaction they have with men on the job. Therefore, our hypothes is must be rejected. Contradictory expectations might come from either or both men or women colleagues. However, it should be realized that the 
respondents' perceptions of contradictory personal behavior expectations of colleagues did not carry an implication of personal conflict. Respondents were expected to be supportive and cooperative. The majority, with a few exceptions, conformed to those expectations.

This finding seems to support the theorem of integration as an orienting idea. People generally want to do what they are supposed to do, and this is what the society needs to have done in order to continue. However, there are always some persons who cannot conform. This could be due to individuality or to unique situations (Goode, 1960: 485). Role demands are not always so pleasant that conformity with them becomes automatic. Conformity can be a source of difficulty. The data showed that some respondents were dissatisfied with their own unnatural, conservative behavior. In order to gain respect among male colleagues, professional women felt they had to be overly formal in their dress and their actions. This was a matter which disturbed some women more than others.

Conformity to work behavior expectations was perceived by the respondents in an ambivalent way. Relationships among individuals at work fluctuated between formality and informality. There appeared to be some contradiction between institutionalized authority and personal authority. Work instructions were often incompatible; for example, job demands created some strain between the norms of quantity and quality, universalism and particularism. It seems that work behavior itself is in a state of transition, since the whole society is undergoing change. The area of employment vacillates between institutionalization and deinstitutionalization; between more bureaucracy and less bureaucracy; 
between a hierarchy of organized staff, rules, and regulations and a de-emphasizing of such a hierarchy. 
CHAPTER VII

THE PROBLEM OF ASSERTING AN IDENTITY

In this section the writer will discuss the problem professional women have in asserting an identity in the work situation. For the purposes of the study, we are trying to discover whether the exclusion of males in the work situation has an effect on the development of women's identities. Our hypothesis is that women with the least interaction with men at work are not placed in sex-related roles rather than work-related roles. Second, those with the most interaction with men at work face the most difficulty in asserting their identities.

It is realized the the whole process of being identified may be characterized by ambiguity. That is, a male's action which is seen as either more or less placing female colleagues in sex-related roles instead of work-related roles depends on a woman's interpretation of that male action.

In order to analyze males' actions toward their female colleagues, Erving Goffman's concepts of deference and demeanor will be used. Deference characterizes activities such as salutations, compliments, and nonverbal expressions. Demeanor describes any appearance, gesture, or verbal contact, such as jokes or serious comments. Deference and demeanor establish the meaning of the relationship, and they work together to create a particular image of self for each participant in the situation (Goffman, 1967). 
This study will focus on three deference and demeanor rituals. The three dimensions center on male deference which women may interpret as discriminatory or as placing them in a "typical female" category. The first dimension is the invasion of a woman's personal privacy; for example, when men address women with certain adjectives, such as "pretty," "pleasant," or "accommodating." A second dimension is the action of a male toward female colleagues which could be interpreted as the action of a superordinate to a subordinate, such as treating her as a listener only; ignoring her almost totally, resenting any independence she exhibits, and speaking to her only when it is necessary. A third dimension is where women perceive men as imposing certain "feminine" traits upon them, such as compassion, helpfulness, empathy, and faithfulness.

The analysis of colleagues' actions will be primarily focused on male action. However, female colleagues' actions as well as actions of other workers (e.g., clerical workers, drivers, and guards) will be considered. Patients' actions toward professional medical women will also be included.

Regardless of the degree of interaction with men at work, respondents reported discrimination within the work organizations. This discrimination will be discussed.

Our consideration of female colleagues, other workers, patients, and organizations is based upon important implications derived from the data. These implications will help delineate the problem professional women have in asserting an identity. 
The data suggest the following: (1) women with the least contact with men (school teachers) showed a mild reaction. They did not make much distinction between their treatment in sex-related roles and their treatment in work-related roles. (2) Women with occasional contact with men (college teachers and administrators, social workers, investigators, and newspaper editors) were able to differentiate between being treated as females and being treated as co-workers. (3) Women with the most contact with men (physicians, radio broadcasters, interior decorators, and interpreters) had a clear perception of the difference between being treated as women and being treated as colleagues. They also had stronger emotional reactions about their treatment as women.

WOMEN WITH LEAST INTERACTION WITH MEN

Female Colleagues' Actions

Comments of school teachers did not reflect a belief that female colleagues placed the teachers in sex-related roles rather than workrelated roles. The respondents reported mutual friendliness, courtesy, and consideration between themselves and their female colleagues. They called each other by first names; they praised each other's work and complimented each other's appearance; and they were considerate with each other in times of emergency. They reported that they talked with each other about work and other subjects. The relationship among female colleagues was described as a sisterhood relationship. They expected to be help-oriented and compassionate, and only one respondent spoke of feelings of superiority or inferiority between colleagues. 
Respondent \#1 had only a mild reaction to the matter of sexrelated roles vs. work-related roles. She said:

We are all women working together. I'm being treated as an employee and as a co-worker. I feel that I am treated as a teacher and not as a woman. For example, there's no special consideration for those with physical and family emergencies.

Respondent \#6 illustrated clearly that there was no differentiation made between treatment as a female and treatment as a colleague. She reported:

I don't know what you mean about the difference in treating me as a woman or as a colleague. I feel I'm treated as a teacher and as a colleague. We address each other by first names, we frequently. compliment each other's work and appearance, and we talk together about work and other things. I like my job. I think of each student as a daughter or as a sister.

Respondent \#3 commented, "There's no superior or inférior relationship between me and my colleagues--we're all equals."

Three respondents spoke of their conformity to expected feminine traits. Respondent \#4 said:

All of us treat each other as sisters. There is no formality and it's not a matter of being respectful or disrespectful. Our relationship is based on compassion, affection, love, and empathy.

Female colleagues frequently praise my work and sometimes praise my appearance. They don't ask me personal questions. The school principal is reasonable about our family emergencies.

Colleagues don't act superior as a rule. The only example I can think of is when a rich teacher likes to show off, and she makes poor teachers feel inadequate. The guard calls me by my first name and sometimes addresses me. I respect him because of his age and think of him as a father. I know he respects me as a teacher.

Respondent \#7 stated:

I feel I'm treated as a teacher, an employee, and a daughter. 01der colleagues expect me to be helpful and empathetic. They blame me if I don't conform to their expectations; they say, "You're just like a young daughter--why don't you do so-and-so?"

Respondent \#5 reported satisfaction with the work atmosphere: 
I enjoy the work atmosphere with women colleagues very much. In fact, it's the only thing that makes me continue working. The working atmosphere is full of cooperation, caring, affection, and empathy.

The data showed no indication that these women felt discriminated against because of the deference they showed each other. There appeared to be several reasons for their comfortable relationship. They were in a homogenous enviroment. Feminine traits were viewed by colleagues and some respondents as desirable; thus respondents conformed to their colleagues' expectations. They were not confronted with making a choice between a passive female identity or an aggressive, male-like identity; rather, they had access to a full range of identities. Consequently, women's consistent application of colleagues' expectations made being a woman resemble having a "total identity."

It is important to note that some respondents felt closer to some colleagues than to others. This could be due to the fact that there were both native and non-native teachers, and non-native teachers were in the majority. The native teachers felt that they had more in common with each other than with non-natives.

WOMEN WITH OCCASIONAL CONTACT WITH MEN

Male Colleagues' Actions

With respect to women's personal privacy, a number of the respondents differentiated between two types of male action: that which took place in an informal setting (letters, memos, phone calls) and that which took place in a formal setting (business and professional meetings). They pointed out that males practiced a double standard in their treatment of women. During informal contacts, where there were 
no cultural restrictions, some male workers attempted to invade the personal privacy of women by such means as extending phone calls, bestowing compliments, attempting to find out women's names, and making funny comments. During formal meetings, where the cultural strains were present, men treated women as co-workers. During these meetings, all colleagues discussed subjects related to work. None of the male colleagues called women by their first names or referred to them as "pretty" or "pleasant."

It should be noted that male co-workers with whom women came into contact during formal meetings were not necessarily the same colleagues with whom they came into contact in informal settings.

The respondents could be divided into three groups. The first group, few in number, interpreted male actions in informal situations as an invasion of their personal privacy, and they reported dissatisfaction with male actions. Respondent \#13 said, "It bothers me when a male colleague calls me by my first name. I only talk about work. I am conservative with men and would like to keep our relationship formal." Respondent \#36 told how she coped with males' attempts to invade her privacy:

When I first started to work, there were two male colleagues who kidded around and complimented me. I put an end to their comments --I quit talking to them! At the beginning people wondered if I was really the one who was writing--I wrote on a variety of subjects and my writing was stylish and influential. Male colleagues couldn't seem to believe that a woman could write so well. They thought a man was actually doing the writing. I was amused by their reactions--it was disappointing to them to find out that they were wrong.

Female colleagues were also suspicious about my writing, but not as much as male colleagues. Now my relationship with male colleagues is sort of companionable. They call me "sister" and I call them "brothers." We work well together, and when they have family celebrations, such as weddings, they sometimes invite me. They 
respect me a lot. They make me feel as though they are really my brothers. For example, they defend me when somebody objects to my writing. They tell me, "You are a dear sister." They respect me; they respect my brother when I send him in with material. They try to be friendly and hospitable with our driver. They respect my opinion and try to not put my work down.

The second group of the respondents showed a tolerant attitude toward male actions. They were aware that some men were attempting to invade their personal privacy, but they did not see this as a problem. They interpreted male remarks as fun or diversion rather than insulting. Two single college administrators described their reactions. Respondent \#9 reported:

Sometimes some male colleagues are interested in talking with me in a personal way or want to find out who I am. However, I don't encourage them. It isn't that their attention upsets me--it's just that I prefer to have a formal relationship with them.

Respondent \#12 said:

Sometimes some male colleagues try to find out my name. They like to talk a long time. I guess you could say they treat me as a woman, not a co-worker, but this doesn't bother me. They might ask me questions about my plans for graduate study or make amusing comments or complain about having too much work to do. I don't get the impression that they're trying to bother me. Their talk is innocent. What I usually do is become more formal, and talk only about work. I'm afraid that they might get the idea that I want to have a personal relationship or that they will think I'm immature. I don't know them well. I don't know anything about their morals. That's why I'm careful and conservative.

Female colleagues treat me as a co-worker and as a lady. We compliment each other's work and appearance. We talk about work as well as other subjects. I cooperate with them because of sisterhood. We consider each other's health problems and emergencies. Some colleagues who have higher degrees might show superiority.

It appears from the previous data that women in both groups attempted to maintain formal relationships with males. They avoided talking to them except when it was necessary and they avoided talking about subjects that were not work-related. Respondents might have felt 
that by keeping the relationship forma1, their self-respect as workers would be guaranteed. This belief was best illustrated by a single socia1 worker, Respondent \#18, who said:

I have the impression that working women are respected by their co-workers as long as they are conservative in the way they dress and behave. In other words, instead of acting feminine, they must be more masculine. Then they will be respected.

The third group of the respondents--the majority--did not interpret males' actions as discriminatory. Respondent \#10, a single college administrator, reported:

I feel I am treated as both a woman and a co-worker by both male and female colleagues. During formal meetings with male colleagues, I wear the Abbaya and am conservative in the way I talk. However, when I discuss work matters, I am treated as a co-worker. Neither male nor female colleagues act superior toward me. Guards, drivers, and messengers treat me as an employee.

A married college teacher, Respondent \#16, was aware that some males discriminated against women teachers with respect to teaching authority. However, as a native teacher, she was not discriminated against. She said:

Male colleagues usually address me as "sister" or "Mrs." The professor I'm working with calls me by my son's name. In my case, I am not treated with mistrust or suspicion by male colleagues. This could be because I'm a native teacher. For instance, male teachers show me their finals questions. During the year I'm the one who puts midterms and other quizzes together. It's not the same way with some non-natives and foreigners. I was bothered once when the male teacher's final was given to my students instead of the one I had prepared. With some male colleagues I have a family relationship; that is, we visit each other. Those colleagues ask me about my husband and children. With other colleagues, I only talk about work.

There's nothing unusual about my relationship with female colleagues. We call each other by first names, which I prefer. We compliment each other's appearance. They praise my teaching techniques. We consider each other's family emergencies and responsibilities. I feel I am a teacher and a lady. 
Respondent \#18, a single social worker, spoke of the influence of Is-

Tamic teaching:

Brotherhood and sisterhood is the way I would describe the relationship between male and female colleagues. This kind of relationship is partly due to the fact that some colleagues are related by blood or marriage. Another possible explanation is the influence of Islamic teachings. Male colleagues call us "sister" and we call them "brother" or "Mr." They respect women. They feel working women need support and encouragement. They listen to our opinions. However, at the beginning, the relationship was conservative. Male colleagues were nervous. They were also curious about us and surprised that women were working. There is a consideration for our personal problems--for instance, if a child is sick or a woman is having her occasional period.

Another social worker, Respondent \#20, reported that she was not trusted when she first started working. However, she did not interpret this as discrimination, but felt that the lack of trust stemmed from her newness on the job. She stated:

Sometimes male colleagues think that some of the work is too difficult for a woman to do. However, I challenge them, and I do the work. I wasn't trusted when I first started working because I was new, and had to prove myself.

An investigator, Respondent \#22, reported her satisfaction with the way

she was treated by male colleagues:

As a woman, male colleagues show respect for me by the way they talk to me and address me. I go home earlier and start working later, so I don't meet men coming in and out of the building. I sign my name first in the attendance book so I don't come into contact with men. At the beginning males were surprised and curious to find out about me. My boss said once, "Why don't you sign your report by your last name [family name]?" This could be due to the fact that my first name shows I'm a woman. I was the first to enter the field of law. My boss is trying to avoid hassles if some people in charge object to my working in this office.

However, I'm treated as a co-worker. My opinion is respected and colleagues trust my judgment and decisions. We treat each other with respect and understanding. They talk to me with ease. They don't try to get me to empathize with them and they don't ask me personal questions. In fact, I have worked for only eight months and I' $m$ the only native woman here. 
At the time I was interviewing the respondent, she received a scholarship and decided to go on to graduate school.

Female Colleagues' Actions

The actions of women toward their female colleagues differed from male actions in several ways. Females usually called each other by first names, regardless of their occupational positions. This could have been due to the fact that relationships among females were less formal and because they interacted on a daily basis. Another possible explanation is their similarity in age, qualifications, and positions.

The way in which males addressed women could have been based on the fact that the relationship was essentially formal and work-related. Addressing women in a formal manner helped preserve the social distance between males and females. This was also found to be true with respect to appearance compliments. Women got compliments from women colleagues and not from male colleagues. Women colleagues discussed various subjects among themselves, while only work-related subject were discussed by mixed groups for the most part.

WOMEN WITH MOST CONTACT WITH MEN

Women with most contact with men included physicians, interpreters, interior decorators, and radio broadcasters. The data show that women with most contact with men in occupational setting were the most aware of the difference between being treated as women and being treated as professionals. Their comments reflected a great deal of perception and they expressed strong emotional reactions about being treated as 
women rather than as professionals. The fact that this dichotomy existed angered them.

Male Colleagues' Actions

Respondents with the most contact with men could be divided into two groups: those who were aware of and strongly resisted the attempt of any male colleague to invade their personal privacy; and those who reported that they were treated with respect. The women in the first group persisted in maintaining a formal relationship with male col1eagues. Respondent \#23, a single physician, differentiated between actions of natives and non-natives:

Male colleagues sometimes compliment me on my appearance. I won't let anybody say, "You look cute." Non-natives say things like that sometimes, but they quit when I show them that I don't like it: Native colleagues never make comments like that--the relationship is one of mutual respect. In general, male colleagues--both native and non-native--avoid asking me embarrassing questions. Almost everybody calls me "doctor." I like to be called "doctor," particularly by those I don't know very well. I don't mind if my friends who are the same age as I call me by my first name.

An expressive and conversational physician, Respondent \#24, has persistently maintained formal relationships with male colleagues:

We address each other as "doctor." I prefer to keep our relationship formal and to protect my self-respect as a lady. This way no jokes or humor will take place. I don't permit comments on what I wear or my appearance, such as, "Your dress is nice," or, "The way you set your hair is nice." If any male colleague starts talking like that, I avoid talking to him--he has no right to comment on my clothes.

By being formal and serious, I avoid embarrassing stories, particularly concerning my work as a gynecologist. In general, I'm conservative with male colleagues. I avoid talking about subjects that bother me. I talk with them about housing, transportation, inflation--things like that. When they start talking to me about appearance and clothes, the relationship becomes female-to-male, and not physician-to-physician.

Then the respondent reported the advantages of working with men: 
Still, I'd rather work with men than women. I like to have women friends because I feel more at ease with them. I don't know why I prefer working with men. Maybe it's partly because women get jealous and might compete about things like appearance.

Male colleagues are sometimes more cooperative than female colleagues. For a man, work comes first; for a woman, it comes second. If I ask a man for help, he will respond better, since he considers work essential. A woman has other responsibilities to worry about. Male colleagues show gallantry toward women. For instance, they say, "This work is too tiring for you," or they let me be seated if there is one available seat. Female colleagues feel we are all women. I like to work with men since I learn and get experience.

Sometimes male colleagues ask me about my future plans for study. They suggest that it would be better if I got married before I went abroad to study. It embarrasses me when they talk about marriage.

I don't like it. when male colleagues say I'm physically weak and start to take over when I'm delivering a baby. They tell me that gynecology is a man's field. I insist on delivering the babies myself. It bothers me when I can't manage and have to ask for their help. I admit that men are stronger physically. God creates them that way.

Another physician, Respondent \#26, talked about the differences

between male colleagues educated in Saudi Arabia and those educated

outside Saudi Arabia. She reported:

I feel there's a difference between those who are educated inside the country and those who are educated outside the country as far as the way they view women is concerned. Those who are educated in Saudi Arabia don't talk to us, or ask our opinion, or even sit with us.

I expect a male colleague who has been educated inside the country to respect me as a physician but treat me as a woman. He won't ask my opinion, he won't be friendly, and he won't talk with me about anything except work. In fact, he won't talk to me about anything except when it's necessary. He expects me to be shy and to agree with him. I feel it's the other way around with those who are educated abroad.

Then the respondent spoke of the benefits of her professional relationships with male colleagues:

My relationship with colleagues is characterized by respect and companionship. Natives usually know what family I come from. They respect me as a doctor. They know what I went through to become. a doctor. I'm always serious and formal. I want to be this way, since it's unusual for women to work with men in our society. 
The differences between male colleagues educated inside Saudi

Arabia and those educated outside Saudi Arabia could be due to the fact that those educated inside the country may lack experience in interacting with "unrelated" females in schools and colleges. In a work situation, these males seem ambivalent about their interaction with female colleagues, since there has been a lack of established common expected behavior. Thus, males' manners or actions toward female colleagues are not necessarily interpreted as superordinate to subordinate.

Respondent \#27 also spoke of differences between native and nonnative colleagues:

Male colleagues consider my family responsibility. For example, they don't put me on call at night, except when it's necessary. Native colleagues treat me as if I am a member of the family. We treat each other respectfully. I talk with colleagues about different subjects. I'm not a shy person, but I'm too emotional sometimes. I must try to be more rational.

Female colleagues treat me like a sister. At receptions, I participate and talk to foreigners. All of my colleagues are proud of me as a doctor. However, some non-native colleagues feel that they are superior to natives, and they are suspicious about medical operations performed by native doctors. They are not suspicious of me because I'm a woman, but because I'm a native. They sometimes make nasty comments like, "Patients go to native physicians for understanding, not for good medical care."

At the university, I feel that I'm viewed primarily as a female. At the hospita1, I feel I'm a physician. During breaks we all get together and have free and frank discussions. We compliment each other's appearance.

However, to be frank with you, men in general don't trust women's capabilities. They feel women can't work for long hours and think rationally. They feel women often talk too much and complain about family problems. When a woman and a man disagree on a certain issue, a man might tend to withdraw. He feels a woman is helpless and he doesn't want to be hard on her.

It appeared that the respondents differentiated between the actions of native and non-native males. The respondents reported that non-native colleagues were more likely to attempt to invade a woman's personal privacy than native colleagues. Physician-respondents \#23 
and \#24 appeared to resist male colleagues' actions, while physicianrespondents \#26 and \#27 did not seem to feel it necessary to resist such actions, nor did they seem to feel that their capability was being challenged. In general, the respondents did not perceive males' actions as a problem. Although they reported their awareness of what it was to be treated as a worker and colleague, they reported that they were treated with respect. They responded with an appropriate action (such as avoiding conversation with male colleagues) to show certain males that their behavior was undesirable. In this way, the women felt that they were demonstrating to the men that they were serious workers.

The second group of respondents reported that they were treated respectfully. Respondent \#32, a single radio broadcaster, said:

I'm respected by my colleagues at work. It shows in the way they talk to me--they say, "please," "thank you," etc. They don't talk in a rough way. They address me as "miss" or "sister." I call them "brother" or "Mr." They don't make embarrassing comments like, "You look nice," "You look pretty," "Your dress is nice," or "Your hair looks nice." It really depends on how they say it. They don't use bad words or try to be funny or nasty. They don't hurt my feelings. If they criticize my work, they criticize it objective1y. I get consideration if I have a family emergency or get sick. We discuss all sorts of things. We have some rules at work such as don't close the door when you're alone with male colleagues. This is to avoid misinterpretations by guards or other workers.

Respondent \#33, a single radio broadcaster, reported a similar work situation:

Male colleagues call me "sister" or "miss." I call them "brother" or "Mr." They treat me with respect. Nobody enters our room except those who work in our department. Males who do not have any business with our section are not allowed to come into our room. The idea is to limit the number of men who come in and out just to look at women. There are more women working in our section than in any other section. Female colleagues call me by my first name, and I do the same with them. There is nothing unusual about our relationship. 
Respondent \#34, a married radio broadcaster, reported:

I have a close relationship with male colleagues, particularly those I've known for a long time. They treat me like a sister, and I feel they are my brothers. Male broadcasters treat me nicely and with respect.

The diversity of interpretation of male colleagues' actions seems to be related to such factors as the number of male colleagues with whom women come into contact, the nationality of colleagues (native, non-native, or foreign), the educational level of colleagues, the location of the country in which male colleagues received their education, the position colleagues hold in an organization, and the differences in sex-related rules and regulations from one organization to another (i.e., the nature of interaction between men and women workers--the use of space, when and how interactions take place).

Male Clerical Workers' Actions

A number of respondents reported deep dissatisfaction with the actions of some of the male clerical workers. They spoke of a lack of respect, of invasion of their personal privacy, and of being treated like subordinates. This dissatisfaction was best described by a single physician, Rëspondent \#26:

Most clerks in administration offices are native. When I first started working, some of them were really nasty. They wouldn't do the things I asked them to do. I complained, but they didn't care. If the clerk was reprimanded by people in charge, he would say, "The blame came from a man, not from you." He would feel that I couldn't harm him directly because I'm a woman and don't have any authority or power over him. When I lose my temper, some of them say, "If you weren't a physician and a woman, we'd argue with you more seriously." They say, "We're not going to even talk to you. If you were a man, the situation would be different--we would be equals." Some don't even call me "doctor," and I don't like that. When I complain, I'm told not to take it seriously The longer I work, the less hassle there is. Workers think of me as a sister and a co-worker, but not as a 100 percent physician. 
Respondent \#27, a married physician, said, "Some of the administrative clerks don't call me 'doctor,' and they're disrespectful." Respondent \#29, a married phyisican, reported, "One administrative clerk is rough and nasty. He tries to be bossy. He criticizes my work and he's nosy. He even calls me by my first name." Respondent \#34, a married radio broadcaster, described her situation:

Those who are not highly educated and some of those who are literally religious-oriented still think like "old time." They consider me--as a woman--good for nothing but doing housework and having children. They don't believe that a woman could be a manager in charge of something. I've gotten that impression from poorly educated people, not from colleagues. Guards are also rough. They have no respect for women. They say, "Hey, you woman!" Some males who work in clerical administration are envious because of the money I make, even though I'm a woman. Other male broadcasters at the station and the people in charge treat me nicely.

Actions of Manual Workers (Drivers and Guards)

Manual workers' actions were viewed in a negative way by a number of respondents. The women claimed that their personal privacy was invaded by manual workers. Some guards and professional women avoided talking to each other. Some guards would not address women directly; others would shout, "Hey, you woman!". Other manual workers would not take orders from professional women.

Respondents could be divided into two groups on the basis of their judgment of manual workers' actions. The first group (few in number) reported dissatisfaction; the second group (the majority) did not feel that the actions of manual workers presented a serious problem. The second group exhibited tolerant attitudes, and interpreted the actions of the workers as a natural product of their educational level and the influence of their cultural environment. 
Three respondents expressed dissatisfaction with the manual

workers' actions. Respondent \#34 reported:

Guards are tough. For example, they say, "Hey, you woman!" They talk to us like we're trash. They have no respect for women at al1. They're supposed to search employees going in and out of the station. The guard wants to show you he's better than you, even though you're something inside the station.

Respondent \#34 said, "Drivers and manual workers call me by my first name. I wish they'd learn to address me properly." A married editor, Respondent \#37, expressed a great deal of dissatisfaction with the actions of males who occupied lower echelon positions in organizations. The respondent did not specify the kind of work these men did. She saw them in the halls frequently, and assumed that they did manual or clerical work. She stated:

Some workers make us conscious that we are women. They whistle and giggle when they see us. They watch the way we walk and talk. It's disrespectful and disgusting. They don't think of me as a serious professional.

The feelings of the tolerant group were described by several respondents. Respondent \#6 reported:

The guard yelled at me once, "Hey, you woman! Where are you going?" At the beginning I was shocked, then I realized his mentality as an uneducated person. He just meant that I'm a woman. He didn't mean to insult me. Some are Bedouin and this is the way they are. They act naturaliy.

Respondent \#26 said, "Some drivers call me 'woman.' When I complain, I'm told not to feel bad about it or take it seriously." Respondent \#29 reported, "Some manual workers call me 'aunt,' others might say, 'doctor.' Sometimes they don't do what I ask them to do, but this happens to male colleagues too." Respondent \#27 stated:

Manual workers feel very insulted if I lose my temper or if I give them orders in a curt way. This could be due to the fact that I'm a woman. Deep down they respect me and they take orders from me 
because they like me. I don't often ask them to do things, particularly the old workers. They don't like to let on that they respect or like me. Sometimes they stand only for male colleagues to show their respect, but they give me symbolic gifts to show that they like me. They call me by my first name. They don't feel that my status is any higher than theirs, even though I'm a doctor. I call all of them "uncle." I empathize with them and listen to them. In general, drivers and manual workers respect me and treat me like a daughter. I have relatives who work in the hospital. This might partly explain why I get such good treatment. If somebody bothers me, he's punished.

Respondent \#33, a single radio broadcaster, said:

Guards call us "girls" or "women," but then, they call male workers "boys." They're surprised that women are working in the station. I avoid looking at them. They treat us roughly, but they do the same thing with male workers. Some of the guards are supposed to inspect all workers going into the station. I realize that they haven't been around women very much. Other guards are usually walking around or standing in the halls. They don't bother me. The only thing they do to women is just stare at us.

Another respondent even reported that she had been treated respectfully. Respondent \#24 reported:

Most manual workers seem respectful. They don't bother me. They never stare at me or try to find an excuse to come to my clinic. Everybody calls me "doctor." Manual workers treat me nicely and take orders from me. There's no problem. I've only been working for a short period, but this is my impression.

The diversity of interpretations of manual workers' actions could be due to such factors as the frequency of association between native professional women and manual workers in cities, differences in respondents' individual personalities, and respondent's previous interaction with manual workers; and not just the fact that manual workers lacked education, as some respondents reported.

\section{Patients' Actions}

Respondents fe11: into two groups as far as their reactions to patients' actions were concerned. Some showed dissatisfaction with the 
actions of patients, and others showed tolerance and perception. Those who were dissatisfied cited the way patients addressed them, a lack of trust on the part of some patients, the practice of some male patients to challenge their identity as serious workers, and the remarks of some male patients to the professional women. A physician and an interpreter voiced their dissatisfaction. Respondent \#26, a single physican, said:

I usually face a problem with patients. They call me by saying, "Woman." When I complain, I'm told not to feel bad about it. Thank goodness this way of addressing me is decreasing among patients who come to the hospital more than once. On the other hand, I still have the problem with new patients. Some patients are not convinced that I know what I'm doing. I call the police when patients get aggressive. They apologize, but they say, "I'm apologizing only because you're a woman." Young female patients are convinced that I'm a physician and they want to be the same. 01der female patients sometimes go and check with another doctor after I examine them. My patients are from Yeman, Syria, Lebanon, Palestine, Egypt, and Sudan, and a few are natives.

Respondent \#30, a single interpreter, reported:

It's tiresome to work with male patients. They talk too much and sometimes ask embarrassing questions just to see my reaction. They sometimes refuse to follow doctors' instructions. I'm always serious and rough with them. They're looking for an excuse to talk to me and to make the conversation last longer. It's partly because they've probably never been around women except their mothers, daughters, or sisters. I always try to be very serious. I want them to quit treating me as a woman. It really bothers me that they don't consider me a serious person doing her job. They should have respect for my profession and be more cooperative. They argue and exaggerate their pain to get me to empathize with them. I don't smile or laugh very often. I try deliberately to act tough. It bothers me to treat them that way, but I feel I have to. Women patients try to find out about my family and ask why I'm working. They feel comfortable that a woman and a native is helping them by acting as their interpreter.

Four physician-respondents exhibited a tolerance and understanding of their patients' actions. Respondent \#23 said:

Patients sometimes complain. Sometimes they don't trust my treatment and go to another doctor. They do that because they want to double-check, and not because I'm a woman. The same thing happens to male physicians. Female patients try to arouse my sympathy more 
often than male patients do. For instance, when a patient doesn't want to wait for her turn, she says that she has been waiting for so long, or that she came a long distance to see me.

Respondent \#25 spoke in a sensitive manner about her patients. "We should be understanding about our patients' manners and their backgrounds. This way we avoid giving them the chance to be aggressive and rough. I try not to be too easy or too hard." Respondent \#27 stated:

Patients call me by my first name, but I don't really care. Sometimes they say "woman" or "doctor." They don' $t$ mean to put me down or insult me. I know what their home environment is like. Some of them are aggressive and they just need to be treated with dignity. They feel so bad when a woman yells at them. They don't seem to feel the same way if a male physician yells at them. When I first started working, some patients would go see another physician after I examined them. Maybe they were uneasy because I'm young or because I'm a woman. However, they do the same thing with male physicians. My colleagues taught me how to treat patients. Now the patients trust me and recommend me to their friends. In general, I've noticed that patients don' $t$ trust physicians. What bothers me is when aggressive patients fight. If I don't do just what they want, they get mad. Some of them say, "You're just a woman--otherwise we'd cause you trouble." Female patients call me by my first name and treat me as a friend. Some of the male patients are tough and aggressive, even with male physicians. I think I would have more hassle with male patients if I worked at night. I've asked to treat only women patients at night.

Respondent \#29 reported:

During the first two years, some patients didn't trust my treatments but the same thing happens to male physicians. People were surprised to learn that there was a native woman physician. Some male patients came to the clinic just to see what a woman doctor looked like. The uneducated call me by my first name or say, "lady." Educated people call me "doctor.". Now that I've been here awhile, patients have changed--they trust me more and bring their children to me.

The diversity of interpretation of patients' actions could be due to differences in length of time spent working or individual personalities of the respondents. Another explanation might be the availability of female colleagues who have been working in Jeddah, Saudi Arabia for some time. They might have taught the younger professionals how to deal with the actions of patients. 
WORK DISCRIMINATION

A number of issues of discrimination were raised by the respondents. These issues included lack of sufficient authority for women in charge and lack of opportunity for participation in decision-making by women. Opportunities for women, particularly those who are single, to participate in conferences or receive deserved promotions are few. Educational policy is made to further male interests.

These issues were discussed by several respondents. Respondent $\# 11$, a college administrator, talked enthusiastically about her hopes for the future:

I wish we [women's section] would become academically independent. Unfortunately, we still don't have enough good professionals to become administratively independent. Our section is dependent on the male section. They are the source of authority. The women's section doesn't have much authority in important issues--the main decisions are made by the male section. That's why I spend so much time trying to get things done. The women's section is growing fast. We are facing urgent academic and administrative needs, but those in charge haven't realized it yet. This might be due to the fact that there's discrimination against women, but I'm not sure.

As women we don't have the opportunity to participate in conferences. When we asked why we were excluded, we were told, "It's the society's tradition." When it comes to promotion and financial reward, men get it first and faster.

It seems to me that boys' education comes first in importance. There's more interest in educating males than females. This is my personal impression: I'm not denying that there's an interest in girls' education, but it is not considered as important as boys' education.

Respondent \#14, a college administrator, also deplored her lack of paticipation in the decision-making process, "I wish we could participate more in making decisions and could be independent. I know the students would benefit from the change." Respondent \#17, another college administrator, spoke of her desire for development as well as professional equality for women: 
The words of a woman are not as effective as the words of a man. A woman having the same qualifications and holding the same job as a man has to exert three times the effort to get things done . . . if it gets done at all.

Unfortunately, she added, this problem arose not only in dealings with men, but in dealings with many women as wel1. Even non-natives and foreigners, she told me, preferred to take orders from men. To top all this, a foreign consultant was respected and taken more seriously than a native--male or female. She also questioned the decision of schools and universities to extend so many contracts to foreign teachers when there were qualified citizens available. She was grateful to the people in charge and to the government for providing facilities where women could realize their educational rights. However, she kept hoping for more. She felt that girls should have access to good libraries, good teachers, and adequate equipment for specialization. She also expressed the hope that the development of sports facilities for girls at schools and universities would receive more attention.

It is important to note that none of the respondents with least contact with men reported that they would prefer taking orders from a man rather than a woman. This could have been due to the fact that women with occasional and most contact felt that the men's section in the organization was the main source of decision-making. In addition, women were given instructions by phone and at meetings with male colleagues. Respondent \#11 reported, "Female colleagues sometime prefer to take orders or get information from males, not because we are women, but because the men's section is the main source of instructions and final decisions." Another possible explanation is that women might have felt deep down that their male colleagues had worked longer and had 
more experience. Respondent \#26 said, "I don't mind taking orders from a woman who has had experience and is well-qualified."

Respondent \#26 continued:

I still feel that professional women in our society are not considered equal to men. For instance, women can't go to conferences. I feel that we're not trusted to be representatives of our country. We have asked why we were not included in conferences and the answer was, "It's the system." This exclusion deprives us of a valuable opportunity for learning.

Respondent \#27, a married physician, said, "Women don't have a chance to get into hospital administration. It's just out of the question." Respondent \#35, a married radio broadcaster, complained:

As a woman I can't participate in conferences outside the country. I don't know why. I've had invitations, but I was denied the opportunity to attend. I don't participate in making decisions either. Maybe it's because I'm not an official employee yet.

\section{FURTHER IMPLICATIONS}

(1) The data show that a woman's work might be suspect if it is well done. This was best described by a college administrator, Respondent \#15, who spoke of her dissatisfaction:

My impression is that some male workers are surprised when we [women] finish our work correctly and neatly. I feel that I'm treated as a woman, not as a professional, when my work is questioned.

(2) Rules and regulations at work were sometimes interpreted as being discriminatory. A social worker, Respondent \#19, spoke of her anger at not being respected as a person:

During formal meetings with male colleagues, we are instructed to meet in the presence of the boss, and even to call them from her office. This really bothers me. I don't feel that I'm trusted. I don't feel that I have my own identity. 
(3) The data also suggest that a woman might be treated as a serious, dependable professional at her place of work, and as a young girl at home. This has an effect on her perception of herself. A college administrator, Respondent \#11, best described this situation:

My job gives me an identity as a person and as a human being--just like a man. I'm educated, I have a good job, and I earn money. However, at home I'm still treated like a girl. To my parents, I'm just their young daughter. They like to tell me how to dress and what time to come home. I'm not supposed to travel by myself. My brother, of course, does whatever he wants. When I object, my parents say, "He's a man, and you're still a girl. We don't want people to gossip." They're not convinced that I have grown up. This bothers me. However, relatively speaking, my family gives me a lot of freedom.

(4) The data indicate a trend toward the stigmatizing of unmar-

ried, educated women. Respondent \#11 had some thoughts on this problem:

There is fear of marriage to an educated women, particularly one who is college-educated. Families might feel that educated women will try to dominate their sons. A man feels that an educated woman will treat him as an equal. Even those men who have a Ph.D. degree feel this way. This could be partiy due to the fact that interaction between males and females is limited in our society. Women and men who are not related have few chances to associate. Consequently, a stereotype of educated women is developing.

I feel that my chances of getting married are decreasing as I get more education. A man admires a woman who talks, argues, and expresses her opinion, but when it comes to marriage, he prefers a naive woman.

Some time ago, men started to marry women from outside their own country. Their justification was that they couldn't find educated women here. Now women are going to school and getting an education, but men still marry women from outside their own country. There are few chances for educated women to meet males from their own country. An educated woman can't marry someone who proposes if she doesn't like his personality. Consequently, with the limited chances for a woman to meet other males, all she can do if somebody proposes and she doesn't like him is say "no." Others think, "Poor girl, nobody is proposing to her."

An educated woman meets more people, sees men at universities, and talks to some at work. She has an idea about the man she would like to marry. Before, marriage for a woman had so much of an economic function because a woman depended on the husband for support. Now if a woman wants to marry, she is basically looking for a good companion and not for somebody to take over economic responsibility. 
Respondent \#21, a social worker, agreed:

It's sad but true that the majority of educated males in our society would prefer to marry women who are less educated than they are, or not educated at all. They think such women are easier to live with--that they can give orders and these women will obey. I don't want somebody to have control over my decisions or my whole life.

I'm called an old maid. In spite of my education and the fact that I'm working, I am, generally speaking, still nothing. I've gotten that impression from family and from relatives and friends of my family. That's the way they look to me. They feel I haven't achieved much. I don't have a complete identity. I feel that if I reach a certain age, I might as well forget about marriage. You lose hope. This society gives me that feeling. But I still believe that I am something after all.

Respondent \#22, an investigator, said:

Educated or working women are considered "masculine"--this is the stereotype that has developed. In our society men choose wives based on physical appearance, wealth, youth, and willingness to be obedient.

(5) It seems that respondents feel that males, to some extent, have an ambivalent attitude toward them. While the men appear to accept the women's progressive movement, they do not unanimously choose educated women as their wives. Further research, with a larger sample, could examine the previous projection. Perhaps this ambiguity is natural in a society which is undergoing change. Modernization is accompanied by a new ideology that openiy clashes with the traditional idology; this leads to confusion and anxiety for some.

\section{CONCLUSION}

To sum up, the data show a diversity of interpretation of male colleagues' actions. Women with most and occasional contact with males at work were the most aware of being treated in two distinct ways: as women, and as colleagues. Some of the women interpreted males' actions as discriminatory, and they resisted the challenge to their 
professional identity. Others interpreted male remarks as fun or diversion. Still others felt that they were not being discriminated against by men. Women's reactions to the actions of patients and manual workers fell into the same three categories as their reactions to men as a whole.

It appears that the whole area of identification of women is characterized by ambiguity. The women's own interpretations apparentiy determined whether men's actions were seen as placing female colleagues in sex-related roles or work-related roles. That is, a man could behave in precisely the same way with two women with the result that one woman would believe she had been discriminated against, and the other woman would not. According to Daniels, the judgment of discrimination is influenced by two contingencies: the woman's immediate response and her previous interaction with the male. For example, whether a man's addressing his female colleagues by their first names or flattering them with "feminine" adjectives are considered discriminatory or not may depend on how the female sees herself in relation to the male. In addition, if the male is flattering to a woman who has previously worked with him as an equal, the woman may consider the remark as fun or diversion rather than insulting (Daniels, 1967).

The data show, in general, that the exclusion of males in an occupational setting seemed to reduce the problem of identification for the professional. women' of the sample in Jeddah, Saudi Arabia. 


\section{CHAPTER VIII}

\section{CONCLUSIONS}

The findings of this study must be limited to the respondent group. Hopefully, further research will be done in additional cities and regions to determine the limits of the applicability of the findings. However, the findings are sufficiently broad to suggest their relevance to the prescribed diverse population.

In this chapter, implications of the findings for theory and further research are discussed. It has been suggested in role theory (developed by Goode, 1960) that the individual role relationship is overdemanding. Difficulty or "strain" which is aroused in fulfilling role obligations or demands results. However, the strain is said to be associated with some mechanisms for reducing it. At the same time, successful achievement in reducing strain is sometimes determined by structural elements. Social scientists have determined that the employment of mothers outside their homes places them in a continuing conflict between career, marriage, and motherhood. Some social scientists, however, believe that the employee role can be successfully integrated into the woman's total life.

To summarize the results, it was found that the data generally support a11 the hypotheses except Hypothesis \#3. 


\section{HYPOTHESIS \#1}

There seems to be a relationship between marital status and time allocation. Married women reported more difficulty with respect to time allocation than did single women. However, it was found that married women utilized several mechanisms to minimize time difficulty. These mechanisms could be categorized as follows: (1) managing time through the scheduling and delegation of tasks; (2) compromising (the wife , limited her career involvement); (3) giving priority to family demands; (4) redefining the situation favorably; and (5) limiting social relationships. Additional mechanisms reported by only a few respondents included: (1) compartmentalizing through role distance (i.e., keeping home roles distinct from career roles); and (2) compartmentalizing through role relaxation (i.e., the absent husband made the fewest demands).

This finding is compatible with Bates' (1956) and Goode's (1960) statement that the individual tends, when difficulty (strain) is aroused, to act to reduce that difficulty. However, Seaman (1953) and Goode (1960) indicate that there are limitations on the mechanisms which minimize or reduce the difficulty. The findings of this study support Seaman's (1953) and Goode's (1960) conclusion. The respondents' mechanisms for minimizing time difficulty were not always successful. In this regard, the data show the development of three types of respondents:

(1) the adapters, who were able to allocate their time effectively; (2) the temporary withdrawers who felt that the job demanded too much time and decided to stop working temporarily; and (3) the dissatisfied adapters, who reported their dissatisfaction with their own performance. 
The variation in respondents' reactions could have been due to differences in their personalities or in their personal situations. Some respondents could not allocate their time satisfactorily because they did not have adequate resources or energy. Others acquired jobs that were more time-consuming than those of other respondents. Working as a physician appeared to demand more time than being a school teacher.

HYPOTHESIS \#2

It was found that relationships existed between the type of occupation and the amount of network support. Women who worked in education and medicine seemed to receive more support than did women who worked in other fields. This may have been partially due to the fact that educating and healing the sick were perceived as extensions of traditional feminine roles, and because these professionals served a female clientele. This is compatible with Epstein's statement; that is, a woman may avoid role conflict entirely where there is cultural approval of her status, and where roles are defined as complementary (Epstein, 1970:142).

According to Bailyn, employment as a social worker is considered to have a positive effect on a woman's self-image. This is due to the fact that female social workers are faced with problems similar to those which they may face in their private family life. Consequently, the distance between the two roles is reduced to ease. their problems (Epstein, 1970:142). However, the data show that social workers received less support than educators and physicians. This could be partiy due to the fact that at the time of the social survey, 
workers were required to visit strangers' houses in the evenings, and this activity apparentiy hindered the growth of network support for social workers.

It was also found that the degree of support was not only determined by the type of occupation, but by other variables as well. Two of these variables were the degree of interaction of men and women at work and the organizational structure at the place of employment. For example, women might have received less positive support from networks when (1) working at night, moving from one place to another, or traveling; (2) working for long hours; (3) working with men; (4) holding jobs that had low prestige; (5) performing services which were not observed; and (6) specializing in fields in which jobs are not yet open to women. The data also reflected a development of different types of network support. (1). Regarding support of the mothers and sisters of the respondents, two types emerged: (a) high positive support from mothers and sisters; and (b) low positive support from mothers. (2) Regarding behavior of drivers and guards, two types emerged: (a) ambivalent positive support; and (b) lack of positive support. (3) Regarding support of husbands, husbands' families, relatives, fathers, and brothers, two types emerged: (a) positive support; and (b) low positive support. According to Epstein, a husband's disapproval of his wife's job could be due to his fear that his wife will outrank him in occupation or leve1 of success (Epstein, 1970:118). The data did not indicate this finding to be applicable to the subject study. The segregated system in Saudi Arabia has been carried to the occupational sphere. Males are still the source of authority, still make the final decisions, 
and still occupy the highest positions. Consequentiy, men did not fear that women in the professional world would outrank them. Men were not threatened since their dominant role was carried over into the occupational sphere. It was found that the limited amount of interaction between men and women at work reduced the possibility of husbands and wives being threatened by sexual competition in the course of their work. This condition was particularly true with respect to women who had least interaction with men at work. Even for women with occasional interaction with men at work, the interaction was usually structured and regulated. Women with the most interaction with men at work, relatively speaking, were few in number.

According to Epstein, negative pressures may be brought to bear by parents, who sometimes feel ambivalent about their daughters' occupational success (Epstein, 1970:120-121). The data showed that parents might exhibit low positive support only under certain circumstances, such as when daughters worked late at night, worked with men, or traveled in connection with their jobs. While it is true that marriage is still valued and encouraged, some respondents felt that they were not desired or valued as potential companionable wives because they were highly educated. This is compatible with Horner's (1972) argument that women have a motive for avoiding success: they expect social rejection.

With regard to public support of professional women (drivers, guards, and messesngers), it was found that women who worked in the . fields of education and medicine received more support than women who worked in other fields. 
Generally, women are faced with an ambiguous situation. Society approves of women in professions, but does not yet accept the modern behavior which usually accompanies the pursuit of those professions. Less support was given to those women who worked with men, traveled in public without a male related by blood or marriage, took cabs alone, or failed to wear the Abbaya or cover their faces. The data showed that women developed three types of reactions to society's disapproval of their interference with traditional, expected behavior: (1) conformists (compensation and conservative actions); (2) adapters (compensation and conservative actions accompanied by personal dissatisfaction); and (3) progressives (action to gain more social approval for modern behavior).

Differences among respondents could have been due to such factors as place of education and orientation values; that is, some might have been tradition-oriented while others might have been modern-oriented.

\section{HYPOTHESIS \#3}

In general, the quantitative data did not support Hypothesis \#3. It was found that the degree of contradictory role expectations was fairly similar regardless of the degree of interaction respondents had with men on the job. Women with the least interaction with men did not experience the least contradiction in role expectations by their female colleagues; expectations of male colleagues did not show a clear pattern of greater contradiction among women with most interaction with men.

However, this comparison should be interpreted cautiously since the qualitative data were more in line with the hypothesis. These data 
showed that the contradictory expectations were affected by the degree of interaction women had with men on the job. The qualitative data further suggested that perception of contradictory behavior by women with least and occasional interaction with men was a by-product of respondents' personality differences. Perception of contradictory role behavior by women with the most interaction with men was a by-product of associating with men at work.

Respondents' perceptions of contradictory personal behavior expectations did not necessarily include a feeling of personal conflict. Respondents were expected to be supportive and cooperative, and, in general, they fulfilled that expectation. More specifically, the data showed a development of two general types of reactions by the respondents to expected role behavior. (1) Regarding women with least and occasional interaction with men, two types emerged: (a) high positive conciliators; and (b) low positive conciliators. (2) Regarding women with the most interaction with men, two types emerged: (a) conciliators; and (b) non-conciliators.

Regardless of the degree of interaction with men, the respondents were aware of contradictory expectations in regard to their appearance. Although some respondents (school teachers) had no interaction with men at work, they were expected to be highly conservative in the way they dressed. The data also showed that conservative behavior was the dominant behavior when women came into contact with men at work. Respondents could be placed in four categories: (1) those who conformed because they believed they should behave in a conservative manner; (2) those who were conservative because they feared that any other 
behavior would be misunderstood; (3) those who adapted and behaved in a conservative manner to comply with regulations at work; and (4) those who were conservative but reported dissatisfaction with their own behavior.

Women's ambivalence about their own behavior among male colleagues is caused by the emergent pattern of interaction between unrelated men and women in the work situation. This interaction violates the tradition of the society in Saudi Arabia.

It was found that work behavior expectations were viewed as a major problem. The whole area of employment seems to vacillate between institutionalization and de-institutionalization. This uncertainty is also seen in worker relationships, rules and regulations at places of employment, and the hierarchy of authority. These are natural consequences of a society undergoing change.

Further implications were reported by respondents. Cooperation seemed to be the dominant trend in work situations, rather than competition. This was due to such factors as: (1) promotions were not always based on qualifications or good performance; (2) work was sometimes complementary or separated; (3) family and blood ties existed among some colleagues; (4) feedback and guidance were not always available; (5) male colleagues held higher positions, had worked longer, and had more professional experience; and (6) workers were few in number in one field of specialization surveyed.

It was found that males have been supportive of female colleagues, perhaps because the men did not feel threatened by women. Men's dominant role in the society carried over to the working world: 
men held the higher positions and made the decisions. For the most part, women did not compete with men.

It was reported by respondents that they preferred working with women to working with men because they could be less conservative in the way they behaved. On the other hand, working with men was considered desirable by some respondents because of the opportunity to learn and to get more experience.

\section{HYPOTHESIS \#4}

The data support Hypothesis \#4. There was a relationship between the degree of interaction of women with men at work and the difficulty the women experienced in asserting an identity. Women with the most interaction with men had a great deal of perception about the difference between being treated as women and being treated as colleagues. The exclusion of males in occupational settings seemed to reduce the problem of projecting an identity.

The data showed that respondents dealt with the problem of asserting their identities in several ways. First, with respect to male/ female colleagues, (1) it appeared that women with least interaction with men were all of one type: mild, noting no differentiation between their treatment as females and their treatment as co-workers. (2) With respect to women with occasional interaction with men, three types emerged: (a) those who were resistant to challenges to their identity; (b) those who were tolerant and interpreted male actions as fun or diversion; and (c) those who did not interpret male actions as discriminatory. (3) With respect to women who had most interaction with men at work, 
two types emerged: (a) those who were strongly resistant; and (b) those who did not interpret males colleagues' actions as discriminatory.

The diversity of interpretation of male colleagues' actions could have been dependent on the following variables: the number of male colleagues with whom women come into contact, the nationality of colleagues (native, non-native, foreigners), the educationat level of colleagues, the country where they received their education, the positions the colleagues held in the organization, the differences in work regulations from one organization to another, and the use of space, or when and how interaction between the sexes took place.

Second1y, two types of women emerged with respect to the interpretation of patients' and manual workers' actions: (1) dissatisfied, and (2) tolerant.

The diversity of interpretation of patients' actions could have been due to differences in length of time respondents had worked and/or personalities of the respondents. Another possible explanation was the availability of more experienced colleagues who might have helped facilitate the understanding and judgment of less experienced professionals.

The diversity of interpretation of manual workers' actions might have been due to factors such as: (1) the frequency of association between respondents and manual workers; (2) differences in respondents' personalities; and (3) respondents' previous interactions with manual workers.

Thirdly, with respect to actions of male clerical workers, there was only one type of response: "dissatisfied." 


\section{RECOMMENDATIONS FOR FURTHER RESEARCH}

There is a need for detailed, accurate, published statistics covering the population of the labor force of Saudi Arabia to facilitate research and predictions. Comparative studies would be usefur in determining the limit of the findings' applicability. Comparisons between the degree of interaction between men and women at work and of network support are also needed. We might compare the same types of occupations and control for the frequency of interaction between men and women at work and examine the relationships between frequency of interaction of the sexes and of network support.

Different classifications of respondents such as place of education, level of education abroad, and being alone or being accompanied by the family when studying abroad could be useful to see differences in the way respondents perceive contradictory expectations or identity problems. Comparative studies on native vs. non-native colleagues could be done with relation to expected role behavior.

Comparative studies on native male/female colleagues educated abroad vs. those educated inside the country could be useful for examining expected vs. actual behavior. Classifications between respondents oriented to modern roles and those still attached to traditional roles could be useful to see differences in personal behavior expectations and work expectations. Classifications could be made of respondents according to the length of time they have worked and the number of children they have, to see differences in the ways mechanisms of reducing the time difficulty are handled. Over time, studies could also be done 
to see differences among the respondents. Comparative studies could be made between female professionals in different organizations.

Comparative studies of men (father, husbands, male colleagues) could also be useful. Team interviewing is suggested: a female interviewer should interview women and a male interviewer should interview men. Comparisons among social classes could be made, examining professionals, non-professionals (clerks), and manual laborers for differences in network support or identity.

A study could also be made comparing actual with expected behavior in the work setting. Participant observation is suggested in such a study.

Based upon the previous suggested studies, other hypotheses could be formulated and tested. Subsequent research could explore more thoroughly why types of workers differ so markedly and why there are differences with these types.

More studies by specialists about the status of women in Saudi Arabia would be useful. A review and an objective analys is of pertinent literature about Arab women and women's status in Islam could also increase understanding of the social forces affecting the presence and role of women in Saudi Arabia. The time limitation for this study did not allow the researcher to pursue such research.

Combining the two methodologies is useful and is recommended for further research of exploratory and measurement purposes. The poss ibility of developing more types, as we11 as other ways of grouping types, could emerge with the use of a larger sample. 
The typologies approach was useful because: (1) it sets up and relates different variables; (2) it provides a framework within which the relationship can be examined for different groups; and (3) it sets forth a specific way in which different types of individuals can be identified and described.

American theoretical literature was used only to provide a framework for analysis purposes. The purpose was not to impose American concepts, but rather to use the literature as a tool for investigation and exploration. Such a technique seems possible; however, careful. consideration should be given to the achievement of objective analys is for the data. In addition, the researcher's flexibility in collecting the data seems to be crucial.

The findings generally seem to support Altorki's (Nikkel, 1974) statement that career-family combinations can exist in the Middle East, including Saudi Arabia, because of Eastern values regarding family relations. Respondents on different occasions spoke of the child care help they received from their own families or their husbands' families. However, it appears that this situation might change with the increase in mobility. It is also true that with the emergence and spread of a conjugal family pattern, the primary responsibility for managing the household will fall upon the wife. It appears from the data that seven respondents live either with their own family or with their husband's family in the same house or the same building, facilitating the division of household labor among a number of relatives. However, one predicts that this situation will change gradually; some respondents spoke about the difficulty of taking children to their mother every day, and the 
difficulty of finding a reliable person with whom to leave their chitdren. Others expressed their dissatisfaction with the way their children were being raised by an older generation, and still other expressed their dissatisfaction with the way their homes were being managed.

On the other hand, the data do not support Beck's (1957) statement that it is a tragedy that modern Moslem women are breaking with the past and seeking advanced education and professional accomplishment, thus. disqualifying themselves for the traditional Moslem role. It seems more likely, as Theodore reports, that the female professional has developed as an extension of the traditional role functions of the female in tasks requiring nurturing, socializing, and helping (Theodore, 1971: 5). It appears as we11 that wearing the Abbaya is not an obstacle; women who continue to wear the Abbaya are working.

The changes have not been really destructive. Respondents reported that males (colleagues, fathers, husbands, brothers) respected employed women. Women in the sample had self-esteem and a positive self-image because they felt that society was benefiting from their work. It is true that women experienced difficulties because they had a dual responsibility; however, they considered such difficulties tolerable. Respondents showed a genuine desire for participation in their society's developmental process. This does not involve a challenge to the traditional concept of woman's role as wife and mother, but it represents a desire that a woman's life should not be limited to this rale. Planned changes are needed in order for women to participate effectively in the occupational sphere. These changes include more sharing of household responsibilities between husband and wife; effective 
planning for good, standardized nurseries and kindergartens; changes in working hours to conform with the needs of working mothers; convenient transportation; equal opportunities for job training; and participation in professional conferences and meetings. More authority should be given to women to match their responsibilities. There should be real opportunities for women to work in fields other than education and medicine.

In addition, if interaction between the sexes and restrictions on women's behavior become less problematic, some difficulties experienced by professional women will be alleviated. The mass media and women's organizations could play a significant role in the development of more positive attitudes toward career women by the public. If such changes take place, women will be less misunderstood and less suspicious of their reactions. Less energy will be spent trying to understand women's reactions, and wemen will have more control over their working lives.

These changes could be accommodated without too much disturbance, because of the strong societal elements of religion and close famity ties. It is possible that we will find a way to integrate changes and tradition with no destructive tragedy. It appears that the new behavioral pattern is challenging the old; however, there is hope that a "middle way" of accepting modern culture without completely breaking with the traditions of Islam can be found. Changes in the position of women are not necessarily anti-religious. Instead, the changes could be viewed as an opportunity for the development of women as a valuable labor resource in the further development of the society of Saudi 
Arabia, as well as the opportunity for women to work out their full potential. 


\section{BIBLIOGRAPHY}




\section{BIBLIOGRAPHY}

A7gosaibi, Farida

1976 "The veil and the Abbaya are drawn aside." (Jeddah) Saudi Gazette, 17 Apri1, p. 5.

ATrashed, Shoaa

1976 "Let women speak up on their own behalf." (Jeddah, Saudi Arabia) Okaz, 17 January, pp. 6-7.

Bailyn, Lotte

1964 "Notes on the role of choice in the psychology of professional women." Daedalus 93 (Spring):700-10.

Bates, Frederick

1956 "Position, role and status:-A reformulation of concepts." Social Forces 34 (May):313-21.

Beck, Dorothy Fahs

1957 "The changing Moslem family of the Middle East." Marriage and Family Living 19 (November):340-7.

Benedict, Ruth

1938 "Continuities and discontinuities in cultural conditioning." Psychiatry 1 (February-November):161-7.

Bernard, Jessie

1971 Women and Public Interest. Chicago: Aldine.

Burchard, Waldo

1954 "Role conflicts in military chaplains." American Sociological Review XIX (October):528-35.

Carp, Frances

1974 "Position effects on interview responses." Journal of Gerentology 29 (September):581-7.

Coser, Rose and Gerald Rokoff

1974 "Women in the occupational world: Social disruption and conflict." Pp. 490-511, in Rose Laub Coser (ed.), The Family:

Its Structures and Functions. New York: St. Martin's Press.

Daniels, Arlene

1967 "The low caste stranger in social research." Pp. 267-96, in Gideon Sjoberg (ed.), Ethics, Politics and Social Research. Cambridge, Mass.: Schenkman. 
Dinerman, Beatrice

1969 "Women in architecture." Pp. 629-34, in Athena Theodore (ed.), The Professional Woman. Cambridge, Mass.: Schenkman.

Epstein, Cynthia

1970 Woman's Place. Berkeley and Los Angeles: University of California Press; London: University of California Press, Ltd.

Gama 1, Ahmed

1975 Lectures on Islamic Culture. Cairo: Public Company.

Getzels, J. W. and E. G. Guba

1954 "Role, role conflict and effectiveness." American Sociological Review XIX (April):164-75.

G1aser, Barney G. and Ans lem Strauss

1967 The Discovery of Grounded Theory. Chicago: Aldine Publishing Company.

Goffman, Erving

1967 Interaction Ritual Essays on Face to Face Behavior. Garden City, N.Y.: Anchor Books, Doubleday and Company, Inc.

Goode, William J. and Paul K. Hatt

1952 Methods in Social Research. New York: McGraw-Hill Book Company, Inc.

Goode, William

1960 "A theory of role strain." American Sociological Review 25 (August): $483-96$.

Goode, William

1963 World Revolution and Family Patterns. Toronto: The Free Press of Glencoe.

Gorden, Raymond

1969 Interviewing Strategy, Techniques, and Tactics. Homewood, 111.: The Dorsey Press.

Graham, Patricia

1970 "Women in Academe." Pp. 720-35, in Athena Theodore (ed.), The Professional Woman. Cambridge, Mass.: Schenkman.

Gross, N., A. W. McEachern and W. S. Mason

1958 Explorations in Role Analysis: Studies of the School Superinr tendency Role. New York: Wilcy.

Holton, Susan

1969 "The woman physician: A study of role conflict." Journal of the American Medical Women's Association 24 (August):638-45. 
Horner, Matina

1972 "Toward an understanding of achievement-related conflicts in women." Journal of Social Issues 28:157-75.

Izzedin, Nejla

1953 The Arab World: Past, Present and Future. Chicago: Henry Regner Co.

Jacobson, E., W. Charters and Seymour Liberman

1951 "The use of the role concept in the study of complex organization." Journal of Social Issues VII:18-27.

Kievit, B. Mary

1972 Review and Synthes is of Research on Women in the World of Work. Columbus, Ohio: ERIC Clearinghouse on Vocational and Technical Education; Washington, D.C.: U.S. Government Printing Office.

Komarovsky, Mirra

1946 "Cultural contradictions and sex roles." American Journal of Sociology 52 (November): 184-9.

Kosa, John and Coker, Robert E., Jr.

1965 "The female physician in public health: Conflict and reconciliation of the sex and professional roles." Sociology and Social Research 49 (Apri1):294-305.

Kosa, John

1971 "Women and medicine in a changing world." Pp. 709-11, in Athena Theodore (ed.), The Professional Woman. Cambridge, Mass.: Schenkman.

Kretch, Crutchfield

1962 Individual and Society. New York: McGraw-Hill Book Co., Inc.

Lopate, Carol

1968 Women in Medicine. Baltimore: Johns Hopkins Press.

Madni, Ayad

1976 "Women and Progress." (Jeddah, Saudi Arabia) Okaz, 5 January, p. 12.

Malik, Saleh Abdulla

1973 Rural Migration and Urban Growth in Riyadh, Saudi Arabia. Unpublished Ph.D. dissertation, University of Michigan.

Minority Rights Group

1975 Arab Women. London: Minority Rights Group.

Nikkel, Doborah

1974 "A Saudi Arab Ph.D. explains her position." The Christian Science Monitor, 23 September, p. 10. 
Nye, Francis I. and Lois W. Hoffman

1963 The Employed Mother in America. Chicago: Rand McNally.

Nye, Francis I. and Lois W. Hoffman

1974 Working Mother. San Francisco: Jessey Boss Publishers.

Papanek, Hanna

1971 "Purdah in Pakistan: Seclusion and modern occupations for women." Journal of Marriage and the Family 33 (August): 517-30.

Parsons, Talcott

1942 "Age and sex in the social structure of the U.S." American Sociological Review 7 (October):604-16.

Parsons, Talcott

1951 The Social System. Glencoe: The Free Press.

Poloma M. and T. Garland

1970 "The myth of the egalitarian family: Familial roles and the professionally employed wife." Pp. 741-61, in Athena Theodore (ed.), The Professional Woman. Cambridge, Mass.: Schenkman.

Poloma, Margaret

1970 "Role conflict and the married professional woman." Pp. 187-98, in S. Rothschild (ed.), Toward a Sociology of Women. Lexington, Mass.: Xerox College Publishing.

Rugh, William

1973 "Emergence of a new middle class in Saudi Arabia." The Middle East Journal 27 (Winter):7-20.

Sarbin, Theodore

1954 "Role Theory." Pp. 223-58, in Gardner Lindzey (ed.), Handbook of Social Psychology, I. Cambridge, Mass.: Addison-Wesley.

Seeman, Melvin

1953 "Role conflict and ambivalence in leadership." American Sociological Review XVII (August):373-80.

Shobokshi, A7i

1976 "Shobokshi explains his position." (Jeddah, Saudi Arabia) Okaz, 1 January, p. 12.

Stouffer, A. Samuel

1949 "An analys is of conflicting social norms." American Sociological Review XIV (December):707-17.

Stouffer, Samuel A. and Jackson Toby "Role conflict and personality." American Journal of Sociology LVI (March):395-406. 
Theodore, Athena

1971 The Professional Woman. Cambridge, Mass.: Schenkman. Wallin, Paul

1950 "Cultural contradictions and sex roles: A repeat study." American Sociological Review 15 (April):288-93. 
APPENDICES 


\section{APPENDIX A}

\section{INTERVIEW GUIDES AND STANDARDIZED QUESTIONS}

\section{Time Allocation: Interview Guide}

This is a guide for non-standardized discussion on time allocation. The following are examples of the questions that were raised.

--I would like you to tell me about your home responsibility.

--Do you consider your housework time consuming?

--Is it tiring?

--Do you have somebody help with housework?

--Are your husband/parents appreciative of your housework?

--Is your housework satisfying?

--Does your job allow you to dedicate as much time to your housework as you would like to?

--Does your job allow you to devote enough time to your children?

--Do you have somebody help with children?

--Would you leave your job if you felt you were not giving adequate time to your responsibilities as a wife and a mother?

--Would you stop working if you had children? Why?

--Would you stop working if you were married? Why?

- What are the things you have to do for your job in the evening?

--Now tell me about your job.

--Is it time consuming?

--Are working hours and vacations convenient? 
--Is your work tiring (physical1y, menta11y)?

--Do you think more training would make your work easier?

--Are your colleagues (supervisors) considerate? How?

--Is transportation to your work easily available?

--Do you participate in other activities? If no, why?

--Do you think you are able to manage all responsibilities you have? How?

--Do you feel you are facing difficulties in handling your'responsibilities?

--What are these difficulties?

--How much, if any, do these difficulties bother you?

--Do you have any other comments you would like to mention with respect to your job and home responsibilties?

Time Allocation: Standardized Questions

1. Do you have time after working hours for housework? MUCH SOME LITTLE

2. Do you have time after working hours for child care or younger brothers, sisters, the aged? MUCH SOME LITTLE

3. Do you have time to devote to your husband? MUCH SOME LITTLE

4. Do you have time to get together with your family? MUCH SOME LITTLE

5. Do you have time to visit friends? MUCH SOME LITTLE

6. Do you have time to visit relatives? MUCH SOME LITTLE

7. Do you have time for family social activities? MUCH SOME

\section{LITTLE}


8. Do you have time to do work related to your job at home?

MUCH SOME LITTLE

9. Does your schedule allow you to dedicate time to yourself?

MUCH SOME LITTLE

Physical Demands: Standardized Questions

10. Are you tired when you do your housework after working (or help with housework)? MUCH SOME LITTLE

11. Are you tired when you take care of your children or younger siblings or the aged after working? MUCH SOME LITTLE

Delegation of Tasks: Standardized Questions

12. Do you have a servant? FREQUENTLY SOMETIMES NEVER

13. Do you have somebody to help with the housework? FREQUENTLY SOMETIMES IIEVER

14. Do you have somebody to help with the children? FREQUENTLY SOMETIMES NEVER

Reduction of Role Relationship: Standardized Questions

15. How much do you participate in activities related to your job? MUCH SOME LITTLE

16. How much do you participate in activities related to your husband's job? MUCH SOME LITTLE

17. How much do you participate in social organization activities? MUCH SOME LITTLE.

18. How much do you participate in family of orientation or relatives' activities? MUCH SOME LITTLE 
19. How much do you visit your family or close relatives? MUCH SOME LITTLE

Compartmentalization through Role Distance:

Standardized Questions

20. How often when you are at work do you think/speak about family problems? MUCH SOME LITTLE

21. How often when you are at home do you think or talk about work problems? MUCH SOME - LITTLE

22. When you are at work, do you think of your children and worry? MUCH SOME LITTLE

Network Support: Interview Guide

--How does your family (parents, brothers, sisters) feel about your job?

--Does your family think your job takes too much of your time? Or that your job is too tiring? Or that you do not have enough time for yourself?

--Do they think you do not help enough in housework?

--Do they feel you do not participate enough in family social activities?

--Do they object to you working with men?

--Does your family complain about providing you with transportation?

--Did your family ever ask you to stop working or to change your career? Why? (Type of job, time-consuming, working with men, other reasons)

--Does your husband like your job? 
--Does he think your job takes too much of your time? Tiring for you?

--Does he help you with housework?

--Does he like to help you?

--Does he object to your working with other men?

--Did your husband ever ask you to stop working or to change your career? Why? (Type of job you have, inadequate time for him, working with men, other)

--If your husband were to ask you to change or stop working, what would you answer?

--How do you think your in-laws feel about your job?

--How do you think your own relatives or husband's family feel about your job?

--How do you think your colleagues feel about your job?

--Do you think drivers, guards, and manual workers 1 ike to see women in your job?

--Do you think you would be more or less supported by your family, husband, relatives, others (drivers, guards) if you had a different job? Why?

--How do you like your job?

--Would you rather have another job? Why?

Network Support: Standardized Questions

In the following questions, you will be asked to rate how much support you receive in the choice of your career from your network. Check one.

23. Your husband MUCH SOME LITTLE 
24. Your father MUCH SOME LITTLE

25. Your brothers MUCH SOME LITTLE

26. Your sisters MUCH SOME LITTLE

27. Your mother MUCH SOME LITTLE

28. Your own relatives MUCH SOME LITTLE

29. Your husband's family MUCH SOME LITTLE

30. Drivers, guards, and manual workers MUCH SOME LITTLE

\section{Expected Behavior: Interview Guide}

--How do you like the work atmosphere with male/female colleagues?

--Would you rather work with men or women? Why?

--How do you actually act at work with colleagues? (Help, encourage, forgive, compete, criticize, argue)

--Do you feel you are free to conduct yourself as you please, or are there restrictions on your behavior?

--How would you like to act?

--Do you feel you have to dress, act differently when being with male colleagues? How? Does it bother you?

--Do males expect you to act differently from females? How?

--What are the things that you are required/expected to do and which seem contradictory?

Expected Behavior: Standardized Questions

In the following questions you will be asked to rate how much you are expected to behave in the following manner from male/female colleagues.

31. Accepting MUCH SOME LITTLE 
32. Raise the status of others MUCH SOME LITTLE

33. Sympathetic MUCH SOME LITTLE

34. Helpful MUCH SOME LITTLE

35. Arguing MUCH SOME LITTLE

36. Critical MUCH SOME LITTLE

37. Assertive MUCH SOME LITTLE

38. Competitive MUCH SOME LITTLE

The Way Women are Treated: Interview Guide

--What kind of relationship do you have with female colleagues?

--How do you treat each other? (Address, compliment, subjects discussed, ask opinion, ask for heTp)

--Are you bothered by the way you are treated?

--Are there any men employed where you work?

--What is their nationality?

--How often do you see males at work?

--Do native males treat you differently from non-natives? How? Does it bother you?

--How would you describe your relationship with males at work?

--Do males treat you differently from females? How? (Address, compliment, subjects discussed, formal vs. informal, work is trusted, opinion is considered, doubt your ability, asking personal questions, speak freely)

--Are you bothered by the way you are treated? Why?

--How would you like to be treated?

--How would you describe your relation with workers in administration? 
--How do they treat you? (Address, take orders, way of talking to you)

--Are you bothered by the way they treat you?

--Do they treat you differentiy now from when you first started working?

--How do you react to them?

--Do they treat your male colleagues the same way?

Drivers, Guards, Manual Workers: Interview Guide

--How often do you come into contact with drivers, guards, and manual workers?

--How do you feel about the way they treat you? (Look at you, talk to you, address you, take orders from you)

--Are you bothered by the way they treat you?

Patients: Interview Guide

--How do you feel about the way patients behave towards you? (Looking, addressing, following treatment, talking)

--Do female patients treat you differently? How?

Organizational Level: Interview Guide

--How do you feel about the system (organization rules)? (Authority given, making decisions, job training, promotion, conference participation)

--Would you say you are being treated as a woman or as a worker? How?

--Would you like to add anything about yourself, job, home? 


\title{
APPENDIX B
}

RESPONDENTS WHO TOOK PART IN THE STUDY

\begin{abstract}
\#1 - 24-27 years old; single; school teacher
\#2 - 24-27 years old; single; school teacher

\#3 - 20-23 years old; single; school teacher

\#4 - 24-27 years old; single; schoot teacher
\end{abstract}

\#5 - 24-27 years old; married; one child; school teacher

\#6 - 32-35 years old; married; two children; school teacher

\#7 - 24-27 years old; married; no children; school teacher

\#8 - 24-27 years old; married; no children; school teacher

\#9 - 20-23 years old; single; college teacher and administrator.

\#10 - 24-27 years old; single; college administrator

\#11 - 28-31 years old; single; college teacher and administrator

\#12 - 24-27 years old; single; college teacher and administrator

\#13 - 24-27 years old; married; two children; college teacher and administrator

\#14 - 20-23 years old; married; one child; college administrator

\#15 - 28-31 years old; married; five children; college administrator

\#16 - 24-27 years old; married; two children; college teacher and administrator

\#17 - 32-35 years 01d; married; three children; college teacher and administrator

\#18 - 24-27 years old; single; social worker 
\#19 - 24-27 years old; single; social worker

\#20 - 20-23 years 01d; single; social worker

\#21 - 24-27 years old; single; social worker

\#22 - 28-31 years 01d; single; investigator

\#23 - 20-23 years old; single; physician

\#24 - 24-27 years old; single; physician

\#25 - 24-27 years old; single; physician

\#26 - 28-31 years old; single; physician

\#27 - 28-31 years old; married; one child; physician

\#28 - 28-31 years 01d; married; one child; physician

\#29 - 32-35 years old; married; two children; physician

\#30 - 24-27 years old; single; interpreter

\#31 - 24-27 years old; single; interior decorator

\#32 - 24-27 years old; single; radio broadcaster

\#33 - 20-23 years old; single; radio broadcaster

\#34 - 24-27 years old; married; two children; radio broadcaster

\#35 - 28-31 years old; married; two children; radio broadcaster

\#36 - 24-27 years old; single; newspaper editor

\#37 - 28-31 years old; married; two children, newspaper editor 
ᄉУVSSOT9 


\section{GLOSSARY}

Abbaya: A black cloak or cape. The face covering and the Abbaya are worn by women of Saudi Arabia when going out in public.

Foreigners: Citizens of western countries, such as Europe and the United States.

Islam: A religion of submission to the will of God. Islam requires of its believers five obligatory duties or acts known as the "Pillars of Islam." The first is bearing witness to the oneness of God and to the belief in Muhammad as his Prophet. The second requires five daily prayers at prescribed times. The third is the paying of alms. The fourth is fasting during the month of Ramadan. The last pillar is to make the pilgrimage to Mecca at least once during the believer's lifetime.

Moslem: A follower and believer of the religion of Islam.

Natives: Citizens (women/men) of Saudi Arabia.

Non-natives (Arabs and Moslems (women/men) from countries other than Saudi Arabia.

Saudi Arabia: The kingdom of Saudi Arabia, located in the central Arabian Peninsula of Southwest Asia. The word "Saudi" refers to the surname of the royal family controlling the country, and "Arabian" refers to the Peninsula or to its characteristics. Saudi Arabia is divided into four main geographical divisions: Najad, Al-Hijaz, Al-Ahsa, and Asir. Al-Hijaz is the western province. It contains the holiest cities in Islam, Mecca and Medina. Jeddah, where this. study was done, is the country's main port on the Red Sea, and is located in the province of Al-Hijaz.

Veil: Refers to the wearing of a face covering of black cloth in addition to the Abbaya. 